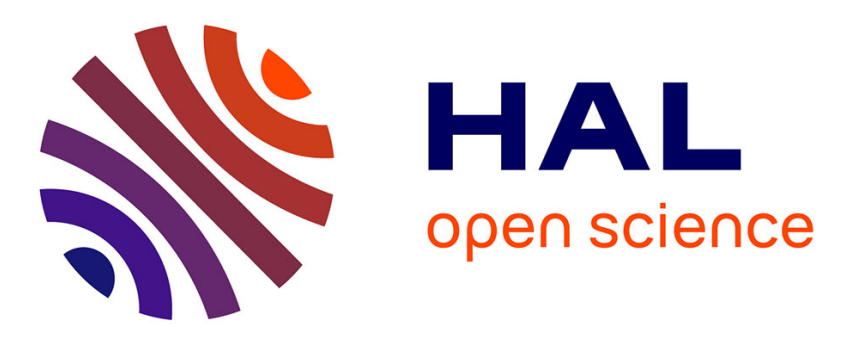

\title{
Radical Polymerization of Vinyl Acetate with Bis(tetramethylheptadionato)cobalt(II): Coexistence of Three Different Mechanisms
}

Santhosh Kumar Kalamblayil Sankaranarayanan, Yves Gnanou, Yohan Champouret, Jean-Claude Daran, Rinaldo Poli

\section{To cite this version:}

Santhosh Kumar Kalamblayil Sankaranarayanan, Yves Gnanou, Yohan Champouret, Jean-Claude Daran, Rinaldo Poli. Radical Polymerization of Vinyl Acetate with Bis(tetramethylheptadionato)cobalt(II): Coexistence of Three Different Mechanisms. Chemistry - A European Journal, 2009, 15 (19), pp.4874-4885. 10.1002/chem.200802388 . hal-00397614

\section{HAL Id: hal-00397614 https://hal.science/hal-00397614}

Submitted on 29 Mar 2021

HAL is a multi-disciplinary open access archive for the deposit and dissemination of scientific research documents, whether they are published or not. The documents may come from teaching and research institutions in France or abroad, or from public or private research centers.
L'archive ouverte pluridisciplinaire HAL, est destinée au dépôt et à la diffusion de documents scientifiques de niveau recherche, publiés ou non, émanant des établissements d'enseignement et de recherche français ou étrangers, des laboratoires publics ou privés. 


\title{
Radical Polymerization of Vinyl Acetate with Bis(tetramethylheptadionato)- cobalt(II): Coexistence of Three Different Mechanisms
}

\author{
Santhosh Kumar K. S., ${ }^{[b]}$ Yves Gnanou, ${ }^{*}{ }^{[b]}$ Yohan Champouret, ${ }^{[a, c]}$ Jean-Claude Daran, ${ }^{[a, c]}$ and \\ Rinaldo Poli*[a,c,d]
}

\begin{abstract}
Compound bis(2,2,6,6tetramethylhepta-3,5-dionato)cobalt(II), $\mathrm{Co}(\mathrm{tmhd})_{2}(\mathbf{4})$, has been investigated as a mediator for the controlled radical polymerization of vinyl acetate and compared with the bis(acetylacetonato)cobalt(II) analogue, $\mathrm{Co}(\mathrm{acac})_{2}$ (1). A relatively well controlled process occurs, after an induction time, with 2,2'-azobis(4-methoxyl-2,4-dimethylvaleronitrile) (V-70) as radical initiator at $30^{\circ} \mathrm{C}$. However, whereas the polymerization essentially stops after ca 6 initiator half-lives in the presence of $\mathbf{1}$ it continues with a first-order rate law in the presence of $\mathbf{4}$. The successful simulation of the kinetic data shows that $\mathbf{4}$ operates simultaneously by associative (degenerative transfer, DT)
\end{abstract}

and dissociative (organometallic radical polymerization, OMRP) mechanisms. The occurrence of OMRP was confirmed by an independent polymerization experiment starting from an isolated and purified $\mathrm{Co}(\mathrm{tmhd})_{2}$ (PVAc) macroinitiator. The polymer molecular weight evolves linearly with conversion in accordance to the expected values for one chain per Co atom when DT is the predominant mechanism and also during the pure OMRP process; however, stagnating molecular weights are observed at long reaction times concomitantly with the breakdown of the first order rate law for monomer consumption, indicating a competitive chain transfer process catalyzed by an increasing amount of
$\mathrm{Co}^{\mathrm{II}}$. In the presence of external donors $\mathrm{L}$ (water, pyridine, triethylamine) the DT pathway is blocked and the OMRP pathway is accelerated, with complex 4 now being ca. 5 times slower than complex 1. The reversal of relative effective OMRP rate constants, $k_{\text {eff }}(4>$ $\mathbf{1}$ in the absence of external donors, $\mathbf{4}<$ $\mathbf{1}$ in their presence) is rationalized through competitive steric effects on $\mathrm{Co}^{\mathrm{III}}-\mathrm{C}$ and $\mathrm{Co}^{\mathrm{II}}-\mathrm{L}$ bond strengths. These propositions are supported by ${ }^{1} \mathrm{H}$ NMR studies and by DFT calculations.

Keywords: controlled radical
polymerization $\cdot$ cobalt $\cdot$ poly $($ vinyl
acetate $) \cdot$ OMRP $\cdot$ degenerative
transfer

\section{Introduction}

In recent years, rapidly increasing attention has been paid to controlled radical polymerization (CRP). ${ }^{[1-6]}$ Consequently, novel polymeric materials with well-defined molecular parameters such as

[a] Dr. Yohan Champouret, Dr. Jean-Claude Daran, Prof. Rinaldo Poli CNRS; LCC (Laboratoire de Chimie de Coordination); 205, route de Narbonne, F-31077 Toulouse Fax: +33-561553003

E-mail: rinaldo.poli@lcc-toulouse.fr

[b] Dr. Santhosh Kumar K. S., Dr. Yves Gnanou Laboratoire de Chimie des Polymères Organiques ENSCPB-CNRS-Université Bordeaux

1, 16, Avenue Pey Berland, 33607 Pessac Cedex, France

[c] Université de Toulouse; UPS, INPT; F-31077 Toulouse, France

[d] Institut Universitaire de France, 103, bd Saint-Michel, 75005 Paris, France average molecular weight, molecular-weight distribution, chain-end functionality, and topological-structure have been accessible through various strategies. A current challenge of CRP is to control the radical polymerization of monomers that generate more reactive radicals such as vinyl acetate, vinyl chloride, vinylidene chloride, and ethylene.

A variety of methods have been devoted to mediating the polymerization of vinyl acetate (VAc) with a certain success, such as degenerative chain transfer with alkyl iodides, ${ }^{[7]}$ dithiocarbamates and xantates (RAFT/MADIX), ${ }^{[8-10]}$ ATRP, ${ }^{[11,12]}$ the use of bis( $\beta$ diketonato)cobalt(II), pioneered by Jérôme and coworkers with acetylacetonatocobalt(II), $\mathrm{Co}(\mathrm{acac})_{2}, \quad \mathbf{1}^{[13-18]}$ being particularly successful. Diblock copolymers of VAc with N-vinylpyrrolidone, ${ }^{[19]}$ styrene, ${ }^{[20]}$ and acrylonitrile ${ }^{[21,22]}$ have also been obtained by use of $\mathrm{Co}(\mathrm{acac}) 2$. The fluorinated analogues bis(1,1,1-trifluoropenta-2,4dionato)cobalt(II), $\quad \mathrm{Co}\left(\mathrm{acac}_{3} \mathrm{~F}_{3}\right), \quad \mathbf{2}, \quad$ and $\operatorname{bis}(1,1,1,5,5,5$ hexafluoropenta-2,4-dionato)cobalt(II), $\operatorname{Co}\left(\text { acac-F}_{6}\right)_{2}, \mathbf{3}$, have also been investigated by the Matyjaszewski group for VAc and related monomers. ${ }^{[23,24]}$ While compound $\mathbf{2}$ exerts a level of control comparable to that of $\mathbf{1}$, compound $\mathbf{3}$ yields higher molecular weights and higher polydispersities. 


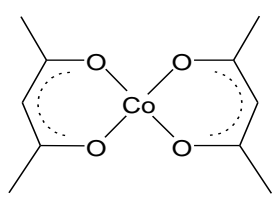

1
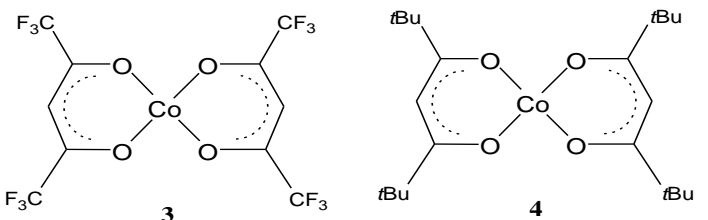

In recent contributions, we have shown that the control exerted by $\mathrm{Co}(\mathrm{acac})_{2}$ on the VAc polymerization occurs by degenerative transfer (DT) when no additional Lewis bases are present, ${ }^{[25]}$ but it switches to reversible deactivation (RD) and more specifically to a process that we have termed "organometallic radical polymerization" (OMRP) $)^{[26]}$ in the presence of donor ligands such as pyridine, NEt3, or water, see Scheme $1 .^{[25,27]}$ Porphyrin-based cobalt systems have also been shown to function either by OMRP ${ }^{[28-}$ ${ }^{31]}$ or by degenerative transfer, ${ }^{[32-36]}$ depending on conditions and on the nature of monomer. Furthermore, the two mechanisms have been shown to cohabitate for the polymerization of acrylic acid in water. ${ }^{[35]}$

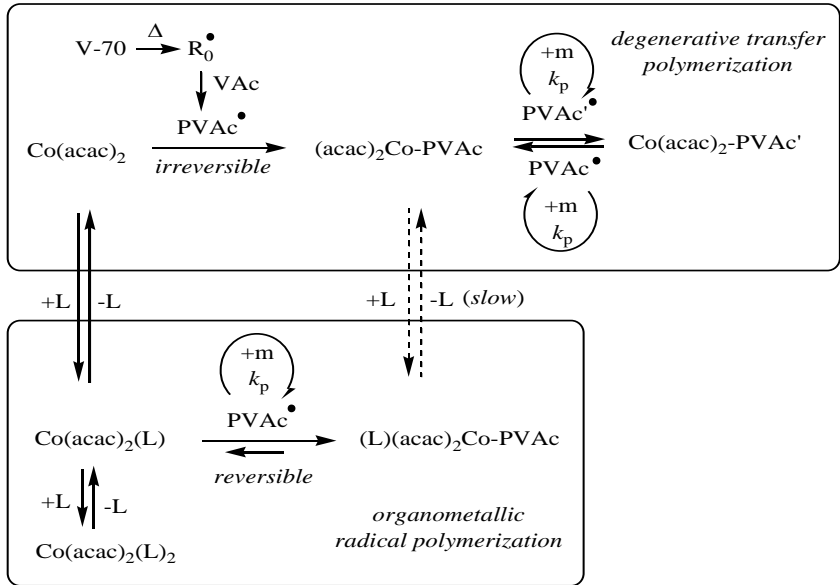

Scheme 1.

It has been argued that OMRP should be particularly suitable for controlling difficult monomers, ${ }^{[26]}$ because the steric effect of the ligand coordination sphere can be adjusted with a view of fine tuning the metal-carbon bond strength in a range suitable for control of any desired monomer. The additional advantage of metal complexes is the variety of available transition metals and ligands, which can be tailored to mediate the polymerization of the monomer of choice. We have already proven the validity of this principle by using a family of half-sandwich chromium $\beta$-diketiminates, $\mathrm{CpCr}\{\operatorname{ArNC}(\mathrm{Me}) \mathrm{CHC}(\mathrm{Me}) \mathrm{NAr}\}$, where the steric bulk of the aryl substituent $\left(\mathrm{Ar}=2,6-\mathrm{C}_{6} \mathrm{H}_{3} \mathrm{Me}_{2}, 2,6-\mathrm{C}_{6} \mathrm{H}_{3} i \mathrm{Pr}_{2}\right)$ was shown to significantly affect the strength of the $\mathrm{Cr}^{\mathrm{III}}-\mathrm{R}$ bond in the OMRP dormant chain. ${ }^{[37]}$

In this paper, we report the use of $\mathrm{Co}(\mathrm{tmhd})_{2}, \mathbf{4}$, (tmhd $=2,2,6,6$ tetramethylhepta-3,5-dionate) in the radical polymerization of vinyl acetate, carried out in the presence of 2,2'-azobis(4-methoxyl-2,4- dimethylvaleronitrile) $(\mathrm{V}-70)$ as a radical source at $30^{\circ} \mathrm{C}$. As will be shown, the introduction of the bulkier $t \mathrm{Bu}$ group allows the complex to bring about the OMRP mechanism, even in the absence of axial bases, although the process can be further accelerated by axial bases. The studies carried out in the absence of axial base have also revealed the cohabitation of DT and OMRP, as well as a weak activity of the $\mathrm{Co}^{\mathrm{II}}$ complex as a chain transfer catalyst which becomes significant when its concentration increases.

\section{Results and Discussion}

\section{(a) Bulk polymerization of vinyl acetate in the absence of external base}

The polymerization of vinyl acetate (VAc) initiated by V-70 in the presence of complex 4 was initially investigated in neat monomer at different V-70/Co ratios. The conversion as a function of time is shown graphically in Figure 1 (all data are available in the Supporting Information Table S1). All polymerizations are characterized by an induction time. For the experiments run with a larger excess of primary radical $\left(\mathrm{R}_{0}\right)$ source, i.e. when $\mathrm{V}-70 / \mathrm{Co} \geq 1$, this corresponds to the time necessary for the primary radicals, after insertion of one or more molecules of monomer, to convert all $\mathrm{Co}(\mathrm{tmhd})_{2}$ to the organocobalt(III) product (tmhd $)_{2} \mathrm{Co}^{\mathrm{III}}-(\mathrm{VAc})_{n} \mathrm{R}_{0}$. In agreement with this view, the induction time is shorter for higher $\mathrm{V}-70 / \mathrm{Co}$ ratios. This process is identical to that exhibited by $\mathrm{Co}(\mathrm{acac})_{2}$ (Scheme 1). Using the $\mathrm{t}_{1 / 2}$ literature value for the $\mathrm{V}-70$ decomposition at $30^{\circ} \mathrm{C}^{[38]}$ and the stoichiometry of one radical chain per cobalt atom, the observed inductions times lead to the calculation of an initiator efficiency $f$ in the range $0.35-0.55$. In agreement with the occurrence of a DT mechanism, the effective polymerization rate constant measured immediately after the induction period increases with the initiator concentration.

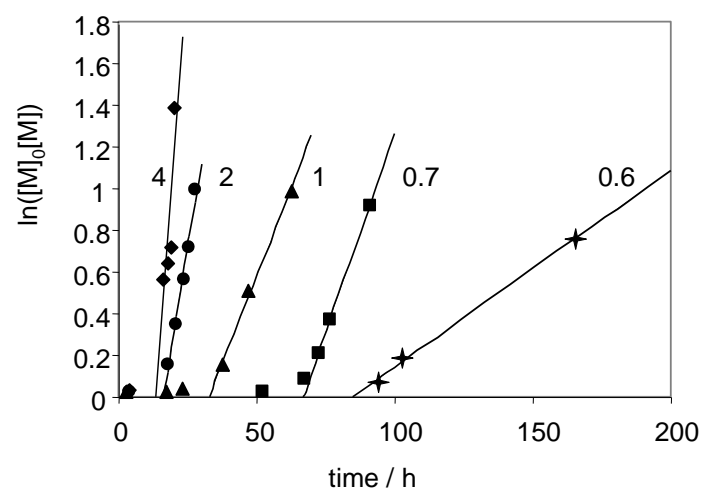

Figure 1. Conversion as a function of time for the bulk VAc polymerization initiated by $\mathrm{V}-70$ at $30^{\circ} \mathrm{C}$. The different data refer to different V-70/Co ratios (values given next to each curve).

Given that the efficiency factor is not greater than ca. 0.5 , the results of the experiments run with 0.7 and especially 0.6 equiv of V-70 per Co atom cannot be rationalized on the basis of a DT mechanism. Indeed, an insufficient amount of primary radicals is produced to convert all $\mathrm{Co}^{\mathrm{II}}$ to $\mathrm{Co}^{\mathrm{III}}$ in these experiments. Note also that these two experiments involve a sustained polymer growth after $60 \mathrm{~h}$ from the beginning of the polymerization, which corresponds to ca. 6 half-lives of the radical initiator. As will be confirmed by the experiments described later, no significant amount of new primary radicals is generated beyond $60 \mathrm{~h}$ at $30^{\circ} \mathrm{C}$. Therefore, these 
experiments suggest that polymerization can also occur by reversible activation/deactivation of the $\mathrm{Co}^{\mathrm{III}}$-capped dormant chains. The level of control is not as good as that reported for $\mathrm{Co}(\mathrm{acac})_{2},{ }^{[13]}$ but the $\mathrm{M}_{\mathrm{n}}$ values show the expected linear growth with respect to conversion, though always greater than the expected values for one chain per cobalt atom. In addition, the molecular weight distributions are relatively narrow (see Figure 2).

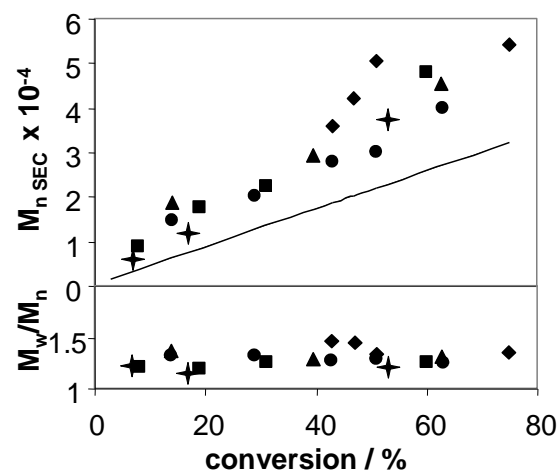

Figure 2. Dependence of the PVAc $\mathrm{M}_{\mathrm{n}}$ and $\mathrm{M}_{\mathrm{w}} / \mathrm{M}_{\mathrm{n}}$ on monomer conversion for the VAc polymerization at $30^{\circ} \mathrm{C}$. The straight line represents the theoretical $\mathrm{M}_{\mathrm{n}}$. The meaning of the different symbols is the same as in Figure 1.

\section{(b) Polymerization of vinyl acetate in toluene solution}

As mentioned in the Introduction, increasing the steric bulk of the ligand coordination sphere should decrease the metal-carbon bond strength: the experiments shown in the previous section with a low V-70/Co ratio appear consistent with polymerization by OMRP. It was previously established ${ }^{[25]}$ that the $\mathrm{Co}$ (acac) 2 -mediated VAc polymerization switches from DT to OMRP in the presence of axial bases, but the action of compound $\mathbf{1}$ via the OMRP mechanism in the absence of external bases was not proven. The reported ${ }^{[13]}$ ability of an isolated and purified $\mathrm{Co}(\mathrm{acac})_{2}$-capped chain (macroinitiator) to undergo chain extension in the absence of new radical source appeared to result from water coordination, caused by the handling operations of the macroinitiator in moist air. Indeed, when the isolation and purification procedures were performed under an inert atmosphere, the subsequent chain extension process in the absence of new radicals was very slow, while the rate increased upon addition of either water (facilitating the OMRP mechanism) or a radical source (triggering the DT mechanism). ${ }^{[27]}$

In order to confirm the existence of OMRP in the Co(tmhd)2mediated polymerization and also, for comparison purpose, whether any OMRP may occur in the $\mathrm{Co}(\mathrm{acac})_{2}$-mediated polymerization, we have taken a different approach, consisting of slowing down the DT mechanism in such a way as to reach an incomplete conversion by the time needed to fully exhaust all radical initiator. This can be easily accomplished by diluting the reaction mixture. Then, if the polymerization continues beyond this point, the existence of an OMRP mechanism is proven.

Figure 3 shows the time evolution of the conversion obtained for 50:50 mixtures in the presence of 2 equiv of V-70 per cobalt (the collective data are assembled in the Supporting Information Table S2). As can be clearly seen in the enlargement of the initial stages of the polymerization process, the conversion evolves essentially along the same curve during the first 60 hours (ca. 6 half-lives of the V-70 initiator), after the initial induction time and through the region of polymer growth by DT. This is expected because the polymerization rate for the degenerative transfer mechanism is the same as that of free radical polymerization and should not depend on the nature or concentration of the transfer agent. However, the polymerization essentially stops after ca. 60 hours for the process mediated by 1 (ca. $3 \%$ additional conversion in the subsequent $265 \mathrm{~h}$ ), whereas it continues at a reduced rate for the process mediated by $\mathbf{4}$, clearly suggesting that an OMRP mechanism remains operational and that this mechanism is much more favoured for $\mathbf{4}$. This experiment also sets a new upper limit for the rate of OMRP of VAc mediated by compound 1 under anhydrous conditions $\left(k_{\text {eff }}=1.374 \cdot 10^{-4} \mathrm{~h}^{-1}\right.$ in $50 \%$ toluene).

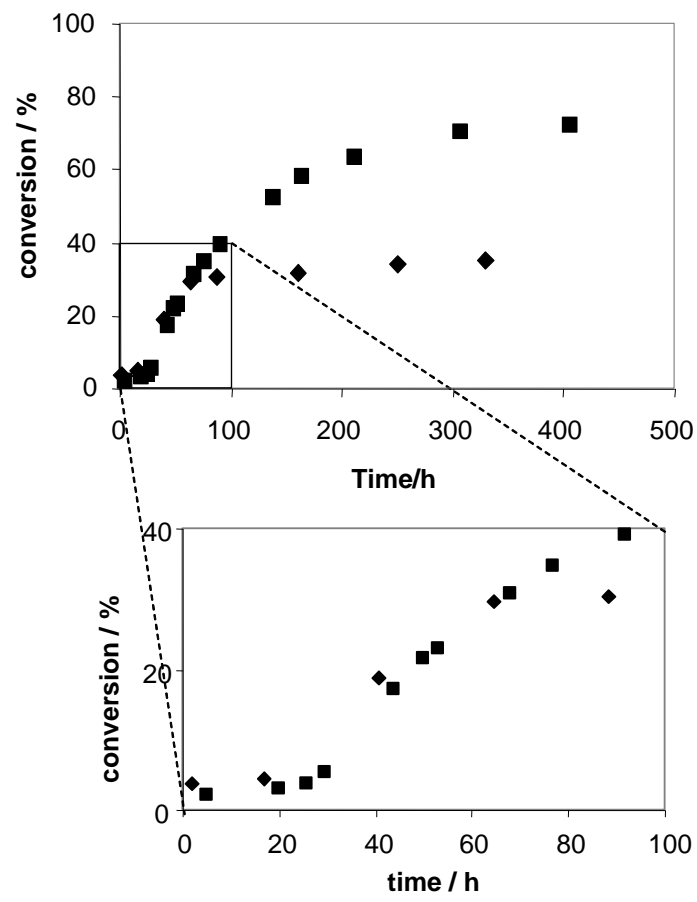

Figure 3. Time dependence of $\ln \left([\mathrm{M}]_{0} /[\mathrm{M}]\right)$ for the polymerization of vinyl acetate at $30^{\circ} \mathrm{C}$ in toluene solution $(50 \% \mathrm{v} / \mathrm{v}) . \mathrm{VAc} / \mathrm{V}-70 / \mathrm{Co}=500: 2: 1$. Squares: polymerization mediated by $\mathbf{4}$; diamonds: polymerization mediated by $\mathbf{1}$.

Figure 4. compares the VAc conversion under the same conditions at different dilutions with toluene (data obtained in toluene/VAc $=25: 75$ are collected in Table S3). It can be seen that the induction time is longer in the experiment carried out at higher dilution. This is caused by the expected reduced initiator efficiency $(f)$ at higher dilution. From the simulations (see below) the efficiency factor was calculated as $0.365,0.325$ and 0.285 for toluene/VAc $=0: 100,25: 75$ and 50:50, respectively. The polymerization rate after the induction period is greater for the more concentrated mixtures, as a result of greater [VAc] and $f$. Consequently, when the transition from DT to OMRP occurs (ca. 60 $\mathrm{h})$, the conversion is greater for the more concentrated mixture.

A more detailed data analysis was carried out as follows (this is summarized here only for the experiment with toluene/VAc $=50: 50$; for additional details and for the other simulations, see Supporting Information). Figure 5 shows that between $60 \mathrm{~h}$ (time at which essentially all V-70 is consumed) and $164 \mathrm{~h}$, a lapse of time during which the conversion increases approximately from 30 to $60 \%$, the monomer consumption follows a first order rate law as expected for the OMRP mechanism. The deviation observed at greater times is attributed to the breakdown of the persistent radical effect (PRE), 
caused by the extremely long reaction times. From the slope of this line, we derive an effective rate constant for the OMRP process ( $k_{\text {eff }}$ $=5.09 \cdot 10^{-3} \mathrm{~h}^{-1}$, over 30 times the upper estimate for the OMRP effective rate in the presence of $\left.\mathrm{Co}(\mathrm{acac})_{2}\right)$. Note that the breakdown of the PRE implies an increase in [4], an indirect evidence of which is provided by the onset of catalytic chain transfer activity (vide infra).

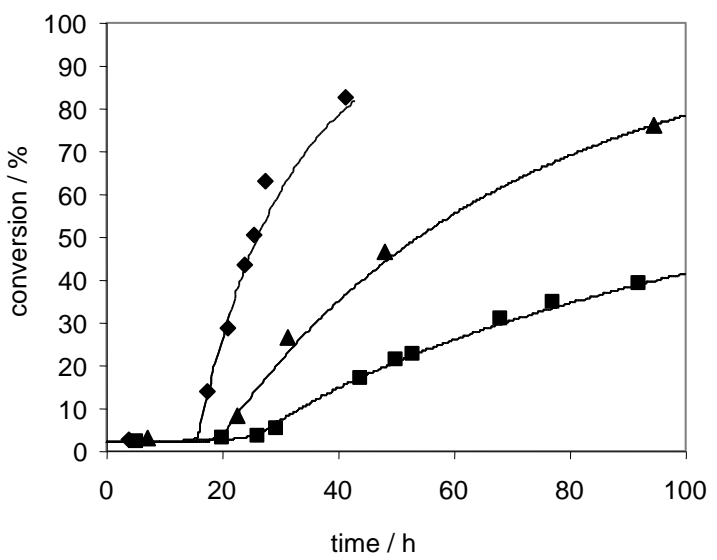

Figure 4. Comparison of the VAc polymerization mediated by complex $\mathbf{4}$ at different dilutions. VAc/V-70/Co $=500: 2: 1 ; \mathrm{T}=30^{\circ} \mathrm{C}$. VAc/toluene $(\mathrm{v} / \mathrm{v})=100: 0$ (diamonds); 75:25 (triangles); 50:50 (squares). The solid lines are the simulated curves (see text).

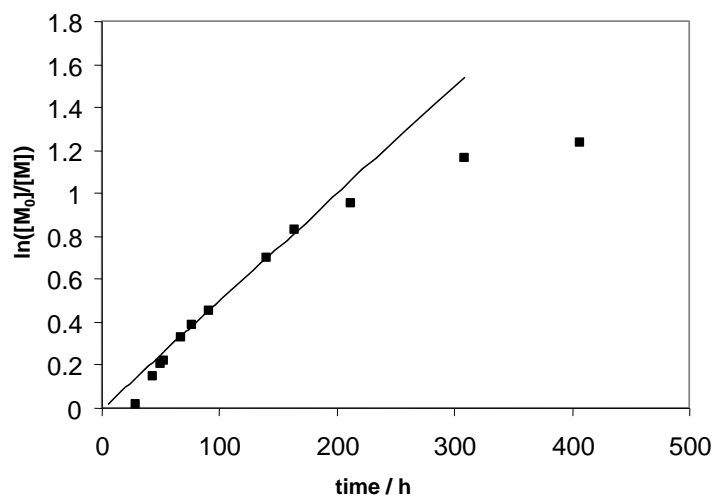

Figure 5 . First order plot of the VAc polymerization mediated by compound 4 . VAc/V$70 / \mathrm{Co}=500: 2: 1 ; \mathrm{T}=30^{\circ} \mathrm{C} ;$ toluene/VAc $(\mathrm{v} / \mathrm{v})=50: 50$.

Taking into account that OMRP may also take place during the induction period, though the radical activation equilibrium is repressed by the excess $\mathrm{Co}^{\mathrm{II}}$ (the $\left[\mathrm{Co}^{\mathrm{III}}\right] /\left[\mathrm{Co}^{\mathrm{II}}\right]$ ratio increases from 0 at $\mathrm{t}=0$ to a maximum value at the onset of the DT process, $\mathrm{tind}_{\mathrm{ind}}$, and that the DT and OMRP mechanisms operate simultaneously after $t_{\text {ind, }}$ equations were derived for the time evolution of $\ln \left([\mathrm{M}]_{0} /[\mathrm{M}]\right)$ and fit to the data during the entire experiment (up to $164 \mathrm{~h}$ ). An adjustment had to be made to account for the small monomer consumption before the induction time ( $2 \%$ at $5 \mathrm{~h}$ ), because this could not properly be accounted for by the intervention of OMRP. We assume that this amount results from the small amount of monomer that adds to the primary radicals before their trapping by $\mathbf{4}$, to form the initial (tmhd $)_{2} \mathrm{Co}-(\mathrm{VAc})_{\mathrm{n}} \mathrm{R}_{0}$ oligomers. Indeed, the corresponding $\mathrm{Co}(\mathrm{acac})_{2}$ system was shown to yield (acac) ${ }_{2} \mathrm{Co}-$ $(\mathrm{VAc})_{\mathrm{n}} \mathrm{R}_{0}$ oligomers with $\mathrm{n} \sim 3$, which were isolated and characterized, under conditions of a large excess of 1 with respect to monomer. ${ }^{[27]}$ The propagation rate constant $\left(k_{\mathrm{p}}\right)$ was fixed at the literature value $\left(117 \mathrm{~s}^{-1} \mathrm{M}^{-1}\right),{ }^{[38]}$ whereas the initiator decomposition rate constant $\left(k_{\mathrm{d}}\right)$ and efficiency factor $(f)$ and the termination rate constant $\left(k_{\mathrm{t}}\right)$ were freely optimized. The curve fitting to the data gave optimized values for these rate constants $\left(k_{\mathrm{d}}=0.072 \mathrm{~h}^{-1}, k_{\mathrm{t}}=\right.$ $\left.1.74 \cdot 10^{8} \mathrm{~s}^{-1} \mathrm{M}^{-1}\right)$ in close agreement with the literature, ${ }^{[38]}$ attesting to the self-consistency of the mechanistic model. The simulated conversion $v s$. time curves are shown in Figure 4.

A final test for the presence of OMRP was carried out as follows. A new experiment was carried out exactly as shown in Figure 4 (50:50 toluene/VAc mixture), but the polymerization was stopped after $41 \mathrm{~h}$, corresponding to a conversion of $13 \%$ (in good agreement with the trend shown in Figure 4). The resulting polymer was isolated by precipitation and washed, which eliminated all residual V-70. It was then added to the same amount of fresh VAc/toluene $(1: 1)$ and warmed again to $30^{\circ} \mathrm{C}$. The results are collected in Table 1 . The successful resumption of the polymerization demonstrates that indeed the isolated polymer is a macroinitiator and that a reversible termination mechanism (OMRP) must be operating. Comparison of the first order kinetics in Figure 6 yields approximately the same effective rate constant, showing that essentially all cobalt-containing chain ends have retained their activity through the polymer isolation and purification procedure.

Table 1. Polymerizations of VAc in toluene solution $(50 \% \mathrm{v} / \mathrm{v})$ initiated by a PVAc-Co(tmhd $)_{2}$ macroinitiator. ${ }^{\mathrm{a}}$

\begin{tabular}{lllll}
\hline $\begin{array}{l}\text { Time } \\
(\mathrm{h})\end{array}$ & $\begin{array}{l}\text { Conv } \\
(\%)\end{array}$ & $\begin{array}{l}\mathrm{M}_{\mathrm{n} \mathrm{SEC}} \\
(\mathrm{x} \mathrm{10})\end{array}$ & $\begin{array}{l}\mathrm{M}_{\mathrm{n} \text { theo }} \\
(\mathrm{x} \mathrm{10})\end{array}$ & $\mathrm{M}_{\mathrm{w}} / \mathrm{M}_{\mathrm{n}}$ \\
\hline 41 & 13.0 & 0.55 & 0.56 & 1.14 \\
65 & 19.2 & 1.00 & 0.83 & 1.20 \\
90 & 28.8 & 1.51 & 1.24 & 1.17 \\
136.75 & 40.3 & 1.76 & 1.73 & 1.21 \\
161 & 45.9 & 1.87 & 1.98 & 1.25 \\
233 & 52.3 & 2.03 & 2.25 & 1.19 \\
\hline
\end{tabular}

[a] Conditions: VAc/V-70/4 $=500: 2: 1 ; \mathrm{T}=30^{\circ} \mathrm{C}$; polymerization stopped after $41 \mathrm{~h}$ (13\% conversion), polymer precipitated and washed, then polymerization resumed by addition of monomer and toluene $(1: 1 \mathrm{v} / \mathrm{v})$. The time values shown include the time used for the macroinitiator preparation $(41 \mathrm{~h})$.

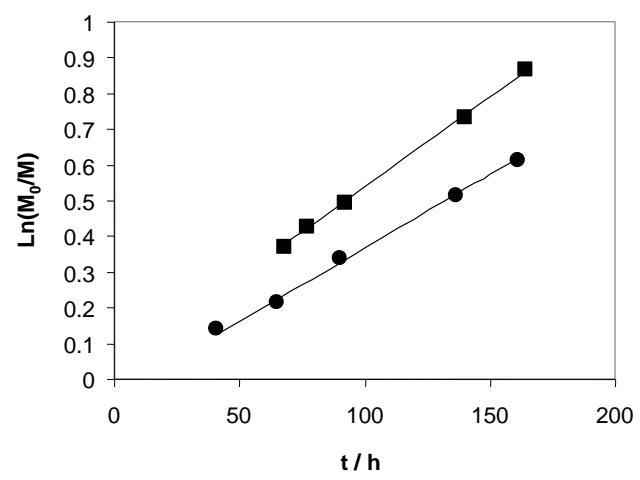

Figure 6. Comparative kinetics in the OMRP region for the VAc polymerizations initiated by V-70/4 (from Figure 5, squares) and by the PVAc-Co(tmhd) 2 macroinitiator (Table 1, circles).

Coming now to the analysis of the average molecular weights and molecular weight distribution (data in the Supporting Information, Figure 2 and Table 1), it is notable that $\mathrm{M}_{\mathrm{n}, \mathrm{SEC}}$ grows linearly with conversion (being only slightly greater than $\mathrm{M}_{\mathrm{n}, \mathrm{theo}}$ ) up to the point in the OMRP region where the monomer consumption follows first order kinetics, but falls below the theoretical value at longer times, when the PRE breaks down. This is clearly shown in the progression of the GPC traces in Figure 7. The major expected 
phenomenon when the PRE breaks down is an increase in concentration for the $\mathrm{Co}^{\mathrm{II}}$ complex $\mathbf{4}$, which may also operate as a chain transfer catalyst through the abstraction of a hydrogen atom and formation of an intermediate $\mathrm{Co}^{\mathrm{III}}-\mathrm{H}$ complex. It is to be noted in this respect that $\mathrm{Co}^{\mathrm{II}}$ complexes are well known to operate as chain transfer catalysts. ${ }^{[39-41]}$

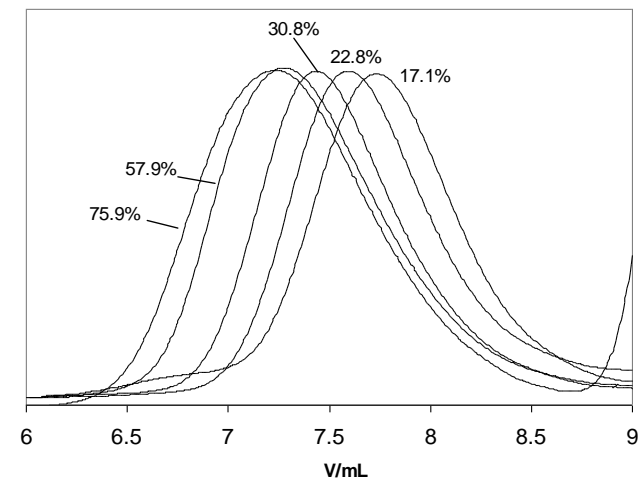

Figure 7. SEC chromatograms for the PVAc from the polymerization controlled by compound 4. $\mathrm{VAc} / \mathrm{V}-70 / \mathrm{Co}=500: 2: 1 ; \mathrm{T}=30^{\circ} \mathrm{C}$; toluene/VAc $(\mathrm{v} / \mathrm{v})=50: 50$.

As long as the DT mechanism dominates, the excess free radicals that are continuously injected into solution by the decomposition of $\mathrm{V}-70$ represses the equilibrium dissociation of the organocobalt(III) dormant chains, keeping the concentration of $\mathrm{Co}^{\mathrm{II}}$ complex (the CCT agent) small. The role of DT on the suppression of CCT has also been pointed out by Wayland for porphyrin $\mathrm{Co}^{\mathrm{II}}$ systems. ${ }^{[34]}$ When no new radicals are injected into solution, the $\mathrm{Co}^{\text {II }}$ concentration increases and CCT starts to compete with a controlled chain growth, but only a rather small $\mathrm{Co}^{\mathrm{II}}$ concentration is enforced by the unfavorable dissociation equilibrium; this results from the strong Co $\mathrm{Co}^{\mathrm{III}}-\mathrm{PVAc}$ bond, as shown by the rather slow polymerization rate. However, the $\mathrm{Co}^{\mathrm{II}}$ concentration continuously increases as a result of irreversible terminations and becomes substantial at very long reaction times. Since the incidence of this phenomenon remains small and the phenomenon becomes effective only when the polymer chains are already rather long, direct evidence for the formation of unsaturated chain ends by NMR or MALDI-TOF MS could not be obtained. It should be remarked that CCT may occur at a significant rate at the beginning of the induction period, where $\left[\mathrm{Co}^{\mathrm{II}}\right] /\left[\mathrm{Co}^{\mathrm{III}}\right]$ is high. However, NMR experiments specifically conceived to probe the formation of small oligomers during the induction period did not provide any positive evidence.

In conclusion, three different functions have been highlighted for complex 4 in the VAc polymerization: (i) reversible trapping of the growing PVAc radical chain (OMRP mechanism); (ii) associative exchange of the growing PVAc radical chains (DT mechanism); (iii) $\mathrm{H}$ atom transfer from the PVAc radical chains to yield catalyzed chain transfer (CCT). Processes (i) and (iii) may cohabitate during the induction period and at long reaction times, whereas all processes may cohabitate after $t_{\text {ind }}$ and as long as new radicals are being injected into solution from the initiator, but their relative importance changes with time. Process (iii) is minimized by the excess free radicals and its relative importance increases with time, whereas process (ii) decreases exponentially, together with the rate of generation of new radicals. The greater incidence of OMRP for the VOAc polymerization mediated by $\mathbf{4}$, relative to that mediated by $\mathbf{1}$, is consistent with a weaker Co-PVAc bond in the presence of the bulkier tmhd ligand. This proposition has been verified by DFT calculations, which will be described later in section (c). Note that the cohabitation of associative (degenerative transfer) and dissociative (reversible deactivation) mechanisms has previously been highlighted not only for the cobalt-mediated radical polymerization of acrylic acid by a cobalt porphyrin system, ${ }^{[35]}$ but also for the organotellurium-mediated living radical polymerization (TERP) of a variety of vinyl monomers. ${ }^{[42]}$

\section{(c) Polymerization of vinyl acetate in the presence of an external base}

Additional experiments of $\mathrm{Co}(\mathrm{tmh})_{2}$-mediated VAc polymerization were carried out in the presence of an external base (pyridine, triethylamine, or water), in order to evaluate the coordinating ligand ability to shut down the DT mechanism and to speed up the OMRP mechanism, by analogy with the previously reported polymerization controlled by compound $\mathbf{1}^{[25]}$ For direct comparison purposes, the polymerizations were conducted under conditions identical to those previously used for $\mathbf{1}$ (bulk, $30^{\circ} \mathrm{C}$, $\mathrm{VAc} / \mathrm{V}-70 / \mathrm{Co} / \mathrm{L}=500: 0.7: 1: 30)$. The results are collected in Table 2. In brief, the behavior is qualitatively identical to that previously observed for the polymerization controlled by $\mathbf{1}$ in terms of the time evolution of the conversion (see Figure 8), namely: (i) there is no induction time for the py and $\mathrm{NEt}_{3}$ experiments (for the $\mathrm{H}_{2} \mathrm{O}$ experiment, vide infra); (ii) the polymerization obeys first order kinetics; (iii) the effective polymerization rate decreases as the added ligand $\mathrm{L}$ varies in the order: $\mathrm{H}_{2} \mathrm{O}>$ py $>\mathrm{NEt}_{3}>$ no ligand (before the induction time); (iv) there is no increase of polymerization rate after all the $\mathrm{Co}^{\mathrm{II}}$ has been transformed to $\mathrm{Co}^{\mathrm{III}}$ (i.e. when excess radicals relative to Co start to be injected into solution). The last observation proves that the $\mathrm{L}$ addition completely shuts down the DT mechanism.

Table 2. Polymerization data for the bulk VAc polymerization mediated by compound 4 in the presence of added ligands (L). ${ }^{\mathrm{a}}$

\begin{tabular}{llllll}
\hline $\mathrm{L}$ & $\begin{array}{l}\text { Time } \\
(\mathrm{h})\end{array}$ & $\begin{array}{l}\mathrm{Conv} \\
(\%)\end{array}$ & $\begin{array}{l}\mathrm{M}_{\mathrm{nSEC}} \\
(\mathrm{x} \mathrm{10})\end{array}$ & $\begin{array}{l}\mathrm{M}_{\mathrm{n} \text { theo }} \\
\left(\mathrm{x} \mathrm{10} 0^{-4}\right)\end{array}$ & $\mathrm{M}_{\mathrm{w}} / \mathrm{M}_{\mathrm{n}}$ \\
\hline $\mathrm{H}_{2} \mathrm{O}$ & 4 & 1.3 & - & - & - \\
$\mathrm{H}_{2} \mathrm{O}$ & 7 & 3.5 & - & - & - \\
$\mathrm{H}_{2} \mathrm{O}$ & 19 & 50.4 & 6.49 & 2.17 & 1.31 \\
$\mathrm{H}_{2} \mathrm{O}$ & 24 & $79 / 0$ & 9.86 & 3.40 & 1.68 \\
\hline py & 4 & 3.5 & - & - & - \\
py & 7 & 4.7 & - & - & - \\
py & 20 & 13.7 & 2.33 & 0.56 & 1.25 \\
py & 44 & 25.6 & 2.46 & 1.10 & 1.60 \\
py & 68 & 32.0 & 3.44 & 1.38 & 1.39 \\
py & 92 & 37.0 & 3.50 & 1.60 & 1.45 \\
\hline $\mathrm{NEt}_{3}$ & 4 & 2.1 & - & - & - \\
$\mathrm{NEt}_{3}$ & 19 & 2.5 & - & - & - \\
$\mathrm{NEt}_{3}$ & 51 & 4.2 & - & - & - \\
$\mathrm{NEt}_{3}$ & 67 & 4.5 & - & - & - \\
$\mathrm{NEt}_{3}$ & 91 & 5.0 & - & - & - \\
\hline
\end{tabular}

[a] Conditions: VAc/V-70/Co/L $=500: 0.7: 1: 30 ; \mathrm{T}=30^{\circ} \mathrm{C}$

In order to explain the small induction time and non linearity of the first order plot observed for the $\mathrm{H}_{2} \mathrm{O}$ experiment (see Figure 8), we advance the hypothesis that $\mathbf{4}$ does not react rapidly with $\mathrm{H}_{2} \mathrm{O}$ because it is confined in the monomer phase, where water is immiscible. Thus, the polymerization starts only after a sufficient 
amount of $\mathbf{4}$ has reacted with $\mathrm{H}_{2} \mathrm{O}$ and the polymerization rate increases as more adduct is generated.

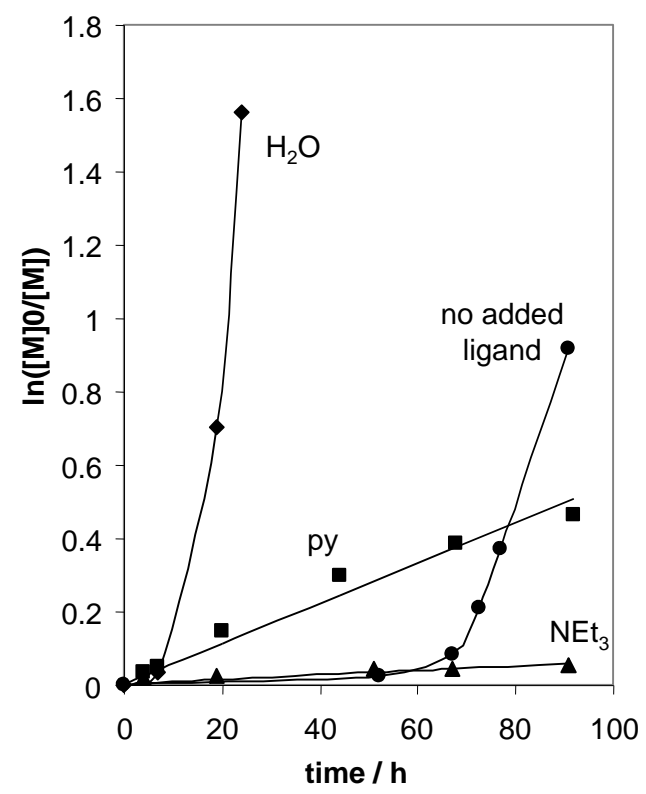

Figure 8. Bulk VAc polymerization in the presence of different added ligands. Conditions are as shown in Table 2. The data obtained in the absence of added base under the same conditions (from Figure 1) is also shown for comparison.

The $\mathrm{M}_{\mathrm{n}}$ values are considerably greater than theory, because the polymer samples are withdrawn when only a fraction of the $\mathrm{Co}^{\mathrm{II}}$ complex has been transformed into $\mathrm{Co}^{\mathrm{III}}$, but the average values increase with conversion and the polydispersities are relatively narrow, similar to those of the polymer obtained in the absence of added ligand, attesting to the similar controlling ability of PVAc$\operatorname{Co}(\text { tmhd })_{2}(\mathrm{~L})$ and PVAc-Co(tmhd $)_{2}$. Thus, the major effect of $\mathrm{L}$ is to speed up the OMRP process, as already established for the polymerization controlled by complex $1 .{ }^{[25,27]}$

It is now of interest to compare the effective polymerization rate constants in the presence of added ligand for compounds $\mathbf{1}$ and $\mathbf{4}$. The approximate pseudo-first order rate constants derived from the data in Figure 8 are $5.50 \cdot 10^{-3} \mathrm{~h}^{-1}$ for $\mathrm{L}=$ py and $6.67 \cdot 10^{-4} \mathrm{~h}^{-1}$ for $\mathrm{L}=$ $\mathrm{NEt}_{3}$. These values are a factor of ca. 5 smaller than those of the polymerization mediated by 1 under identical conditions $\left(2.25 \cdot 10^{-2}\right.$ $\mathrm{h}^{-1}$ for $\mathrm{L}=$ py and $1.40 \cdot 10^{-3} \mathrm{~h}^{-1}$ for $\left.\mathrm{L}=\mathrm{NEt}_{3}\right) \cdot{ }^{[25]}$ This behavior is opposite to what is observed in the absence of added donor: compound $\mathbf{1}$ gives a faster polymerization than compound $\mathbf{4}$ in the presence of coordinating ligands but a slower one in the absence of ligands. The reasons for this unexpected behavior is that the greater weakness of the Co-PVAc bond in the order tmhd < acac is more than compensated by a greater weakness of the Co-L bonds in the same order for the Lewis base stabilized $\mathrm{Co}\{\mathrm{RC}(\mathrm{O}) \mathrm{CHC}(\mathrm{O}) \mathrm{R}\}_{2}(\mathrm{~L})_{2}$ $(\mathrm{R}=\mathrm{Me}, t \mathrm{Bu})$ species. The strength of this interaction has been investigated more in detail by experimental and computational technique for the specific case where $\mathrm{L}=\mathrm{py}$, as shown in the next sections.

\section{(d) Experimental study of the Co(tmhd)2-pyridine interaction}

Compound trans-Co(tmhd $)_{2}(\mathrm{py})_{2}$ has been obtained in the form of single crystals upon interaction between compound $\mathbf{4}$ and a large excess of pyridine. A view of the molecular geometry, obtained by
X-ray diffractometry, is shown in Figure 9 and a list of relevant structural parameters is given in Table 3 . The compound crystallizes with the molecule sitting on an inversion center, thus all trans angles are linear by symmetry. The ground state structure does not reveal any particular steric encumbrance, since the Co-O and $\mathrm{Co}-\mathrm{N}$ distances are very similar to those of the previously described trans-Co(acac $)_{2}(\mathrm{py})_{2}$ analogue. ${ }^{[43]}$ In fact, the Co-N bond length in the tmhd complex is even slightly shorter than that reported for the acac analogue.

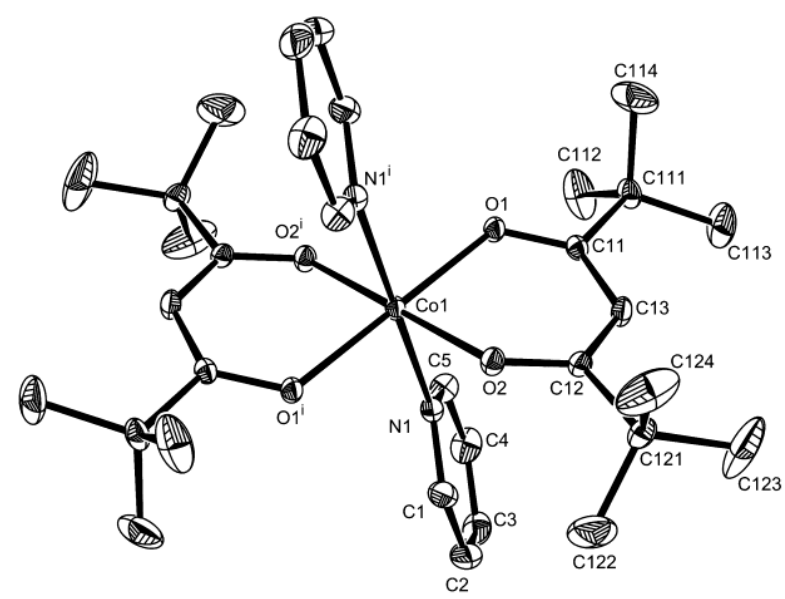

Figure 9. An ORTEP view of the molecular geometry of trans-Co(tmhd $)_{2}(\mathrm{py})_{2}$. Ellipsoid are drawn at the $30 \%$ probability level.

Table 3. Relevant bond distances $(\AA)$ and angles $\left(^{\circ}\right)$ for compounds trans-Co(acac) $)_{2}(\mathrm{py})_{2}$ and trans-Co(tmhd $)_{2}(\mathrm{py})_{2} .{ }^{\mathrm{a}}$

\begin{tabular}{|c|c|c|c|c|}
\hline & \multicolumn{2}{|c|}{ trans $-\mathrm{Co}(\mathrm{acac})_{2}(\mathrm{py})_{2}$} & \multicolumn{2}{|c|}{ trans $-\mathrm{Co}(\mathrm{tmhd})_{2}(\mathrm{py})_{2}$} \\
\hline & X-ray ${ }^{b}$ & DFT & X-ray & DFT \\
\hline \multicolumn{5}{|l|}{ (a) Distances } \\
\hline $\mathrm{Co}-\mathrm{O}$ & $2.034(3)$ & 2.050 & $2.036(12)$ & 2.044 \\
\hline $\mathrm{Co}-\mathrm{N}$ & $2.186(11)$ & 2.205 & $2.1626(15)$ & 2.211 \\
\hline $\mathrm{O}-\mathrm{C}$ & $1.241(6)$ & 1.269 & $1.264(2)$ & 1.271 \\
\hline \multicolumn{5}{|l|}{ (b) Angles } \\
\hline $\mathrm{O}-\mathrm{Co}-\mathrm{O}$ (cis) & $89.8(2)$ & 90.21 & $87.76(5)$ & 89.29 \\
\hline O-Co-O (trans) & $179.2(2)$ & 177.84 & 180 & 178.62 \\
\hline $\mathrm{N}-\mathrm{Co}-\mathrm{N}$ & 180 & 180.00 & 180 & 179.88 \\
\hline
\end{tabular}

[a] Only the average values are given for chemically equivalent parameters. [b] From reference ${ }^{[43]}$.

Further information on the 4-py interaction was obtained by ${ }^{1} \mathrm{H}$ NMR spectroscopy. The ${ }^{1} \mathrm{H}$ NMR spectra of solutions of 4 containing variable amounts of pyridine are shown in Figure 10. The spectra are rather complex but the changes in position and relative intensity of the various resonances as a function of py/4 ratio helps to make a few important assignments. The peak labelled as a at $\delta$ ca. 12.0 is already present in the spectrum of the starting compound. It remains observable at the same chemical shift after addition of pyridine and its intensity decreases until it disappears for a py/4 ratio greater than 3. Concomitantly, a new peak at $\delta$ ca. 20.0 (labelled $b$ ) grows in and its relative intensity no longer varies after reaching a ratio of ca. 3 for py/4. The position of this peak is also invariable. There are no other peaks the intensity of which remains invariant with the py/4 ratio (other than the solvent peak and some 
diamagnetic impurities in the region between $\delta 0$ and 1 , removed from Figure 10 for clarity). It is therefore relatively straightforward to assign the resonance at $\delta 12.0$ to the $t \mathrm{Bu}$ protons of $\mathbf{4}$ and that at $\delta$ 20.0 to the same protons of the bis(pyridine) adduct, which is the isolated product (vide supra). The methyne protons of the tmhd ligand remains unobserved, certainly because of a greater Fermi contact shift and broadening, and a smaller intensity. The disappearance of $\mathbf{4}$ only after the addition of at least 3 equiv of py clearly indicates that the py addition reaction is equilibrated (equation 1). On the other hand, the independent observation of the resonances of reagent and product and their chemical shift invariance with respect to the py/4 ratio indicates that this association/dissociation process is much slower than the chemical shift difference $\left(k<<8 * 250 \mathrm{~Hz}=2000 \mathrm{~s}^{-1}\right)$.

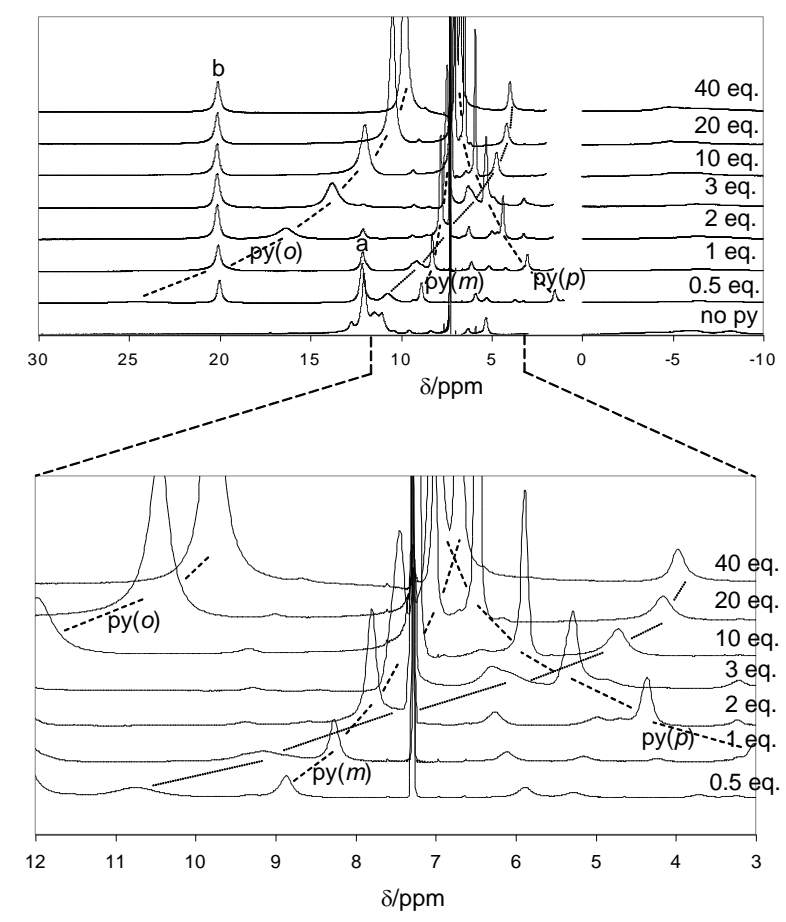

Figure 10. ${ }^{1} \mathrm{H}$ NMR spectra of $\mathrm{C}_{6} \mathrm{D}_{6}$ solutions containing compound $\mathbf{4}$ and pyridine at variable py/4 ratio.

$$
\left.\mathrm{Co}(\mathrm{tmhd})_{2}+2 \mathrm{py} \rightleftharpoons \text { trans-Co(tmhd }\right)_{2}(\mathrm{py})_{2}
$$

Next, we note three resonances the chemical shift of which changes with the py/4 ratio and, at the same time, the intensity of which grows with the py/4 ratio. They must therefore be associated to free pyridine (ortho, meta and para protons). At large py/4 ratio, they converge toward the typical chemical shifts of the free py protons. Their assignment is based on their relative 2:2:1 intensity ( $p$ resonance) and extent of Fermi contact shift ( $o$ resonance). Note that these peaks are already observable for a py/4 ratio of only 0.5 , in agreement once again with the equilibrated nature of equation 1. The strong chemical shift dependence on the py/4 ratio shows that free py exchanges continuously with the paramagnetic $\mathrm{Co}^{\mathrm{II}}$ complex. This process must also be in the slow exchange limit, because the difference $\Delta v$ between coordinated and free pyridine proton resonances is certainly greater than the $8 \mathrm{ppm}$ difference between the $t \mathrm{Bu}$ protons in $\mathbf{4}$ and in the bis(pyridine) adduct. The resonances of the coordinated pyridine protons in complex trans$\left[\mathrm{Co}(\mathrm{tmhd})_{2}(\mathrm{py})_{2}\right]$ could not be detected in the ${ }^{1} \mathrm{H}$ NMR spectrum. The spin density can be readily transmitted to these protons via the aromatic ring conjugation, whereas the $t \mathrm{Bu}$ groups of the tmhd ligand are separated from the conjugated $\beta$-diketonato $\mathrm{CoO}_{2} \mathrm{C}_{3}$ ring by three saturated bonds. Thus, the electron spin density on the coordinated py protons has a stark effect on the diamagnetic free py resonances, even though these resonances are far from the coalescence region.

Other peaks observable in the ${ }^{1} \mathrm{H}$ NMR spectrum could not be clearly attributed, for instance a paramagnetically shifted peak observed at $\delta 11$ for a py/4 ratio of 0.4 , moving upfield and converging toward $\delta$ ca. 4 for large py $/ 4$ ratios. The relative intensity of this peak seems constant, like that of complex trans$\mathrm{Co}(\mathrm{tmhd})_{2}(\mathrm{py})_{2}$, but contrary to the $t \mathrm{Bu}$ resonance its position changes with the py/4 ratio, see Figure 10. Other small peaks are also present, including in the upfield region between -5 and -10 , but their relative intensity and chemical shift change with the py/4 ratio did not allow us to make reasonable hypotheses about their origin. We cannot exclude that some of these peaks are generated by impurities (although the solutions were prepared from a batch of clean single crystals), since the compound is quite sensitive in solution.

The most interesting conclusion from this study comes from a comparison with the previously described ${ }^{1} \mathrm{H}$ NMR study of the 1py interaction. ${ }^{[25]}$ In that case, the three resonances assigned to the free py protons are much more affected by the electron spin density compared with the resonances in the 4-py mixture at the same py/Co ratio. For instance, for a ratio of 3 , the resonances are observed at $\delta$ ca. $33(o), 8(m)$ and $-2(p)$ for 1-py, ${ }^{[25]}$ whereas the same resonances are much closer to the diamagnetic region $(\delta 13.7,7.4$ and 5.3, respectively) for 4-py, see Figure 10. This clearly indicates that equilibrium 1 is much less shifted toward the formation of the bis(pyridine) complex for compound 4 than for compound $\mathbf{1}$. In other words, the formation of the bis(adduct) is thermodynamically less favourable for $\mathbf{4}$ than for $\mathbf{1}$.

\section{(e) DFT calculations}

Since it is important to evaluate how the steric effect of the $t \mathrm{Bu}$ vs Me groups on the $\beta$-diketonate ligands reflects on the $\mathrm{Co}^{\mathrm{III}}$-PVAc and $\mathrm{Co}^{\mathrm{II}}-\mathrm{L}$ bond strengths, calculations were conducted at the full quantum mechanical level on the full molecule, without any simplification for the $\beta$-diketonate and $\mathrm{L}$ ligands. The polymer chain, on the other hand, was modelled by the $\mathrm{CH}\left(\mathrm{OOCCH}_{3}\right) \mathrm{CH}_{3}$ group. The calculations involving an external Lewis base have been restricted to the pyridine system.

In a previous study, we have compared two different hybrid functionals, B3LYP and B3PW91*, and concluded that the latter provides quantitatively more reliable results. ${ }^{[4]}$ Therefore, calculations for the present study were only carried out with B3PW91*. The contribution of the exact exchange is reduced in this functional, thereby providing better estimates of bond energetics for processes involving first-row transition metals where a spin state change is involved. ${ }^{[45,46]} \mathrm{A}$ few bis(acetylacetonato) systems have already been reported in previous studies, but with the energetics given only at the B3LYP level ${ }^{[27]}$ or at the B3PW91* level on the fixed B3LYP-optimized geometries. ${ }^{[44]}$ For better consistency, all geometries have been fully reoptimized here. Previous computational work has also established the preferred stereochemistry of all systems (see Scheme 1), ${ }^{[25]}$ thus no further computational exploration of this issue was necessary in the present 
case. The chelating nature of the ultimate monomer unit in the $\mathrm{Co}^{\mathrm{III}}$ capped dormant chain has been established by combined experimental and computational study for the related bis(acac) system, which included the ${ }^{1} \mathrm{H}$ NMR investigation of an isolated short oligomer, $(\mathrm{acac})_{2} \mathrm{Co}-(\mathrm{VAc})_{\mathrm{n}} \mathrm{R}_{0}$ with $\mathrm{n} \sim 3 .{ }^{[27]}$ The tetrahedral geometry of $\mathrm{Co}(\mathrm{tmhd})_{2}, \mathbf{4}$, is known from a previous $\mathrm{X}$-ray diffraction study, ${ }^{[47]}$ while the trans-octahedral geometry for $\mathrm{Co}(\mathrm{tmhd})_{2}(\mathrm{py})_{2}$ has been verified within the present investigation (vide supra).

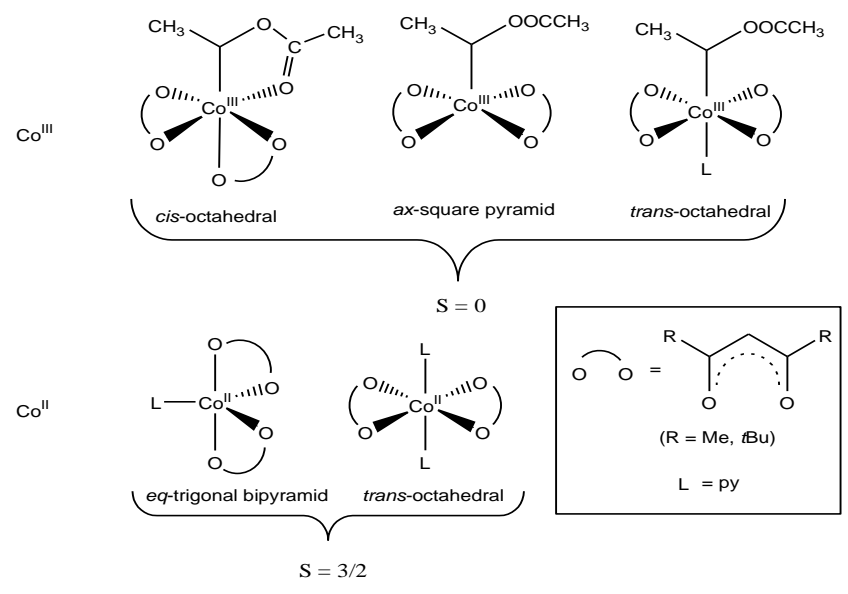

Scheme 1

The energetic results are graphically shown in Figure 11 and the cartesian coordinates and selected bond distances and angles of the optimized geometries are provided in the Supporting Information. Selected bonding parameters for trans- $\left[\mathrm{Co}(\mathrm{acac})_{2}(\mathrm{py})_{2}\right]$ and trans$\left[\mathrm{Co}(\mathrm{tmhd})_{2}(\mathrm{py})_{2}\right]$ are also reported in Table 3 and compared with those established by experiment. The agreement supports the suitability of the computational level. The steric effect of the $t \mathrm{Bu}$ is not significantly reflected in the bond distances [Co-O(acac), Co-C and Co-O(ester) distances change only marginally on going from the acac to the tmhd system]. On the other hand, breaking the $\mathrm{Co}^{\mathrm{III}}-\mathrm{C}$ bond costs less in enthalpy for the tmhd derivative $\left(15.8 \mathrm{kcal} \mathrm{mol}^{-1}\right.$ for tmhd vs. $17.2 \mathrm{kcal} \mathrm{mol}^{-1}$ for acac, $\left.\Delta \mathrm{H}=1.4 \mathrm{kcal} \mathrm{mol}^{-1}\right)$. Part of this enthalpy difference is related to the easier opening of the 5membered chelate ring and the rest comes from the homolytic rupture of the $\mathrm{Co}^{\mathrm{III}}-\mathrm{C}$ bond in the 5-coordinate complex (see Figure 11).

For the recently published calculations of complexes $\mathrm{CpCr}\{\mathrm{ArNC}(\mathrm{Me}) \mathrm{CHC}(\mathrm{Me}) \mathrm{NAr}\}\left\{\mathrm{CH}\left(\mathrm{OCOCH}_{3}\right) \mathrm{CH}_{3}\right\},{ }^{[37]}$ a much greater bond weakening for the $\mathrm{Cr}^{\mathrm{III}}-\mathrm{C}$ bond (by $8.7 \mathrm{kcal} \mathrm{mol}^{-1}$ as $\mathrm{Ar}$ is changed from $\mathrm{Ph}$ to $2,6-\mathrm{C}_{6} \mathrm{H}_{3} \mathrm{Me}_{2}$ ) is accompanied by a significant bond lengthening of $0.015 \AA$. In the present case, the increase of steric bulk does not reflect itself in a metal-ligand bond lengthening effect. Therefore, the bond weakening must be related to a more subtle effect of increased ligand-ligand repulsions, reflected in the adoption of less favorable conformations, rather than longer metalligand bonds. At any rate, the computational result agrees with the experimental observation of a faster radical activation from the dormant chain in the order tmhd > acac, in the absence of external donors. Recent calculations on a bis(pyridylimino)isoindolato system with $\mathrm{R}=\mathrm{CHEtCO}_{2} \mathrm{Me}$ have revealed no significant effect of the pyridyl and indolato substituents on the Co ${ }^{\text {III }}-\mathrm{R}^{\mathrm{BDE}}{ }^{[48]}$

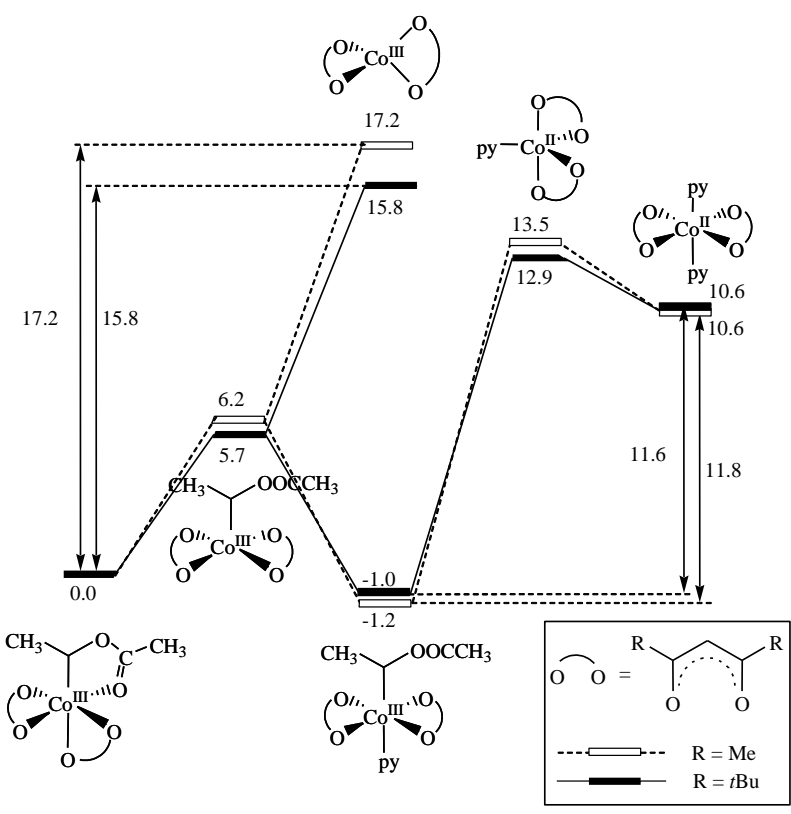

Figure 11. Relative enthalpy changes for processes involving compounds $\mathbf{1}$ or $\mathbf{4}$, the $\mathrm{CH}\left(\mathrm{OOCCH}_{3}\right) \mathrm{CH}_{3}$ radical, and pyridine.

In the presence of external ligands, the dormant chain may open the 5-membered chelate to yield a 6-coordinate adduct, depending on the donor strength of the ligand. For pyridine, the calculations indicate that this adduct is slightly enthalpically favored with respect to the chelated complex (by 1.2 and $1.0 \mathrm{kcal} \mathrm{mol}^{-1}$ for acac and tmhd, respectively, see Figure 11). The dormant chain, however, may remain as a chelated ligand-free complex, because of the unfavorable entropy term associated to the pyridine addition to the system. This term cannot be evaluated quantitatively in the condensed phase. Note that although the chelate opening step is easier for the tmhd derivative, the subsequent py coordination stabilizes the acac system to a greater extent. In this case, a steric effect on the strength of the Co-py bond is supported by the observation of a significantly longer Co-N bond (by $0.016 \AA$ ) for the tmhd derivative.

In the presence of pyridine, the $\mathrm{Co}^{\mathrm{II}}$ complex will exist in solution in the form of the bis(pyridine) adduct, as proven by its isolation in crystalline form and by the NMR study. The calculations show that pyridine coordination entails a significant enthalpic stabilization, in agreement with the accelerating effect on the OMRP mechanism. According to the calculations, the bis(pyridine) adducts are essentially at the same relative enthalpy with respect to the dormant chain for the acac and tmhd systems. This means that the more difficult $\mathrm{Co}^{\mathrm{III}}-\mathrm{C}$ bond breaking for the acac system is compensated by a more favorable $\mathrm{Co}^{\mathrm{II}}$-py bond formation having the same net enthalpy effect. The weaker $\mathrm{Co}^{\mathrm{II}}$-py bond for the tmhd system may once again be associated to a steric effect: the Co-N bond is $0.006 \AA$ longer in the bulkier tmhd system.

The computed relative enthalpy change does not perfectly reproduce the faster OMRP in the order acac $>$ tmhd in the presence of pyridine. It should be noted, however, that the effective rate constant ratio (4.09 at $303 \mathrm{~K}$ in favor of $\mathbf{1}$ ) corresponds to a free energy difference of only $0.85 \mathrm{kcal} \mathrm{mol}^{-1}$, a small value in comparison with the computational accuracy. The discrepancy may be associated to the neglect of entropic effects and solvation effects, which may be subtle, as well as to the accuracy of the chosen computational level (functional and basis sets). The calculation of 
bond strengths for weak bonds is also significantly affected by the basis set superposition error (BSSE) ${ }^{[49]}$ which should however be largely compensated in the calculation of the enthalpy differences. The most valuable contribution of this computational study is not in the perfect reproduction of the experimentally observed trends, but rather in a better insight into the causes of the relative OMRP rate reversal for the two systems $\mathbf{1}$ and $\mathbf{4}$ in the presence and absence of external donor ligands. This is unambiguously attributed to a small but significantly weaker $\mathrm{Co}^{\mathrm{III}}-\mathrm{C}$ bond for the tmhd system, opening the OMRP pathway for the VAc polymerization controlled by complex 4 in the absence of external donors, whereas the presence of external donors provides a greater stabilization to the $\mathrm{Co}^{\mathrm{II}}$ system in the presence of the less encumbering acac ligand, overruling the negative effect of the $\mathrm{Co}^{\mathrm{III}}-\mathrm{C}$ bond strength.

\section{Conclusion}

We have shown that increasing the steric bulk of the ligand coordination sphere has important effects on the competitive rates of different processes in metal-mediated radical polymerization, using the specific example of ( $\beta$-diketonato)cobalt(II) complexes, $\{\mathrm{RC}(\mathrm{O}) \mathrm{CHC}(\mathrm{O}) \mathrm{R}\}_{2} \mathrm{Co}$. On going from the acetylacetonato $(\mathrm{R}=$ $\mathrm{Me})$ to the 2,2,6,6-tetramethylhepta-3,5-dionato $(\mathrm{R}=t \mathrm{Bu})$ compound, the $\mathrm{Co}^{\mathrm{III}}-\mathrm{C}$ bond of the metal-capped dormant chain is slightly weakened. This weakening effect (ca. $1.5 \mathrm{kcal} \mathrm{mol}^{-1}$ according to DFT calculations) allows the $t$ Bu system to contribute to the polymer growth process with a dissociative mechanism (OMRP), whereas the Me system operates only by an associative mechanism (DT), the OMRP component being negligible in the absence of external Lewis bases (L). The addition of $\mathrm{L}$ molecules, however, overturns this trend because the steric bulk of the $\beta$ diketonato ligands has an even greater effect on the $\mathrm{Co}^{\mathrm{II}}-\mathrm{L}$ bonds. Understanding how the ligand coordination sphere tunes metalcarbon and metal-ligand bond strength is essential for the future development of systems that may be capable of controlling the polymerization of more challenging monomers.

\section{Experimental Section}

Materials. Vinyl acetate (VAc) (>99\%, Alfa Aeser) was dried over calcium hydride, distilled under argon at $90^{\circ} \mathrm{C}$ and degassed by several freeze-thawing cycles and stored under argon. Toluene was distilled from sodium benzophenone complex. 2,2'-azobis(4methoxy-2,4-dimethylvaleronitrile) (V-70) was used as received. The cobalt complex $\mathrm{Co}(\mathrm{tmhd})_{2}, \mathbf{4}$, was synthesized according to the literature procedure. ${ }^{[50]}$

Characterizations. ${ }^{1} \mathrm{H}$ NMR spectra were recorded on a Bruker ARX 250 spectrometer. Deuterated benzene was degassed and stocked in a Schlenk tube under argon. Size exclusion chromatography (SEC) of poly (vinyl acetate) was carried out in filtered THF (flow rate: $1 \mathrm{ml} / \mathrm{min}$ ) at $35^{\circ} \mathrm{C}$ on a $300 \times 7,5 \mathrm{~mm}$ PL gel 5micrometer mixed-D column (polymer laboratories), equipped with multiangle light scattering (minidawn Tristar, Wyatt Technology Corporation) and refractive index (RI2000, Sopares) detectors or with a waters column pack (300x7,5 mm, ultrastyragel 104,103,100 ̊), equipped with multiangle light scattering (miniDawn Tristar,Wyatt Technology Corp.) and refractive index (waters 410) detectors.

General procedure for the radical polymerization of vinyl acetate. All polymerisations were conducted following the same experimental procedure. A typical procedure is described here as representative example. All operations were carried out under a protective argon atmosphere. Complex $4(36.9 \mathrm{mg}, 0.086 \mathrm{mmol})$ and V-70 (18.7 mg $0.061 \mathrm{mmol}$ ) were introduced in a Schlenk tube, followed by the addition of degassed vinyl acetate $(4 \mathrm{~mL}, 43 \mathrm{mmol})$. The Schlenk tube was then immersed in an oil bath at $30^{\circ} \mathrm{C}$ and aliquots were withdrawn periodically for reaction monitoring by GPC. The monomer conversion was determined gravimetrically after removal of the unconverted monomer under reduced pressure and the resulting residue was used for SEC characterization. For those polymerisations carried out in the presence of toluene, an additional $4 \mathrm{~mL}$ of toluene (monomer/toluene $=1: 1(\mathrm{v} / \mathrm{v})$ ) was introduced in the Schlenk tube at the beginning of the experiment.
X-ray crystallography. Single crystals of trans-Co(tmhd $)_{2}(\text { py })_{2}$ were prepared by dissolving compound $\mathrm{Co}(\mathrm{tmhd})_{2}(0.200 \mathrm{~g}, 0.466 \mathrm{mmol})$ in $5 \mathrm{~mL}$ of diethyl ether to afford a pink solution. Addition of few drops of pyridine ( $c a .10$ eq) resulted in an immediate colour change to orange. The solution was filtered through Celite and placed at $-20^{\circ} \mathrm{C}$ overnight $(96 \mathrm{mg}, 35 \%)$. An orange single crystal was mounted under inert perfluoropolyether at the tip of a glass fibre and cooled in the cryostream of a Bruker APEXII diffractometer. Data were collected using the monochromatic MoK $\alpha$ radiation $(\lambda=0.71073)$. The structure was solved by direct methods (SIR97) ${ }^{[51]}$ and refined by least-squares procedures on $F^{2}$ using SHELXL-97. ${ }^{[52]}$ All $\mathrm{H}$ atoms attached to carbon were introduced in idealised positions and treated as riding models in the calculations. The drawing of the molecules was realised with the help of ORTEP $3 .{ }^{[53]}$ Crystal data and refinement parameters are shown in Table 4. Crystallographic data (excluding structure factors) have been deposited with the Cambridge Crystallographic Data Centre as supplementary publication no. CCDC 706747. Copies of the data can be obtained free of charge on application to the Director, CCDC, 12 Union Road, Cambridge CB2 1EZ, UK (fax: (+44) 1223-336-033; e-mail: deposit@ ccdc.cam.ac.uk).

Table 4. Crystal data and structure refinement for trans$\mathrm{Co}(\mathrm{tmhd})_{2}(\mathrm{py})_{2}$.

\begin{tabular}{|c|c|}
\hline Empirical formula & $\mathrm{C}_{32} \mathrm{H}_{48} \mathrm{Co} \mathrm{N}_{2} \mathrm{O}_{4}$ \\
\hline Formula weight & 583.65 \\
\hline Temperature, $\mathrm{K}$ & $180(2)$ \\
\hline Wavelength, $\AA$ & 0.71073 \\
\hline Crystal system & Triclinic \\
\hline Space group & $\mathrm{P}-1$ \\
\hline $\mathrm{a} \AA ; \alpha^{\circ}$ & $8.8350(4) ; 76.971(3)$ \\
\hline $\mathrm{b} \AA ; \beta^{\circ}$ & $9.8230(5) ; 73.068(2)$ \\
\hline $\mathrm{c} \AA ; \gamma^{\circ}$ & $11.0047(5) ; 65.737(2)$ \\
\hline Volume, $\AA^{3}$ & $826.80(7)$ \\
\hline $\mathrm{Z}$ & 1 \\
\hline Density (calculated), $\mathrm{Mg} / \mathrm{m}^{3}$ & 1.172 \\
\hline Absorption coefficient, $\mathrm{mm}^{-1}$ & 0.554 \\
\hline $\mathrm{F}(000)$ & 313 \\
\hline Crystal size, $\mathrm{mm}^{3}$ & $0.548 \times 0.213 \times 0.137$ \\
\hline Theta range for data collection, ${ }^{\circ}$ & 2.29 to 28.28 \\
\hline Reflections collected & 14132 \\
\hline Independent reflections (Rint) & $4085(0.0557)$ \\
\hline Completeness to theta $=28.28^{\circ}, \%$ & 99.5 \\
\hline Absorption correction & Semi-empirical from equivalents \\
\hline Max. and min. transmission & 1.0 and 0.888 \\
\hline Refinement method & Full-matrix least-squares on $\mathrm{F}^{2}$ \\
\hline Data / restraints / parameters & $4085 / 0 / 184$ \\
\hline Goodness-of-fit on $\mathrm{F}^{2}$ & 1.079 \\
\hline $\mathrm{R}, \mathrm{wR} 2[\mathrm{I}>2 \sigma(\mathrm{I})]$ & $0.0410,0.1072$ \\
\hline $\mathrm{R}$, wR2 (all data) & $0.0498,0.1141$ \\
\hline Largest diff. peak and hole, e $\AA^{-3}$ & 0.857 and -0.677 \\
\hline
\end{tabular}

[a] Only the average values are given for chemically equivalent parameters. [b] From reference ${ }^{[43]}$

Computational details. All geometry optimizations were performed with the Gaussian03 suite of programs ${ }^{[54]}$ using the B3PW91* functional. This is a modified version of the B3PW91 functional, which combines the three-parameter hybrid density functional method of Becke ${ }^{[55]}$ with the exchange component of Perdew and Wang's 1991 functional, ${ }^{[56,57]}$ where the $c_{3}$ coefficient in Becke's original three-parameter fit to thermochemical data was changed to 0.15 . The basis functions consisted of the standard $6-31 \mathrm{G}^{* *}$ for all light atoms $(\mathrm{H}, \mathrm{C}, \mathrm{N}, \mathrm{O})$, plus the LANL2DZ function, which included the Hay and Wadt effective core potentials (ECP) ${ }^{[58]}$ for Co. The latter basis set was however augmented with an $f$ polarization function $(\alpha=0.8)$ in order to obtain a balanced basis set and to improve the angular flexibility of the metal functions. All geometry optimizations were carried out without any symmetry constraint and all final geometries were characterized as local minima of the potential energy surface (PES) by verifying that all second derivatives of the energy were positive. The unrestricted formulation was used for open-shell molecules. The value of $\left\langle\mathrm{S}^{2}\right\rangle$ at convergence was very close to the expected value of 0.75 for the radical species and 3.75 for the spin quartet species [the greatest deviation was 3.7582 for complex Co(tmhd $)_{2}$ ], indicating minor spin contamination. All energies were corrected for zero point vibrational energy and for thermal energy to obtain the bond dissociation enthalpies at $298 \mathrm{~K}$. The standard approximations for estimating these corrections were used (ideal gas, rigid rotor and harmonic oscillator) as implemented into Gaussian03. 


\section{Acknowledgements}

Support for this work from the Agence Nationale de la Recherche (contract ANR No NT05-2_42140) is gratefully acknowledged. RP also thanks the Institut Universitaire de France for additional support and the "Centre Interuniversitaire de Calcul de Toulouse" (Project CALMIP) for granting free computational time.

[1] K. Matyjaszewski and J. H. Xia, Chem. Rev. 2001, 101, 2921-2990.

[2] M. Kamigaito, T. Ando and M. Sawamoto, Chem. Rev. 2001, 101, 3689-3745.

[3] C. J. Hawker, A. W. Bosman and E. Harth, Chem. Rev. 2001, 101, 3661-3688.

[4] J. Chiefari, Y. K. Chong, F. Ercole, J. Krstina, J. Jeffery, T. P. T. Le, R. T. A Mayadunne, G. F. Meijs, C. L. Moad, G. Moad, E. Rizzardo and S. H. Thang, Macromolecules 1998, 31, 5559-5562.

[5] A. Dureault, Y. Gnanou, D. Taton, M. Destarac and F. Leising, Angew. Chem., Int Ed. Engl. 2003, 42, 2869-2872.

[6] V. Sciannamea, R. Jerome and C. Detrembleur, Chem. Rev. 2008, 108, 1104-1126.

[7] T. Ando, M. Kamigaito and M. Sawamoto, Polym. Prepr. 2002, 43, 179-180.

[8] E. Rizzardo, J. Chiefari, R. T. A. Mayadunne, G. Moad and S. H. Thang, ACS Symp. Ser. 2000, 768, 278-296.

[9] E. Rizzardo, J. Chiefari, R. Mayadunne, G. Moad and S. Thang, Macromol. Symp. 2001, 174, 209-212

[10] M. Destarac, D. Charmot, X. Franck and S. Z. Zard, Macromol. Rapid Commun. 2000, 21, 1035-1039.

[11] M. Wakioka, K. Y. Baek, T. Ando, M. Kamigaito and M. Sawamoto, Macromolecules 2002, 35, 330-333.

[12] M. C. Iovu and K. Matyjaszewski, Macromolecules 2003, 36, 9346-9354.

[13] A. Debuigne, J. R. Caille and R. Jérôme, Angew. Chem., Int. Ed. Eng. 2005, 44, 1101-1104.

[14] A. Debuigne, J. R. Caille, C. Detrembleur and R. Jerome, Angew. Chem., Int. Ed. Eng. 2005, 44, 3439-3442.

[15] A. Debuigne, J.-R. Caille and R. Jérôme, Macromolecules 2005, 38, 5452-5458.

[16] A. Debuigne, J. R. Caille, N. Willet and R. Jerome, Macromolecules 2005, 38 9488-9496.

[17] C. Detrembleur, A. Debuigne, R. Bryaskova, B. Charleux and R. Jerome, Macromol. Rapid Commun. 2006, 27, 37-41.

[18] R. Bryaskova, C. Detrembleur, A. Debuigne and R. Jerome, Macromolecules 2006 39, 8263-8268

[19] A. Debuigne, N. Willet, R. Jerome and C. Detrembleur, Macromolecules 2007, 40, 7111-7118.

[20] R. Bryaskova, N. Willet, A. Debuigne, R. Jerome and C. Detrembleur, J. Polym. Sci., Part A: Polym. Chem. 2006, 45, 81-89.

[21] A. Debuigne, J. Warnant, R. Jerome, I. Voets, A. De Keizer, M. A. Stuart and C. Detrembleur, Macromolecules 2008, 41, 2353-2360.

[22] A. Debuigne, C. Michaux, C. Jérôme, R. Jérôme, R. Poli and C. Detrembleur, Chem. Eur. J. 2008, 14, 7623-7637.

[23] H. Kaneyoshi and K. Matyjaszewski, Macromolecules 2005, 38, 8163-8169.

[24] H. Kaneyoshi and K. Matyjaszewski, Macromolecules 2006, 39, 2757-2763.

[25] S. Maria, H. Kaneyoshi, K. Matyjaszewski and R. Poli, Chem. Eur. J. 2007, 13, 2480-2492.

[26] R. Poli, Angew. Chem., Int. Ed. Engl. 2006, 45, 5058-5070.

[27] A. Debuigne, Y. Champouret, R. Jérôme, R. Poli and C. Detrembleur, Chem. Eur. J. 2008, 14, 4046-4059.

[28] B. B. Wayland, G. Poszmik and S. Mukerjee, J. Am. Chem. Soc. 1994, 116, 7943 7944

[29] B. B. Wayland, L. Basickes, S. Mukerjee, M. Wei and M. Fryd, Macromolecules 1997, 30, 8109 - 8112

[30] B. B. Wayland, S. Mukerjee, G. Poszmik, D. C. Woska, L. Basickes, A. A Gridnev, M. Fryd and S. D. Ittel, ACS Symp. Ser. 1998, 685, 305-315.

[31] Z. Lu, M. Fryd and B. B. Wayland, Macromolecules 2004, 37, 2686-2687.

[32] B. B. Wayland, X.-F. Fu, Z. Lu and M. Fryd, Polymer Preprints 2005, 230th ACS National Meeting, August 28-September 1, 2005, Washington, DC.
[33] B. B. Wayland, X. Fu, C.-H. Peng, Z. Lu and M. Fryd, ACS Symp. Ser 2006, 944, 358-371.

[34] B. B. Wayland, C.-H. Peng, X. Fu, Z. Lu and M. Fryd, Macromolecules 2006, 39 8219-8222.

[35] C.-H. Peng, M. Fryd and B. B. Wayland, Macromolecules 2007, 40, 6814-6819.

[36] C. H. Peng, J. Scricco, S. Li, M. Fryd and B. B. Wayland, Macromolecules 2008 , $41,2368-2373$

[37] Y. Champouret, U. Baisch, R. Poli, L. Tang, J. L. Conway and K. M. Smith, Angew. Chem., Int. Ed. Engl. 2008, 47, 6069-6072.

[38] J. Brandrup, E. H. Immergut and E. A. Grulke in Polymer Handbook, Vol. (Ed.: John Wiley \& Sons, Inc., Hoboke, NJ, 1999, pp.

[39] B. Smirnov, I. Bel'govskii, G. Ponomarev, A. Marchenko and N. Enikolopian, Dokl. Akad. Nauk SSSR 1980, 254, 127-130.

[40] A. A. Gridnev, Vysokomol. Soed. Ser. A 1989, 31, 2153-2159.

[41] A. A. Gridnev and S. D. Ittel, Chem. Rev. 2001, 101, 3611-3659.

[42] A. Goto, Y. Kwak, T. Fukuda, S. Yamago, K. Iida, M. Nakajima and J. Yoshida, J. Am. Chem. Soc. 2003, 125, 8720-8721.

[43] R. C. Elder, Inorg. Chem. 1968, 7, 1117-1123.

[44] A. Debuigne, C. Michaux, C. Jérôme, R. Jérôme, R. Poli and C. Detrembleur, Chem. Eur. J. in press.

[45] J. Harvey and M. Aschi, Faraday Disc. 2003, 124, 129-143.

[46] J. N. Harvey, Struct. Bonding 2004, 112, 151 - 184

[47] F. A. Cotton and J. S. Wood, Inorg. Chem. 1964, 3, 245-251

[48] B. K. Langlotz, J. Loret Fillol, J. H. Gross, H. Wadepohl and L. H. Gade, Chem. Eur. J. 2008, 14, 10267-10279.

[49] S. F. Boys and F. Bernardi, Mol. Phys. 1970, 19, 553-566.

[50] F. A. Cotton, C. Y. Liu, C. A. Murillo and X. P. Wang, Inorg. Chem. 2003, 42, 4619-4623.

[51] A. Altomare, M. Burla, M. Camalli, G. Cascarano, C. Giacovazzo, A. Guagliardi, A. Moliterni, G. Polidori and R. Spagna, J. Appl. Cryst. 1999, 32, 115-119.

[52] G. M. Sheldrick, SHELXL97. Program for Crystal Structure refinement, University of Göttingen, Göttingen, Germany, 1997, pp.

[53] L. J. Farrugia, J. Appl. Crystallogr. 1997, 32, 565.

[54] G. W. T. M. J. Frisch, H. B. Schlegel, G. E. Scuseria, M. A. Robb, J. R. Cheeseman, J. Montgomery, J. A., T. Vreven, K. N. Kudin, J. C. Burant, J. M. Millam, S. S. Iyengar, J. Tomasi, V. Barone, B. Mennucci, M. Cossi, G. Scalmani, N. Rega, G. A. Petersson, H. Nakatsuji, M. Hada, M. Ehara, K. Toyota, R. Fukuda, J. Hasegawa, M. Ishida, T. Nakajima, Y. Honda, O. Kitao, H. Nakai, M. Klene, X. Li, J. E. Knox, H. P. Hratchian, J. B. Cross, C. Adamo, J. Jaramillo, R. Gomperts, R. E. Stratmann, O. Yazyev, A. J. Austin, R. Cammi, C Pomelli, J. W. Ochterski, P. Y. Ayala, K. Morokuma, G. A. Voth, P. Salvador, J. J. Dannenberg, V. G. Zakrzewski, S. Dapprich, A. D. Daniels, M. C. Strain, O. Farkas, D. K. Malick, A. D. Rabuck, K. Raghavachari, J. B. Foresman, J. V. Ortiz, Q. Cui, A. G. Baboul, S. Clifford, J. Cioslowski, B. B. Stefanov, G. Liu, A. Liashenko, P. Piskorz, I. Komaromi, R. L. Martin, D. J. Fox, T. Keith, M. A. Al-Laham, C. Y. Peng, A. Nanayakkara, M. Challacombe, P. M. W. Gill, B. Johnson, W. Chen, M. W. Wong, C. Gonzalez, J. A. Pople,, Gaussian 03 , Revision C.02, Gaussian, Inc., Wallingford CT 2004.

[55] A. D. Becke, J. Chem. Phys. 1993, 98, 5648-5652.

[56] J. P. Perdew in Vol. (Ed.: P. Ziesche and H. Eschrig), Akademie Verlag, Berlin, 1991, pp. 11.

[57] K. Burke, J. P. Perdew and Y. Wang in Vol. (Ed.: J. F. Dobson, G. Vignale and M. P. Das), Plenum Press, New York, 1998, pp.

[58] P. J. Hay and W. R. Wadt, J. Chem. Phys. 1985, 82, 270-283.

Received: ((will be filled in by the editorial staff))

Revised: ((will be filled in by the editorial staff) Published online: ((will be filled in by the editorial staff)) 
Poly(vinyl acetate) by OMRP

Santhosh Kumar K. S., Yves Gnanou*, Yohan Champouret, Jean-Claude Daran, and Rinaldo Poli*

Radical Polymerization of Vinyl Acetate with Bis(tetramethylheptadionato)cobalt(II): the Cohabitation of Three Different Mechanisms
Increasing the steric encumberance of the $\beta$-diketonate $\mathrm{R}$ substituents in $\mathrm{Co}[\mathrm{OC}(\mathrm{R}) \mathrm{CHC}(\mathrm{R}) \mathrm{O}]_{2}$ from $\mathrm{Me}$ to $t \mathrm{Bu}$ sufficiently weakens the $\mathrm{Co}^{\mathrm{III}}$-PVAc bond to allow a reversible termination controlled polymerization under mild conditions. The Co ${ }^{\mathrm{III}}$-PVAc also acts as a transfer agent in the absence of Lewis bases, while the $\mathrm{Co}^{\mathrm{II}}$ complex shows catalytic chain transfer activity. 


\title{
Radical Polymerization of Vinyl Acetate with
}

\section{Bis(tetramethylheptadionato)cobalt(II): the Cohabitation of Three Different}

\section{Mechanisms}

\author{
K.S. Santhosh Kumar, Yves Gnanou*, \\ Laboratoire de Chimie des Polymères Organiques, ENSCPB-CNRS-Université Bordeaux 1, 16, \\ Avenue Pey Berland, 33607 Pessac Cedex, France \\ Yohan Champouret, Jean-Claude Daran, Rinaldo Poli* \\ Laboratoire de Chimie de Coordination CNRS UPR 8241, 205 Route de Narbonne, 31077
}

Toulouse Cedex France

\section{SUPPORTING INFORMATION}

Table S1. Results of the bulk VAc polymerization initiated by V-70 at $30^{\circ} \mathrm{C}$ in the presence of compound 4.

Table S2. Polymerization of VAc in toluene solution $(50 \% \mathrm{v} / \mathrm{v})$ initiated by V-70 in the presence of complexes $\mathbf{1}$ and $\mathbf{4}$.

Table S3. Polymerization of VAc in toluene solution $(75 \% \mathrm{v} / \mathrm{v})$ initiated by V-70 in the presence of complex 4.

A. Kinetic analysis of the VOAc polymerization in $50 \%$ toluene $(\mathrm{v} / \mathrm{v})$, initiated by $\mathrm{V}-70$, in the presence of $\mathrm{Co}(\mathrm{tmhd})_{2}$ at $30^{\circ} \mathrm{C}$.

B. Kinetic analysis of the VOAc polymerization in $50 \%$ toluene $(\mathrm{v} / \mathrm{v})$, initiated by $\mathrm{V}-70$, in the presence of $\mathrm{Co}(\mathrm{acac})_{2}$ at $30^{\circ} \mathrm{C}$.

C. Kinetic analysis of the VOAc polymerization in $25 \%$ toluene $(\mathrm{v} / \mathrm{v})$, initiated by $\mathrm{V}-70$, in the presence of $\mathrm{Co}(\mathrm{tmhd})_{2}$ at $30^{\circ} \mathrm{C}$

D. Kinetic analysis of the VOAc polymerization in bulk, initiated by V-70, in the presence of $\mathrm{Co}(\mathrm{tmhd})_{2}$ at $30^{\circ} \mathrm{C}$.

E. Cartesian Coordinates for all optimized structures

F. Selected Bond Distances and Angles for the Optimized Structures and View of their Geometry 
Table S1. Results of the bulk VAc polymerization initiated by V-70 at $30^{\circ} \mathrm{C}$ in the presence of compound $4 .^{\text {a }}$

\begin{tabular}{llllll}
\hline V-70/Co & Time (h) & Conv $(\%)$ & $\begin{array}{l}\mathrm{M}_{\mathrm{n} \text { SEC }} \\
\left(\mathrm{x} \mathrm{10} 0^{-4}\right)\end{array}$ & $\begin{array}{l}\mathrm{M}_{\mathrm{n} \text { theo }} \\
(\mathrm{x} \mathrm{10})\end{array}$ & $\mathrm{M}_{\mathrm{w}} / \mathrm{M}_{\mathrm{n}}$ \\
\hline 0.6 & 94 & 7 & 0.57 & 0.30 & 1.23 \\
0.6 & 103 & 17 & 1.18 & 0.73 & 1.14 \\
0.6 & 165.5 & 53 & 3.73 & 2.28 & 1.21 \\
\hline 0.7 & 52.25 & 2.3 & - & - & - \\
0.7 & 67.25 & 8 & 0.89 & 0.33 & 1.20 \\
0.7 & 72.75 & 19 & 1.74 & 0.82 & 1.19 \\
0.7 & 77 & 31 & 2.23 & 1.32 & 1.26 \\
0.7 & 91 & 60 & 4.79 & 2.60 & 1.26 \\
\hline 1 & 3 & 2.4 & - & - & - \\
1 & 17.5 & 2.5 & - & - & - \\
1 & 23 & 3.8 & - & - & - \\
1 & 38 & 14 & 1.87 & 0.60 & 1.37 \\
1 & 47 & 39.6 & 2.94 & 1.70 & 1.29 \\
1 & 62.5 & 62.7 & 4.52 & 2.70 & 1.28 \\
\hline 2 & 4 & 2.4 & - & - & - \\
2 & 17.75 & 14 & 1.48 & 0.60 & 1.31 \\
2 & 21 & 29 & 2.00 & 1.25 & 1.32 \\
2 & 24 & 43 & 2.78 & 1.85 & 1.27 \\
2 & 25.75 & 51 & 3.01 & 2.20 & 1.28 \\
2 & 27.75 & 63 & 4.00 & 2.71 & 1.25 \\
\hline 4 & 16.5 & 43 & 3.60 & 1.85 & 1.46 \\
4 & 17.75 & 47 & 4.22 & 2.02 & 1.44 \\
4 & 19 & 51 & 5.06 & 2.20 & 1.33 \\
4 & 20.5 & 75 & 5.40 & 3.23 & 1.35 \\
\hline
\end{tabular}

[a] VAc/Co $=500: 1$. 
Table S2. Polymerization of VAc in toluene solution (50\% v/v) initiated by V-70 in the presence of complexes 1 and $4 .{ }^{\text {a }}$

\begin{tabular}{clllll}
\hline Complex & Time $(\mathrm{h})$ & Conv $(\%)$ & $\begin{array}{l}\mathrm{M}_{\mathrm{n} \text { SEC }} \\
(\mathrm{x} \mathrm{10})\end{array}$ & $\begin{array}{l}\mathrm{M}_{\mathrm{n} \text { theo }} \\
\left(\mathrm{x} \mathrm{10} 0^{-4}\right)\end{array}$ & $\mathrm{M}_{\mathrm{w}} / \mathrm{M}_{\mathrm{n}}$ \\
\hline $\mathbf{1}$ & 2 & 3.7 & & 0.16 & \\
$\mathbf{1}$ & 17 & 4.4 & & 0.19 & \\
$\mathbf{1}$ & 40.75 & 18.8 & 1.25 & 0.81 & 1.21 \\
$\mathbf{1}$ & 64.5 & 29.5 & 1.5 & 1.27 & 1.39 \\
$\mathbf{1}$ & 88.5 & 30.3 & & 1.30 & \\
$\mathbf{1}$ & 160.5 & 31.6 & 1.45 & 1.36 & 1.43 \\
$\mathbf{1}$ & 250 & 32.1 & & 1.38 & \\
$\mathbf{1}$ & 329 & 32.7 & & 1.41 & \\
$\mathbf{4}$ & 5 & 2.02 & & 0.09 & \\
$\mathbf{4}$ & 20 & 3.1 & & 0.13 & \\
$\mathbf{4}$ & 26 & 3.6 & & 0.15 & \\
$\mathbf{4}$ & 29.5 & 5.3 & & 0.23 & \\
$\mathbf{4}$ & 44 & 17.1 & 0.90 & 0.74 & 1.44 \\
$\mathbf{4}$ & 50 & 21.4 & & 0.92 & - \\
$\mathbf{4}$ & 53 & 22.8 & 1.04 & 0.98 & 1.45 \\
$\mathbf{4}$ & 68 & 30.8 & 1.22 & 1.32 & 1.25 \\
$\mathbf{4}$ & 77 & 34.7 & & 1.49 & \\
$\mathbf{4}$ & 92 & 39.0 & 1.39 & 1.68 & 1.25 \\
$\mathbf{4}$ & 140 & 52.0 & 1.50 & 2.24 & 1.19 \\
$\mathbf{4}$ & 164 & 57.9 & 1.55 & 2.49 & 1.21 \\
$\mathbf{4}$ & 212 & 63.0 & 1.68 & 2.71 & 1.27 \\
$\mathbf{4}$ & 308.5 & 69.9 & 1.70 & 3.01 & 1.38 \\
$\mathbf{4}$ & 406.5 & 72.1 & 1.79 & 3.10 & 1.33 \\
$\mathbf{4}$ & 524.5 & 75.9 & 1.82 & 3.26 & 1.32 \\
\hline
\end{tabular}

[a] Conditions: VAc/V-70/Co $=500: 2: 1 ; \mathrm{T}=30^{\circ} \mathrm{C}$.

Table S3. Polymerization of VAc in toluene solution $(75 \% \mathrm{v} / \mathrm{v})$ initiated by V-70 in the presence of complex $4 .^{\mathrm{a}}$

\begin{tabular}{lllll}
\hline Time (h) & Conv $(\%)$ & $\begin{array}{l}\mathrm{M}_{\mathrm{n} \text { SEC }} \\
\left(\mathrm{x} 10^{-4}\right)\end{array}$ & \begin{tabular}{l}
$\mathrm{M}_{\mathrm{n} \text { theo }}\left(\mathrm{x} 10^{-4}\right)$ \\
\hline 7
\end{tabular} $\mathrm{M}_{\mathrm{w} / \mathrm{M}_{\mathrm{n}}}$ \\
\hline 22.5 & 8.4 & - & 0.12 & - \\
31.25 & 26.5 & 0.72 & 0.36 & 1.33 \\
48 & 46.4 & 1.73 & 1.14 & 1.26 \\
94.5 & 76.2 & 3.30 & 2.00 & 1.29 \\
173.25 & 80.1 & 3.30 & 3.28 & 1.28 \\
\hline
\end{tabular}

[a] $\mathrm{VAc} / \mathrm{V}-70 / \mathrm{Co}=500: 2: 1 ; \mathrm{T}=30^{\circ} \mathrm{C}$. 


\section{A. Kinetic analysis of the VOAc polymerization in $50 \%$ toluene $(\mathrm{v} / \mathrm{v})$, initiated by $\mathrm{V}-70$, in the presence of $\mathrm{Co}(\mathrm{tmhd})_{2}$ at $30^{\circ} \mathrm{C}$.}

Initial amounts:

VAc: $4 \mathrm{~mL}(3.73 \mathrm{~g}, 43.3 \mathrm{mmol})$

$$
\begin{aligned}
& {[\mathrm{VAc}]_{0}=5.41 \mathrm{M}} \\
& {\left[\mathrm{Co}^{\mathrm{II}}\right]_{0}=1.084 \cdot 10^{-2} \mathrm{M}} \\
& {[\mathrm{V}-70]_{0}=2.172 \cdot 10^{-2} \mathrm{M}}
\end{aligned}
$$

Co(tmhd $)_{2}: 36.9 \mathrm{mg}(0.0867 \mathrm{mmol})$

toluene: $4 \mathrm{~mL}$

$\left([\mathrm{M}]_{0} /\left[\mathrm{Co}^{\mathrm{II}}\right]_{0} /[\mathrm{V}-70]_{0}=500: 1: 2\right)$

Total volume: $8 \mathrm{~mL}$

Results (data only up to $164 \mathrm{~h}$ )

$\begin{array}{cccccc}\text { time }(\mathrm{h}) & \text { conv }(\%) & \operatorname{Ln}\left(\mathrm{M}_{\mathrm{N}} / \mathrm{M}\right) & \mathrm{Mn}_{\mathrm{n}} & \mathrm{Mn}_{\mathrm{n}} \text { (theo) } & \mathrm{M}_{\mathrm{w}} / \mathrm{Mn} \\ 5 & 2.0 & 0.02040681 & & 868.6 & \\ 20 & 3.1 & 0.03149067 & & 1333 & \\ 26 & 3.6 & 0.03666398 & & 1548 & \\ 29.5 & 5.3 & 0.05445619 & & 2279 & \\ 44 & 17.1 & 0.18753512 & 55850 & 7353 & 1.45 \\ 50 & 21.4 & 0.24079849 & & 9202 & \\ 53 & 22.8 & 0.25877073 & 29660 & 9804 & 1.54 \\ 68 & 30.8 & 0.36816932 & 27060 & 13244 & 1.25 \\ 77 & 34.7 & 0.42617815 & & 14921 & \\ 92 & 39 & 0.49429632 & 31430 & 16770 & 1.25 \\ 140 & 52 & 0.73396918 & 28000 & 22360 & 1.19 \\ 164 & 57.9 & 0.86512245 & 26480 & 24897 & 1.21\end{array}$

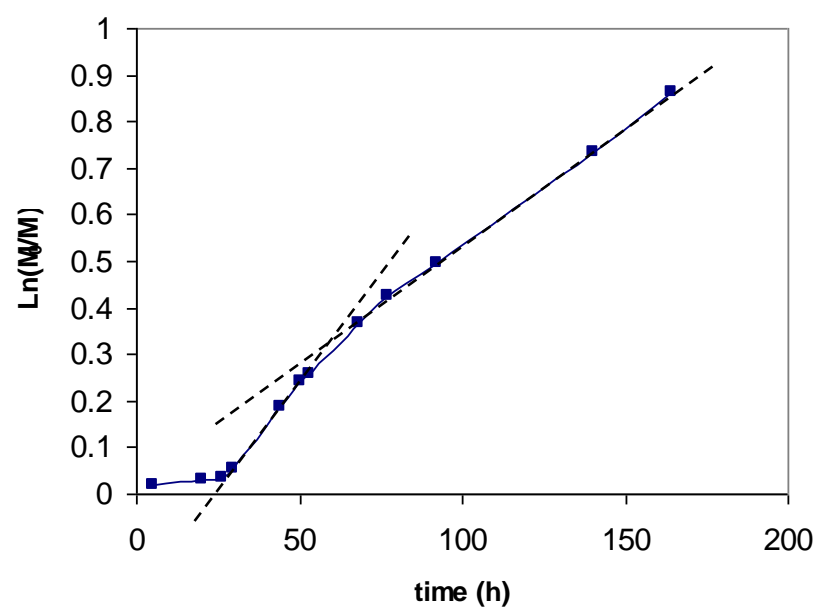

\section{Interpretation}

Before the induction time, the radical produced by V-70 are trapped by $\mathrm{Co}^{\mathrm{II}}$ to generate $\mathrm{Co}^{\mathrm{III}}$. The trapping equilibrium is not as irreversible as for the related $\mathrm{Co}(\mathrm{acac})_{2}$, therefore a slow polymerization may take place by the OMRP mechanism. The dissociation equilibrium, however, is moderated by the excess $\mathrm{Co}^{\mathrm{II}}$. There are no excess free radicals; therefore, no associative exchange (degenerative transfer) can take place. 
After an amount of radicals equivalent to that of $\mathrm{Co}^{\mathrm{II}}$ has been injected into the solution, corresponding to the induction time $t_{\text {ind }}$, the excess radicals start a faster polymerization process by DT. The OMRP can continue to operate at the same time.

After a certain time (ca. 6 half-lives of V-70), essentially all the initiator has been consumed and no more new radicals are injected into the solution. Therefore, the polymerization continues by a pure OMRP mechanism as in the first period before the DT induction time. However, now the entire Co complex (except for a minor amount allowed by the dissociation equilibrium) is in the $\mathrm{Co}^{\mathrm{III}}$ form, whereas initially the $\mathrm{Co}^{\mathrm{II}} / \mathrm{Co}^{\mathrm{III}}$ ratio changes with time.

\section{Kinetic analysis}

\section{Equations:}

$$
\begin{aligned}
& \mathrm{I} \rightarrow 2 \mathrm{R}_{0} \quad\left(\mathrm{k}_{\mathrm{d}}\right) \quad \text { initiation; } \mathrm{I}=\mathrm{V}-70 \\
& \mathrm{R}_{\mathrm{n}}+\mathrm{M} \rightarrow \mathrm{R}_{\mathrm{n}+1} \quad\left(\mathrm{k}_{\mathrm{p}}\right) \quad \text { propagation } \\
& \begin{array}{lll}
\mathrm{R}_{\mathrm{n}}+\mathrm{Co}^{\mathrm{II}} \rightarrow \mathrm{Co}^{\mathrm{III}} & (\mathrm{k}-) & \text { deactivation } \\
\mathrm{Co}^{\mathrm{III}} \rightarrow \mathrm{Co}^{\mathrm{II}}+\mathrm{R}_{\mathrm{n}} & \left(\mathrm{k}_{+}\right) & \text {activation; } \mathrm{K}=\mathrm{k}_{+} / \mathrm{k}_{-} \frac{\left[R_{n}\right]\left[C o^{I I}\right]}{\left[C o^{I I I}\right]}=
\end{array}
\end{aligned}
$$

The rate constant of the degenerative transfer is not necessary for the analysis of the monomer conversion.

\section{Time dependence of relevant species:}

- V-70 not yet consumed: $[\mathrm{I}]_{\mathrm{t}}=[\mathrm{I}]_{0} \mathrm{e}^{-\mathrm{k}_{\mathrm{d}} t}$

- Radicals produced (each I molecule that decomposes generates $2 \mathrm{R}_{0}$, multiplied by the efficiency factor $\mathrm{f}$ ) :

$\left[\mathrm{R}_{0}\right]_{\mathrm{t}}=2 \mathrm{f}\left([\mathrm{I}]_{0}-[\mathrm{I}]\right)=2 \mathrm{f}[\mathrm{I}]_{0}\left(1-\mathrm{e}^{-\mathrm{k}_{\mathrm{d}} t}\right)$

- $\mathrm{Co}^{\mathrm{III}}$ generated (each generated radical is considered to transform a $\mathrm{Co}^{\mathrm{II}}$ into $\mathrm{Co}^{\mathrm{III}}$ rapidly and quantitatively):

$\left[\mathrm{Co}^{\mathrm{III}}\right]_{\mathrm{t}}=\left[\mathrm{R}_{0}\right]_{\mathrm{t}}=2 \mathrm{f}[\mathrm{I}]_{0}\left(1-\mathrm{e}^{-\mathrm{k}_{\mathrm{d}} t}\right) \quad\left(\right.$ valid for $\mathrm{t}<\mathrm{t}_{\text {ind }}$, after which $\left.\left[\mathrm{Co}^{\mathrm{III}}\right] \sim\left[\mathrm{Co}^{\mathrm{II}}\right]_{0}\right)$

- $\mathrm{Co}{ }^{\mathrm{II}}$ remaining: $\left[\mathrm{Co}^{\mathrm{II}}\right]_{\mathrm{t}}=\left[\mathrm{Co}^{\mathrm{II}}\right]_{0}-\left[\mathrm{Co}^{\mathrm{III}}\right]_{\mathrm{t}}=\left[\mathrm{Co}^{\mathrm{II}}\right]_{0}-2 \mathrm{f}[\mathrm{I}]_{0}\left(1-\mathrm{e}^{-\mathrm{k}_{\mathrm{d}} t}\right)$

(valid for $\mathrm{t}<\mathrm{t}_{\text {ind }}$, after which $\left[\mathrm{Co}^{\mathrm{II}}\right]=$ amount determined by the OMRP equilibrium)

\section{Calculation of the consumed monomer:}

- A. Before the induction time $t_{\text {ind: }}$

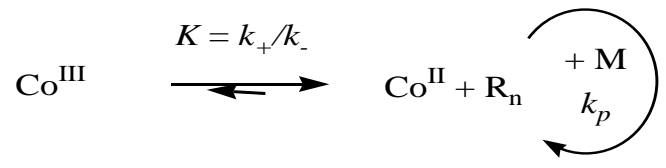

The polymerization takes place solely by

\section{OMRP:}


$\frac{-d[M]}{d t}=k_{p}\left[R_{n}\right][M]=k_{p} K \frac{\left[C o^{I I I}\right]}{\left[C o^{I I}\right]}[M]$

Using the equations above that give $\left[\mathrm{Co}^{\mathrm{III}}\right]_{\mathrm{t}}$ and $\left[\mathrm{Co}^{\mathrm{II}}\right]_{\mathrm{t}}$,

$$
\frac{-d[M]}{d t}=k_{p} K \frac{2 f[I]_{0}\left(1-e^{-k_{d} t}\right)}{\left[C o^{I I}\right]_{0}-2 f[I]_{0}\left(1-e^{-k_{d} t}\right)}[M]=\frac{k_{p} K[M]}{\frac{\left[C o^{I I}\right]_{0}}{2 f[I]_{0}\left(1-e^{-k_{d} t}\right)}-1}
$$

Separating the variable and integrating:

$$
\int_{[M]_{0}}^{[M]_{t}} \frac{-d[M]}{[M]}=\ln \frac{[M]_{0}}{[M]_{t}}=\int_{0}^{t<t_{\text {ind }}} \frac{k_{p} K}{\frac{\left[C o^{I I}\right]_{0}}{2 f[I]_{0}\left(1-e^{-k_{d} x}\right)}-1} d x
$$

This integral can be evaluated numerically (vide infra). Integration to tind allows the calculation of residual $[\mathrm{M}]$ at the induction time $t_{\text {ind, }}[\mathrm{M}]_{\text {ind }}$.

- B. After tind:

All the $\mathrm{Co}^{\mathrm{II}}$ (except for a small equilibrium amount, $\left[\mathrm{Co}^{\mathrm{II}}\right]_{\mathrm{eq}}$ ), has been converted into $\mathrm{Co}^{\mathrm{III}}$. If the equilibrium is considered as heavily shifted to the dormant species, $\left[\mathrm{Co}^{\mathrm{III}}\right] \sim\left[\mathrm{Co}^{\mathrm{II}}\right]_{0}$ and will not further change. $\left[\mathrm{Co}^{\mathrm{II}}\right]_{\mathrm{eq}}$ also will not further change.

The polymerization takes place by both OMRP and DT:

$$
\begin{aligned}
& \frac{-d[M]}{d t}(\text { OMRP })=k_{p}\left[R_{n}\right][M]=k_{p} K \frac{\left[C o^{I I I}\right]}{\left[C o^{I I}\right]}[M]=k_{p} K \frac{\left[C o^{I I}\right]_{0}}{\left[C o^{I I}\right]_{e q}}[M] \\
& \frac{-d[M]}{d t}(D T)=k_{p}\left(\frac{2 f k_{d}[I]}{k_{t}}\right)^{1 / 2}[M]=k_{p}\left(\frac{2 f k_{d}[I]_{0}}{k_{t}}\right)^{1 / 2}[M] e^{-\left(\frac{k_{d} t}{2}\right)}
\end{aligned}
$$

(rate of free radical polymerization)

$$
\frac{-d[M]}{d t}(\text { total })=\left(k_{p} K \frac{\left[C o^{I I}\right]_{0}}{\left[C o^{I I}\right]_{e q}}+k_{p}\left(\frac{2 f k_{d}[I]_{0}}{k_{t}}\right)^{1 / 2} e^{-\left(\frac{k_{d} t}{2}\right)}\right)[M]
$$

Separating the variables and integrating (integration is trivial):

$$
\int_{[M]_{\text {ind }}}^{[M]_{t}} \frac{-d[M]}{[M]}=\ln \frac{[M]_{\text {ind }}}{[M]_{t}}=\int_{t_{\text {ind }}}^{t>t_{\text {ind }}}\left(k_{p} K \frac{\left[C o^{I I}\right]_{0}}{\left[C o^{I I}\right]_{e q}}+k_{p}\left(\frac{2 f k_{d}[I]_{0}}{k_{t}}\right)^{1 / 2} e^{-\left(\frac{k_{d} x}{2}\right)}\right) d x
$$




$$
\ln \frac{[M]_{\text {ind }}}{[M]_{t}}=k_{p} K \frac{\left[C o^{I I}\right]_{0}}{\left[C o^{I I}\right]_{e q}}\left(t-t_{\text {ind }}\right)+k_{p}\left(\frac{2 f k_{d}[I]_{0}}{k_{t}}\right)^{1 / 2}\left(\frac{-2}{k_{d}}\right)\left(e^{-\left(\frac{k_{d} t}{2}\right)}-e^{-\left(\frac{k_{d} t_{\text {ind }}}{2}\right)}\right)
$$

or

$$
\ln \frac{[M]_{\text {ind }}}{[M]_{t}}=k_{p} K \frac{\left[C o^{I I}\right]_{0}}{\left[C o^{I I}\right]_{e q}}\left(t-t_{\text {ind }}\right)-k_{p}\left(\frac{8 f[I]_{0}}{k_{t} k_{d}}\right)^{1 / 2}\left(e^{-\left(\frac{k_{d} t}{2}\right)}-e^{-\left(\frac{k_{d} t_{\text {ind }}}{2}\right)}\right)
$$

- C. At very long times (when the initiator is all gone):

The exponential term tends to zero and only the constant term of the DT portion remains, plus the first order term of the OMRP portion:

$$
\ln \frac{[M]_{\text {ind }}}{[M]_{t}}=k_{p} K \frac{\left[C o^{I I}\right]_{0}}{\left[C o^{I I}\right]_{e q}}\left(t-t_{\text {ind }}\right)+k_{p}\left(\frac{8 f[I]_{0}}{k_{t} k_{d}}\right)^{1 / 2} e^{-\left(\frac{k_{d} t_{\text {ind }}}{2}\right)}
$$

\section{Exploitation of the results}

The graph on the right shows a conversion of $4.0 \%$ at the induction time. Therefore:

$$
\begin{aligned}
& {[\mathrm{M}]_{\text {ind }}=0.96[\mathrm{M}]_{0}} \\
& \text { and } \\
& \ln \left([\mathrm{M}]_{\text {ind }} /[\mathrm{M}]\right)=\ln \left(0.96[\mathrm{M}]_{0} /[\mathrm{M}]\right)
\end{aligned}
$$

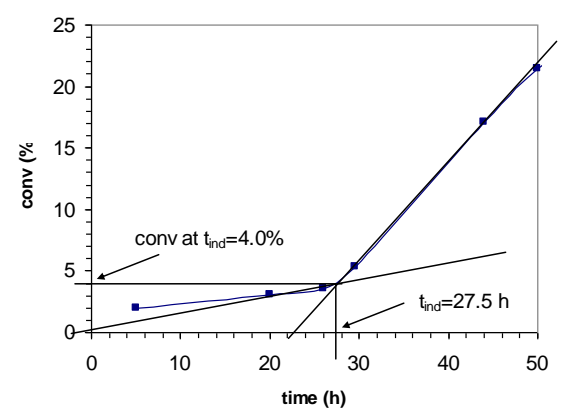

From the data at long times plotted as $\ln \left([\mathrm{M}]_{\text {ind }} /[\mathrm{M}]\right)$ vs. time, we recover $k_{p} K \frac{\left[C o^{I I}\right]_{0}}{\left[\mathrm{Co}^{I I}\right]_{e q}}$ from the slope and $\left[k_{p}\left(\frac{8 f[I]_{0}}{k_{t} k_{d}}\right)^{1 / 2} e^{-\left(\frac{k_{d} t_{\text {ind }}}{2}\right)}-k_{p} K \frac{\left[C o^{I I}\right]_{0}}{\left[C o^{I I}\right]_{e q}} t_{i n d}\right]$ from the intercept.

The data after 68 hours (ca. 7 half lives of V-70) are quite well aligned. From the slope:

$$
k_{\mathrm{eff}}=k_{p} K \frac{\left[C o^{I I}\right]_{0}}{\left[C o^{I I}\right]_{e q}}=5.090 \cdot 10^{-3} \mathrm{~h}^{-1}=1.414 \cdot 10^{-6} \mathrm{~s}^{-1}
$$

From the intercept :

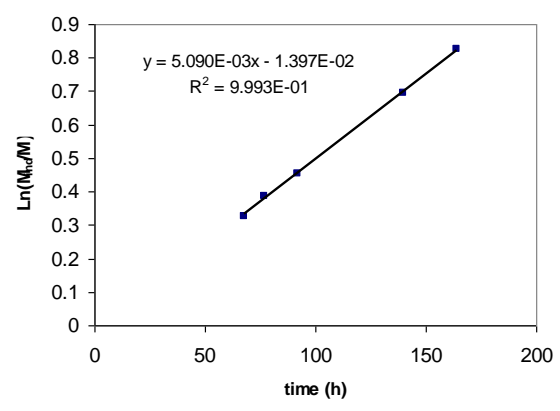




$$
\begin{aligned}
& {\left[k_{p}\left(\frac{8 f[I]_{0}}{k_{t} k_{d}}\right)^{1 / 2} e^{-\left(\frac{k_{d} t_{\text {ind }}}{2}\right)}-k_{p} K \frac{\left[C o^{I I}\right]_{0}}{\left[C o^{I I}\right]_{e q}} t_{\text {ind }}\right]=-1.397 \cdot 10^{-2} \sim-0.014} \\
& \text { time (h) } \quad \text { conv (\%) } \quad \operatorname{Ln}\left(\mathrm{M}_{\text {ind }} / \mathrm{M}\right) \quad \mathrm{y}=0.00590 \mathrm{t}-0.01397 \\
& \begin{array}{cccc}
5 & 2.02 & -0.02041518 & 0.01148 \\
20 & 3.1 & -0.00933133 & 0.08783
\end{array} \\
& \begin{array}{llll}
26 & 3.6 & -0.00415801 & 0.11837
\end{array} \\
& \begin{array}{llll}
29.5 & 5.3 & 0.013634191 & 0.136185
\end{array} \\
& \begin{array}{llll}
44 & 17.1 & 0.146713129 & 0.20999
\end{array} \\
& \begin{array}{llll}
50 & 21.4 & 0.199976492 & 0.24053
\end{array} \\
& \begin{array}{lllr}
53 & 22.8 & 0.217948734 & 0.2558 \\
68 & 30.8 & 0.327347329 & 0.33215
\end{array} \\
& \begin{array}{lccc}
77 & 34.7 & 0.385356155 & 0.37796 \\
92 & 39 & 0.453474327 & 0.45431
\end{array} \\
& \begin{array}{llll}
92 & 39 & 0.453474327 & 0.45431
\end{array} \\
& \begin{array}{llll}
140 & 52 & 0.693147181 & 0.69863
\end{array} \\
& \begin{array}{llll}
164 & 57.9 & 0.824300451 & 0.82079
\end{array}
\end{aligned}
$$

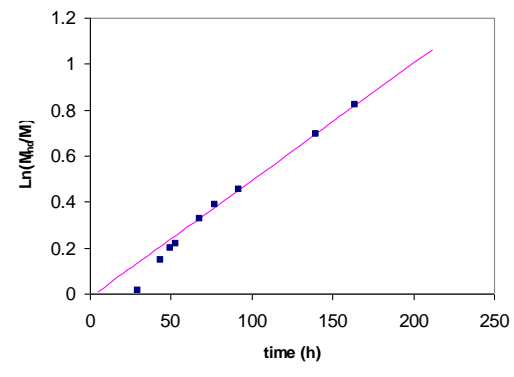

The second term of the intercept is known from the slope and from the estimated tind value $(27.5 \mathrm{~h})$ :

$$
k_{p} K \frac{\left[C o^{I I}\right]_{0}}{\left[C o^{I I}\right]_{e q}} t_{\text {ind }}=\left(5.090 \cdot 10^{-3} \mathrm{~h}^{-1}\right)(27.5 \mathrm{~h})=0.140
$$

which leaves

$$
k_{p}\left(\frac{8 f[I]_{0}}{k_{t} k_{d}}\right)^{1 / 2} e^{-\left(\frac{k_{d} t_{\text {ind }}}{2}\right)}=-0.014+0.140=0.126
$$

Considering the known $\mathrm{k}_{\mathrm{d}}$ value for $\mathrm{V}-70$ at $30^{\circ} \mathrm{C}\left(\mathrm{t}_{1 / 2}=10 \mathrm{~h} ; \mathrm{k}_{\mathrm{d}}=0.0693 \mathrm{~h}^{-1}\right)$ and the value of $\mathrm{t}_{\text {ind }}(27.5 \mathrm{~h})$, giving $e^{-\left(\frac{k_{d} t_{\text {ind }}}{2}\right)}=0.386$, we recover

$$
k_{p}\left(\frac{8 f[I]_{0}}{k_{t} k_{d}}\right)^{1 / 2}=0.126 / 0.386=0.326
$$

We can now analyze the data in the second period (just after the induction time):

Changing variable: $t^{\prime}=t-t_{\text {ind }}$

$$
\ln \frac{[M]_{\text {ind }}}{[M]_{t}}=k_{p} K \frac{\left[C o^{I I}\right]_{0}}{\left[C o^{I I}\right]_{e q}}\left(t^{\prime}\right)-k_{p}\left(\frac{8 f[I]_{0}}{k_{t} k_{d}}\right)^{1 / 2} e^{-\left(\frac{k_{d} t_{\text {ind }}}{2}\right)}\left(e^{-\left(\frac{k_{d} t^{\prime}}{2}\right)}-1\right)
$$

Numerically:

$$
\ln \frac{[M]_{\text {ind }}}{[M]_{t}}=5.090 \cdot 10^{-3} t^{\prime}-0.126\left(e^{-\left(\frac{k_{d} t^{\prime}}{2}\right)}-1\right)
$$




$\begin{array}{cccr}\mathrm{t}^{\prime}=\mathrm{t}-\mathrm{t}_{\text {ind }} & \text { conv }(\%) & \operatorname{Ln}\left(\mathrm{M}_{\text {ind }} / \mathrm{M}\right) & 0.00509 \mathrm{t}^{\prime}+0.126 \\ 2 & 5.3 & 0.013634191 & 0.13618 \\ 16.5 & 17.1 & 0.146713129 & 0.209985 \\ 22.5 & 21.4 & 0.199976492 & 0.240525 \\ 25.5 & 22.8 & 0.217948734 & 0.255795 \\ 40.5 & 30.8 & 0.327347329 & 0.332145 \\ 49.5 & 34.7 & 0.385356155 & 0.377955 \\ 64.5 & 39 & 0.453474327 & 0.454305 \\ 112.5 & 52 & 0.693147181 & 0.698625 \\ 136.5 & 57.9 & 0.824300451 & 0.820785\end{array}$

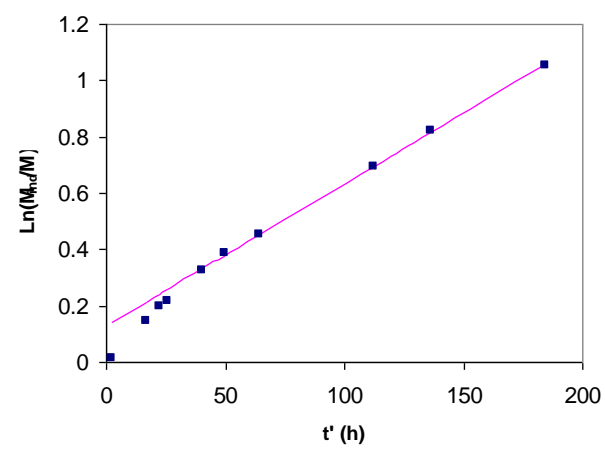

The raw data can be corrected for the

OMRP term:

$$
X=\left[\ln \frac{[M]_{\text {ind }}}{[M]_{t}}-5.090 \cdot 10^{-3} t^{\prime}\right]=0.126\left(1-e^{-\left(\frac{k_{d} t^{\prime}}{2}\right)}\right)
$$

and plotted as X vs. t'. The function X converges to $k_{p}\left(\frac{8 f[I]_{0}}{k_{t} k_{d}}\right)^{1 / 2} e^{-\left(\frac{k_{d} t_{\text {ind }}}{2}\right)}=0.126$.

$\begin{array}{cc}\mathrm{t}^{\prime}=\mathrm{t}-\mathrm{tind} & \mathrm{X} \\ 2 & 0.003454191 \\ 16.5 & 0.062728129 \\ 22.5 & 0.085451492 \\ 25.5 & 0.088153734 \\ 40.5 & 0.121202329 \\ 49.5 & 0.133401155 \\ 64.5 & 0.125169327 \\ 112.5 & 0.120522181 \\ 136.5 & 0.129515451\end{array}$

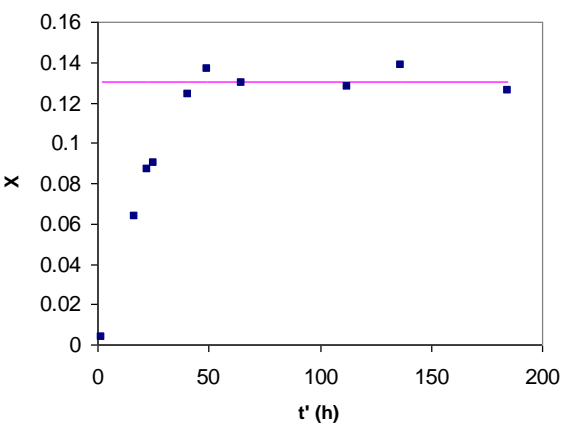

Further transformation as

$Y=\left[\ln \frac{[M]_{t}}{[M]_{\text {ind }}}+5.090 \cdot 10^{-3} t^{\prime}+0.126\right]=0.126 e^{-\left(\frac{k_{d} t^{\prime}}{2}\right)}$

and plotting Y vs t', or lnY vs. t', allows an independent estimation of the pre-exponential factor and $k_{\mathrm{d}}$.

$\begin{array}{cccc}\mathrm{t}^{\prime}=\mathrm{t}-\mathrm{t} \text { ind } & \mathrm{Y} & \operatorname{Ln}(\mathrm{Y}) & \exp \left(-1.5683-0.0826 \mathrm{t}^{\prime}\right) \\ 2 & 0.1225 & -2.0993 & 0.1767 \\ 16.5 & 0.0633 & -2.7603 & 0.0533 \\ 22.5 & 0.0405 & -3.2053 & 0.0325 \\ 25.5 & 0.0378 & -3.2742 & 0.0254 \\ 40.5 & 0.0048 & -5.3396 & 0.0073 \\ 49.5 & -0.0074 & & 0.0035 \\ 64.5 & 0.0008 & & 0.0010 \\ 112.5 & 0.0055 & & 0.0000 \\ 136.5 & -0.0035 & & 0.0000\end{array}$



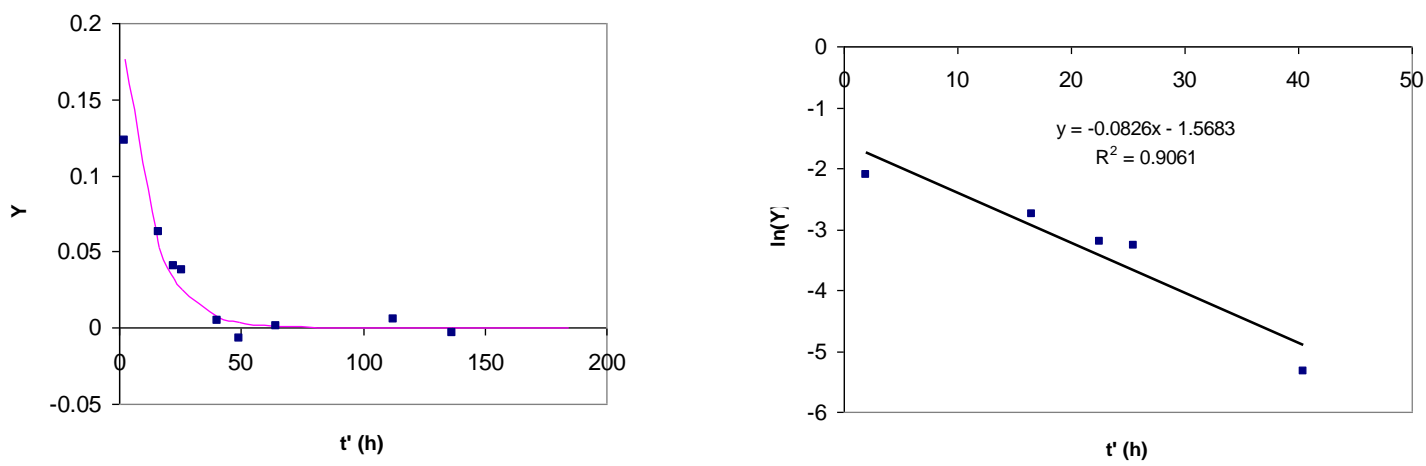

This analysis yields:

- $k_{\mathrm{d}}=2 * 0.0826 \mathrm{~h}^{-1}=0.165 \mathrm{~h}^{-1}\left(\right.$ not too far from $\left.0.0693 \mathrm{~h}^{-1}\right)$.

- Pre-exponential $=k_{p}\left(\frac{8 f[I]_{0}}{k_{t} k_{d}}\right)^{1 / 2} e^{-\left(\frac{k_{d} t_{\text {tind }}}{2}\right)}=\exp (-1.5683)=0.208$ (not too far from $0.126)$

(considering $e^{-\left(\frac{k_{d} t_{\text {ind }}}{2}\right)}=0.386$, we calculate $k_{p}\left(\frac{8 f[I]_{0}}{k_{t} k_{d}}\right)^{1 / 2}=0.541$; cf. 0.326 from the analysis of the OMRP region above)

which illustrates the self-consistency of this analysis.

\section{Estimation of the radical concentration in the OMRP regime.}

From the data at long times $(\mathrm{t}>50 \mathrm{~h})$,

$$
k_{\text {eff }}=k_{p}\left[R_{n}\right]=k_{p} K \frac{\left[C o^{I I}\right]_{0}}{\left[C o^{I I}\right]_{e q}}=5.090 \cdot 10^{-3} \mathrm{~h}^{-1}=1.414 \cdot 10^{-6} \mathrm{~s}^{-1}
$$

and from the literature ${ }^{1}$ value of $k_{\mathrm{p}}$ (free radical polymerization of vinyl acetate in benzene at $30^{\circ} \mathrm{C}$ ), $117 \mathrm{~s}^{-1} \mathrm{M}^{-1}$, we estimate

$$
\left[\mathrm{R}_{\mathrm{n}}\right]=\left(1.414 \cdot 10^{-6} \mathrm{~s}^{-1}\right) /\left(117 \mathrm{~s}^{-1} \mathrm{M}^{-1}\right)=1.21 \cdot 10^{-8} \mathrm{M}(\text { during the third period, } \mathrm{t}>50 \mathrm{~h})
$$

The values of $\mathrm{K}$ and $\left[\mathrm{Co}^{\mathrm{II}}\right]_{\text {eq }}$ cannot be individually estimated from the effective polymerization rate constant. However, from the above analysis, we know the ratio:

$$
\frac{K}{\left[C o^{I I}\right]_{e q}}=\frac{k_{e f f}}{k_{p}\left[C o^{I I}\right]_{0}}=\left(1.414 \cdot 10^{-6} \mathrm{~s}^{-1}\right) /\left(117 \mathrm{~s}^{-1} \mathrm{M}^{-1}\right)\left(1.084 \cdot 10^{-2} \mathrm{M}\right)=1.115 \cdot 10^{-6}
$$




\section{Estimation of the initiator efficiency factor}

From the analysis of the induction time $(27.5 \mathrm{~h}=99000 \mathrm{~s})$ and $[\mathrm{I}]_{0} /\left[\mathrm{Co}^{\mathrm{II}}\right]_{0}$ ratio, considering the literature ${ }^{1} k_{\mathrm{d}}$ value, it is possible to estimate $f$. The induction time tind corresponds to the time needed to generate an amount of radicals equivalent to $\left[\mathrm{Co}^{\mathrm{II}}\right]_{0}$, therefore:

$$
\left[C o^{I I}\right]_{O}=2 \mathrm{f}[\mathrm{I}]_{0}\left(1-\mathrm{e}^{-\mathrm{k}_{\mathrm{d}} t_{\text {ind }}}\right)=2 f\left(2.17 \cdot 10^{-2}\right)\left(1-\mathrm{e}^{-0.069327 .5}\right)=1.084 \cdot 10^{-2}
$$

from which

$f=1.084 \cdot 10^{-2} /\left(2 \cdot 2.17 \cdot 10^{-2} \cdot 0.8513\right)=0.293$

The evolution of $\left[\mathrm{Co}^{\mathrm{II}}\right]$ and $\left[\mathrm{Co}^{\mathrm{III}}\right]$ during the induction period is consequently calculated on the bases of the formulas given above, and is plotted here.

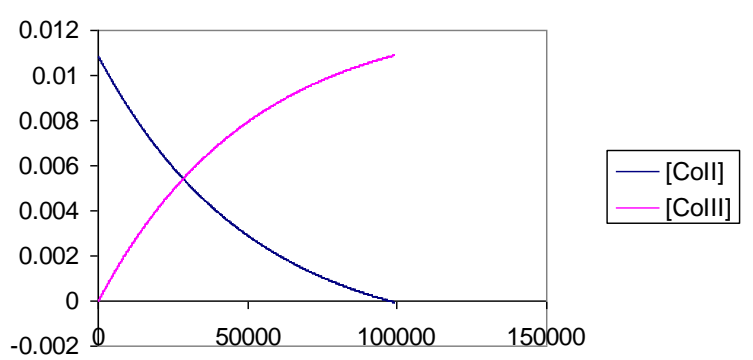

\section{Estimation of the OMRP equilibrium}

It is not possible to estimate this from the effective polymerization rate constant in the OMRP regime, because there are two unknown in the $k_{\text {eff }}$ expression: $\mathrm{K}$ and $\left[\mathrm{Co}^{\mathrm{II}}\right]_{\mathrm{eq}}$. The $\left[\mathrm{Co}^{\mathrm{II}}\right]_{\mathrm{eq}}$ cannot be assumed to be equal to $\left[\mathrm{R}_{\mathrm{n}}\right]$, because the weak but non zero level of irreversible terminations will ensure that a little excess $\left[\mathrm{Co}^{\mathrm{II}}\right]$ relative to $\left[\mathrm{R}_{\mathrm{n}}\right]$ will persist (persistent radical effect). One possible way to estimate these values is to match $[\mathrm{M}]_{\text {ind }}$ with the theory

Numerical integration during the induction time:

$$
\ln \frac{[M]_{0}}{[M]_{t}}=\int_{0}^{t<t_{\text {ind }}} \frac{k_{p} K\left[C o^{I I I}\right]_{t}}{\left[C o^{I I}\right]_{t}} d x=\int_{0}^{t<t_{\text {ind }}} \frac{(117) \mathrm{K}\left[C o^{I I I}\right]_{t}}{\left[C o^{I I}\right]_{t}} d x
$$

with $\left[\mathrm{Co}^{\mathrm{III}}\right]_{\mathrm{t}}=2 \mathrm{f}[\mathrm{I}]_{0}\left(1-\mathrm{e}^{-\mathrm{k}_{\mathrm{d}} t}\right)$ and $\left[\mathrm{Co}^{\mathrm{II}}\right]_{\mathrm{t}}=\left[\mathrm{Co}^{\mathrm{II}}\right]_{0}-\left[\mathrm{Co}^{\mathrm{III}}\right]_{\mathrm{t}}$.

The constant $\mathrm{K}$ is left as an adjustable parameter, in order to match convind $=4 \%$ $\left(\ln \left(\left[\mathrm{M}_{0}\right] /[\mathrm{M}]\right)=\ln (100 / 96)=0.0408\right.$. The integration is carried out by summing up the primitive values using a step $\Delta \mathrm{x}=60 \mathrm{~s}$. The solution is provided for

$\mathrm{K}=1.96 \cdot 10^{-10}$

which in turns yields:

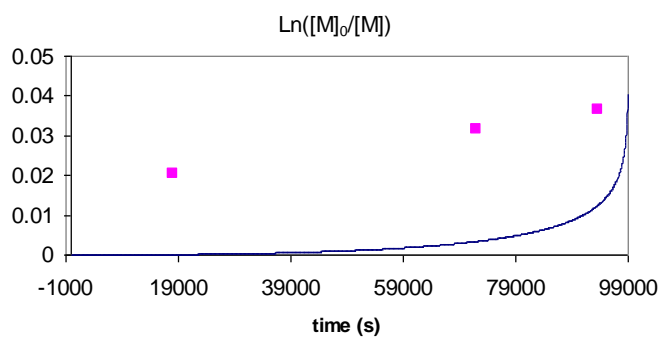


$\left[\mathrm{Co}^{\mathrm{II}}\right]_{\mathrm{eq}}=1.70 \cdot 10^{-4}$

This is 14000 times greater than the concentration of free radicals and constitutes $1.57 \%$ of the cobalt. This seems reasonable. However, these values need to be modified because of the following considerations:

1. The experimental values of the conversion are immediately large (2\%), whereas the simulation does not predict a significant polymer production until much later;

2. The slope of the $\ln \left([\mathrm{M}]_{0} /[\mathrm{M}]\right)$ curve immediately prior to the induction time is greater than after the induction time.

The first discrepancy is easily accounted for, considering an inefficient radical trapping by the $\mathrm{Co}^{\mathrm{II}}$ complex. Thus, the primary radicals have time to polymerize a significant amount of monomer before being reversibly deactivated by coordination to cobalt. This is also the time when the radical concentration in solution is maximum, thus irreversible terminations compete more efficiently with reversible deactivation.

The second discrepancy is caused by the incorrect assumption that $\left[\mathrm{Co}^{\mathrm{II}}\right]$ at the end of the induction period is zero. Indeed, the estimation of $\mathrm{K}$ leads to a significant $\left[\mathrm{Co}^{\mathrm{II}}\right]_{\mathrm{eq}}$ (see above). In order to correct for this discrepancy, we can consider that the induction time corresponds to the time needed for $\left[\mathrm{Co}^{\mathrm{II}}\right]$ to reach $\left[\mathrm{Co}^{\mathrm{II}}\right]_{\mathrm{eq}}$, rather than zero. Furthermore, given that a certain amount of polymer is initially formed in an uncontrolled fashion (at least $2 \%$, initial point), then the OMRP process in the induction period does not need to produce a $4 \%$ conversion, but rather $2 \%$ at the most.

The simulation has been revised as follows:

- Consideration of $2 \%$ polymer formed immediately by an uncontrolled process;

- $2 \%$ polymer formed by OMRP in the induction period;

- $\quad \mathrm{t}_{\mathrm{ind}}=27.5 \mathrm{~h}=$ time needed to obtain $\left[\mathrm{Co}^{\mathrm{II}}\right]=1.70 \cdot 10^{-4}(1.57 \%$ of cobalt $)$;

In order to fix the third point, it is sufficient to slightly reduce the efficiency factor :

$f=0.2885$

Then the conversion at $\mathrm{t}_{\text {ind }}$ is made equal to $4 \%\left(\ln [\mathrm{M}]_{0} /[\mathrm{M}]=0.0408\right)$ by adjusting the value of $K: K=2.71 \cdot 10^{-10}$

which in turns yields: $\left[\mathrm{Co}^{\mathrm{II}}\right]_{\mathrm{eq}}=2.36 \cdot 10^{-4}(2.17 \%$ of the cobalt $)$

Then the procedure is iterated:

1. f adjusted to obtain the new $\left[\mathrm{Co}^{\mathrm{II}}\right]_{\mathrm{eq}}$ at $\mathrm{t}_{\text {ind; }}$;

2. $\mathrm{K}$ adjusted to obtain $\ln [\mathrm{M}]_{0} /[\mathrm{M}]=0.0408$ at $\mathrm{t}_{\text {ind }}$; 
3. New $\left[\mathrm{Co}^{\mathrm{II}}\right]_{\mathrm{eq}}$ calculated from $\mathrm{K}$ and $\mathrm{K} /\left[\mathrm{Co}^{\mathrm{II}}\right]_{\mathrm{eq}}=1.15 \cdot 10^{-6}$.

\begin{tabular}{|l|l|l|l|}
\hline interation & $\mathrm{f}$ & $\mathrm{K}$ & {$\left[\mathrm{Co}^{\mathrm{II}}\right]_{\mathrm{eq}}$} \\
\hline 1 & 0.2885 & $2.71 \cdot 10^{-10}$ & $2.36 \cdot 10^{-4}$ \\
\hline 2 & 0.2867 & $3.08 \cdot 10^{-10}$ & $2.68 \cdot 10^{-4}$ \\
\hline 3 & 0.2858 & $3.26 \cdot 10^{-10}$ & $2.83 \cdot 10^{-4}$ \\
\hline 4 & 0.28545 & $3.32 \cdot 10^{-10}$ & $2.89 \cdot 10^{-4}$ \\
\hline 5 & 0.2853 & $3.35 \cdot 10^{-10}$ & $2.91 \cdot 10^{-4}$ \\
\hline 6 & 0.28525 & $3.37 \cdot 10^{-10}$ & $2.93 \cdot 10^{-4}$ \\
\hline 7 & 0.2852 & $3.38 \cdot 10^{-10}$ & $2.94 \cdot 10^{-4}$ \\
\hline $\mathbf{8}$ & $\mathbf{0 . 2 8 5 1 5}$ & $\mathbf{3 . 3 8 \cdot 1 0 ^ { - 1 0 }}$ & $\mathbf{2 . 9 4 \cdot 1 0 ^ { - 4 }}$ \\
\hline
\end{tabular}

This $\left[\mathrm{Co}^{\mathrm{II}}\right]_{\text {eq }}$ corresponds to $2.71 \%$ of the cobalt and 24300 times the radical concentration during the OMRP-only region $(\mathrm{t}>50 \mathrm{~h})$.

\section{Global simulation}

The $\ln \left([\mathrm{M}]_{0} /[\mathrm{M}]\right)$ function is calculated separately in the two regions before and after the induction time, with the equations given above, using the tentative parameters obtained as shown above.

- Before the induction time

Equation given in the previous section, numerical integration with step $\Delta \mathrm{x}=60 \mathrm{~s}$.

- $\quad$ After the induction time

Integrated expression giving $\ln \left([\mathrm{M}]_{\mathrm{ind}} /[\mathrm{M}]\right)$ :

$\ln \frac{[M]_{\text {ind }}}{[M]_{t}}=k_{p} K \frac{\left[C o^{I I}\right]_{0}}{\left[C o^{I I}\right]_{e q}}\left(t-t_{\text {ind }}\right)-k_{p}\left(\frac{8 f[I]_{0}}{k_{t} k_{d}}\right)^{1 / 2}\left(e^{-\left(\frac{k_{d} t}{2}\right)}-e^{-\left(\frac{k_{d} t_{\text {ind }}}{2}\right)}\right)$

These values are then converted into $\ln \left([\mathrm{M}]_{0} /[\mathrm{M}]\right)=\ln \left([\mathrm{M}]_{\text {ind }} / 0.96[\mathrm{M}]\right)$

The fitting is carried out with the least-squares procedure of Excel (Solver Macro).

Fixed parameters:

- $\quad k_{\mathrm{p}}=117 \mathrm{M}^{-1} \mathrm{~s}^{-1}$ (literature value);

- initial concentrations $\left([\mathrm{I}]_{0}=0.02172 \mathrm{M} ;\left[\mathrm{Co}^{\mathrm{II}}\right]_{0}=0.01084 \mathrm{M}\right)$;

- $\mathrm{f}=0.28515$

- $\mathrm{K}=3.38 \cdot 10^{-10}$ (fit to give $4 \%$ conversion at $\mathrm{t}_{\text {ind }}=27.5 \mathrm{~h}$ )

- $K /\left[\mathrm{Co}^{\mathrm{II}}\right]_{\mathrm{eq}}=1.15 \cdot 10^{-6}$

Adjustable parameters:

- $k_{\mathrm{d}}$ 


$$
-k_{p}\left(\frac{8 f[I]_{0}}{k_{t} k_{d}}\right)^{1 / 2}
$$

The optimized values of these two parameters are:

$k_{\mathrm{d}}=7.3(2) \cdot 10^{-2}\left(\right.$ not too far from the literature value of $\left.0.0693 \mathrm{~h}^{-1}\right)=2.03(7) \cdot 10^{-5} \mathrm{~s}^{-1}$

$k_{p}\left(\frac{8 f[I]_{0}}{k_{t} k_{d}}\right)^{1 / 2}=0.31(4)$ (not too far from the value of 0.326 calculated from the OMRPonly region)

The agreement between theory and experiment now looks better:
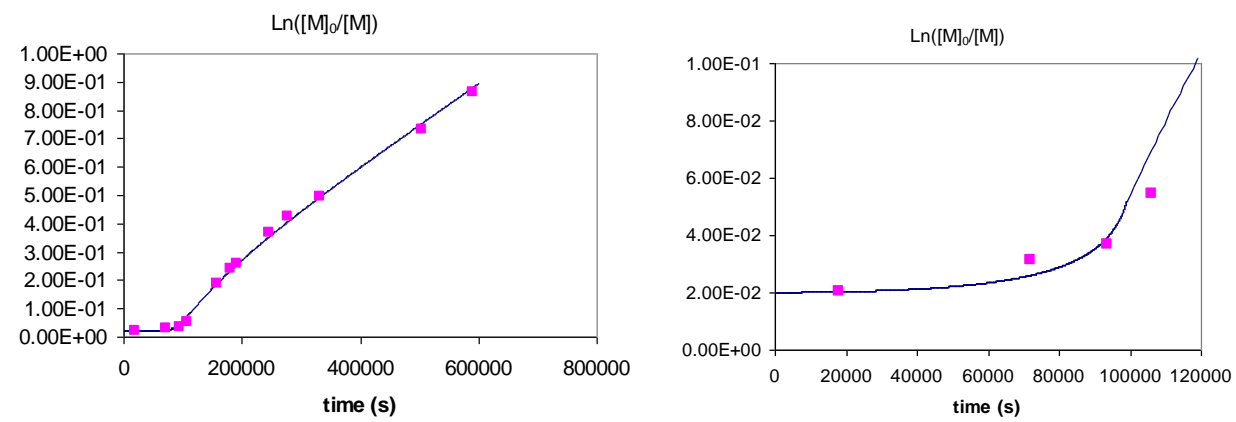

Obviously, this simulation is still idealized, because a bit of uncontrolled polymer keeps forming throughout the induction period (as well as later), but the current analysis represents an acceptable approximation.

Note: from the optimized value of

$k_{p}\left(\frac{8 f[I]_{0}}{k_{t} k_{d}}\right)^{1 / 2}=0.31(4)$

and the values of the other parameters, we can calculate $k_{\mathrm{t}}$ :

$$
k_{t}=\left(\frac{k_{p}}{0.31}\right)^{2} \frac{8 f[I]_{0}}{k_{d}}=k_{t}=\left(\frac{117}{0.31}\right)^{2} \frac{8 \cdot 0.28515 \cdot 2.172 \cdot 10^{-2}}{2.03 \cdot 10^{-5}}=3.48 \cdot 10^{8} \mathrm{~s}^{-1} \mathrm{M}^{-1}
$$

This value compares rather well with the termination rate constant available in the literature ${ }^{1}$ for VOAc under the same conditions $\left(3.19 \cdot 10^{8} \mathrm{~s}^{-1} \mathrm{M}^{-1}\right)$.

Table. Summary of parameters used in the kinetic analysis. ${ }^{\mathrm{a}}$

\begin{tabular}{|l|l|l|l|c|c|}
\hline \multicolumn{2}{|c|}{ Concentrations } & \multicolumn{2}{c|}{ Rate constants } & \multicolumn{2}{c|}{ Other parameters } \\
\hline$[\mathrm{VAc}]_{0}$ & $5.41 \mathrm{M}$ & $k_{\mathrm{d}}$ & $\begin{array}{l}\mathbf{2 . 0 3 ( 7 )} \cdot \mathbf{1 0}^{-5} \\
\mathbf{s}^{-1}\end{array}$ & $K /\left[\mathrm{Co}^{\mathrm{II}}\right]_{\mathrm{eq}}$ & $\mathbf{1 . 1 5} \cdot \mathbf{1 0}^{-\mathbf{6}} \mathbf{M}^{-\mathbf{1}}$ \\
\hline$\left[\mathrm{Co}^{\mathrm{II}}\right]_{0}$ & $1.084 \cdot 10^{-2} \mathrm{M}$ & $k_{\mathrm{p}}$ & $117 \mathrm{~s}^{-1} \mathrm{M}^{-1}$ & $f$ & $\mathbf{0 . 2 8 5 1 5}$ \\
\hline
\end{tabular}




\begin{tabular}{|l|l|l|l|l|l|}
\hline$[\mathrm{V}-70]_{0}$ & $2.172 \cdot 10^{-2} \mathrm{M}$ & $k_{\mathrm{t}}$ & $\begin{array}{l}\mathbf{3 . 4 8} \cdot \mathbf{1 0} \mathbf{8}^{\mathbf{8}} \mathbf{s}^{-} \\
\mathbf{1}^{-1}\end{array}$ & $k_{p}\left(\frac{8 f[I]_{0}}{k_{t} k_{d}}\right)^{1 / 2}$ & $\mathbf{0 . 3 1 ( 4 )}$ \\
\hline
\end{tabular}

${ }^{\mathrm{a} O}$ Optimized values are shown in bold character. 
B. Kinetic analysis of the VOAc polymerization in $50 \%$ toluene $(\mathrm{v} / \mathrm{v})$, initiated by $\mathrm{V}-70$, in the presence of $\mathrm{Co}(\mathrm{acac})_{2}$ at $30^{\circ} \mathrm{C}$.

Initial amounts:

VAc: $4 \mathrm{~mL}(3.73 \mathrm{~g}, 43.3 \mathrm{mmol})$

$[\mathrm{VAc}]_{0}=5.41 \mathrm{M}$

$\mathrm{Co}(\mathrm{acac})_{2}: 22.4 \mathrm{mg}(0.0871 \mathrm{mmol})$

$\left[\mathrm{Co}^{\mathrm{II}}\right]_{0}=1.084 \cdot 10^{-2} \mathrm{M}$

V-70: $53.5 \mathrm{mg}(0.173 \mathrm{mmol})$

$[\mathrm{V}-70]_{0}=2.172 \cdot 10^{-2} \mathrm{M}$

toluene: $4 \mathrm{~mL}$

$\left([\mathrm{M}]_{0} /\left[\mathrm{Co}^{\mathrm{II}}\right]_{0} /[\mathrm{V}-70]_{0}=500: 1: 2\right)$

Total volume: $8 \mathrm{~mL}$

Results

$\begin{array}{ccccccc}\text { time }(\mathbf{h}) & \text { time }(\mathbf{s}) & \text { conv }(\%) & \mathbf{L n}\left(\mathbf{M}_{\mathbf{0}} / \mathbf{M}\right) & \mathbf{M n} & \mathbf{M n}(\mathbf{t h e o}) & \mathbf{M w} / \mathbf{M n} \\ 2 & 7200 & 3.7 & 0.0377 & & 1593 & \\ 17 & 61200 & 4.4 & 0.0450 & & 1894 & \\ 40.75 & 146700 & 18.8 & 0.2083 & 12500 & 8092 & 1.21 \\ 64.5 & 232200 & 29.5 & 0.3496 & 15000 & 12698 & 1.39 \\ 88.5 & 318600 & 30.3 & 0.3610 & & 13043 & \\ 160.5 & 577800 & 31.6 & 0.3798 & 14500 & 13602 & 1.43 \\ 250 & 900000 & 32.1 & 0.3871 & & 13817 & \\ 329 & 1184400 & 32.7 & 0.3960 & & 14076 & \end{array}$

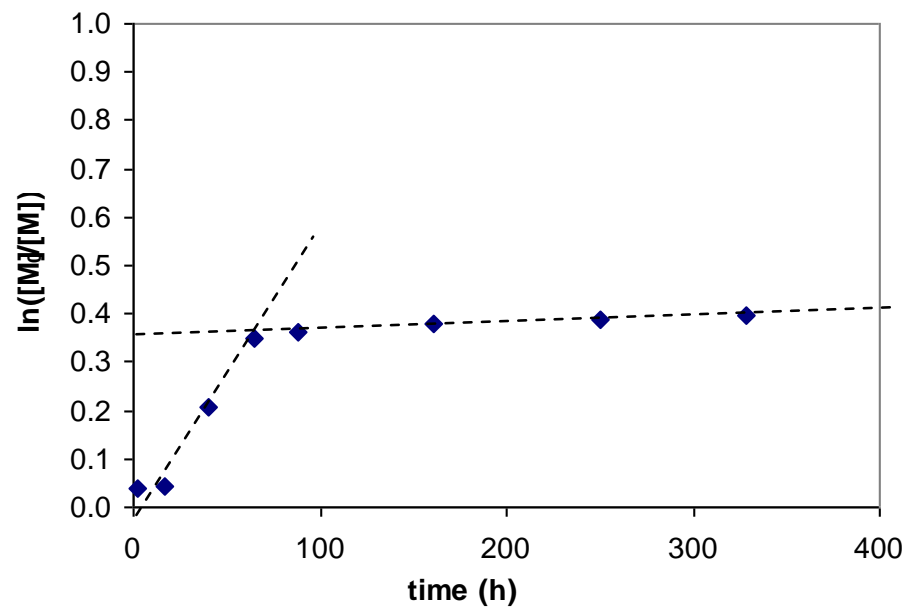

The analysis of these data paralleled exactly that done in the previous section. Although in principle the induction time should be exactly the same (giving the same value for the initiator efficiency factor, $f$ ), the analysis using this value was not satisfactory. Although only fewer points are available In the DT region, it seems that $t_{\text {ind }}$ is slightly shorter in this

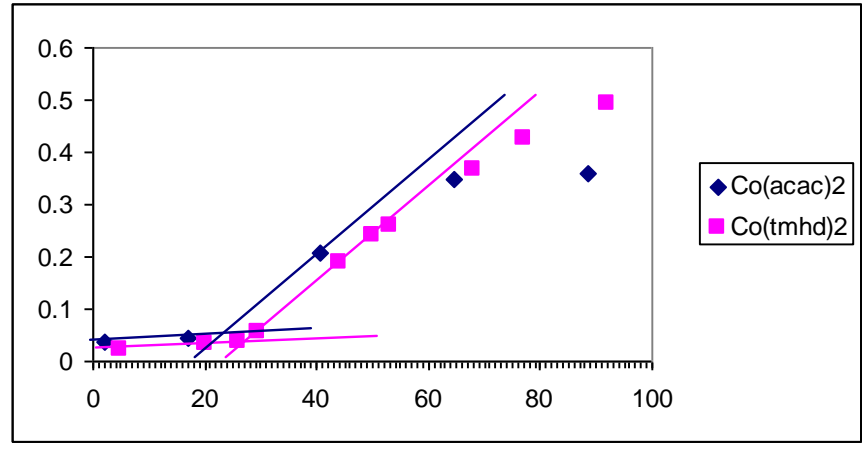
case. It was estimated as $23 \mathrm{~h}$, at which the conversion is ca. $4.4 \%$. 
The data after 50 hours gave the following results.

From the slope:

$k_{\text {eff }}=k_{p} K \frac{\left[C o^{I I}\right]_{0}}{\left[C o^{I I}\right]_{e q}}=1.374 \cdot 10^{-4} \mathrm{~h}^{-1}=3.817 \cdot 10^{-8} \mathrm{~s}^{-}$

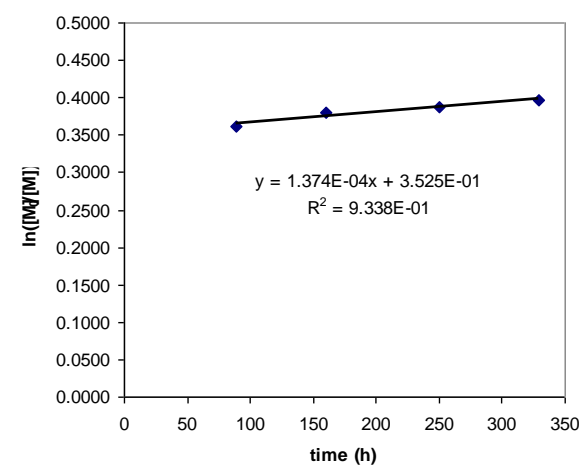

From the intercept:

$\left[k_{p}\left(\frac{8 f[I]_{0}}{k_{t} k_{d}}\right)^{1 / 2} e^{-\left(\frac{k_{d} t_{\text {ind }}}{2}\right)}-k_{p} K \frac{\left[C o^{I I}\right]_{0}}{\left[C o^{I I}\right]_{e q}} t_{\text {ind }}\right]=0.3525$

The second term is known from the slope and from the estimated tind value $(23 \mathrm{~h})$ :

$k_{p} K \frac{\left[C o^{I I}\right]_{0}}{\left[C o^{I I}\right]_{e q}} t_{\text {ind }}=\left(1.374 \cdot 10^{-4} \mathrm{~h}^{-1}\right)(23 \mathrm{~h})=3.16 \cdot 10^{-3}$

which leaves

$k_{p}\left(\frac{8 f[I]_{0}}{k_{t} k_{d}}\right)^{1 / 2} e^{-\left(\frac{k_{d} t_{\text {ind }}}{2}\right)}=0.3525+0.0032=0.3558$

Considering the known $\mathrm{k}_{\mathrm{d}}$ value for $\mathrm{V}-70$ at $30^{\circ} \mathrm{C}\left(\mathrm{t}_{1 / 2}=10 \mathrm{~h} ; \mathrm{k}_{\mathrm{d}}=0.0693 \mathrm{~h}^{-1}\right)$ and the value of $\mathrm{t}_{\text {ind }}(23 \mathrm{~h})$, giving $e^{-\left(\frac{k_{d} t_{\text {ind }}}{2}\right)}=0.451$, we recover $k_{p}\left(\frac{8 f[I]_{0}}{k_{t} k_{d}}\right)^{1 / 2}=0.3563 / 0.451=0.790$

From $k_{e f f}=k_{p}\left[R_{n}\right]=k_{p} K \frac{\left[C o^{I I}\right]_{0}}{\left[C o^{I I}\right]_{e q}}$ and $k_{\mathrm{p}}=117 \mathrm{~s}^{-1} \mathrm{M}^{-1}$, we estimate

$\left[\mathrm{R}_{\mathrm{n}}\right]=\left(3.817 \cdot 10^{-8} \mathrm{~s}^{-1}\right) /\left(117 \mathrm{~s}^{-1} \mathrm{M}^{-1}\right)=3.26 \cdot 10^{-10} \mathrm{M}($ during the third period, $\mathrm{t}>50 \mathrm{~h})$ and

$\frac{K}{\left[C o^{I I}\right]_{e q}}=\frac{k_{e f f}}{k_{p}\left[C o^{I I}\right]_{0}}=\left(3.817 \cdot 10^{-8} \mathrm{~s}^{-1}\right) /\left(117 \mathrm{~s}^{-1} \mathrm{M}^{-1}\right)\left(1.089 \cdot 10^{-2} \mathrm{M}\right)=2.996 \cdot 10^{-8}$

The new $f$ value was calculated as before, from the estimated induction time $(23 \mathrm{~h}=82800$ s) and $[\mathrm{I}]_{0} /\left[\mathrm{Co}^{\mathrm{II}}\right]_{0}$ ratio.

$\left[C o^{I I}\right]_{O}=2 \mathrm{f}[\mathrm{I}]_{0}\left(1-\mathrm{e}^{-\mathrm{k}_{\mathrm{d}} t_{\text {ind }}}\right)=2 f\left(2.17 \cdot 10^{-2}\right)\left(1-\mathrm{e}^{-0.069323}\right)=1.084 \cdot 10^{-2}$

from which $f=1.084 \cdot 10^{-2} /\left(2 \cdot 2.17 \cdot 10^{-2} \cdot 0.7969\right)=0.313$ 
In this case, the amount of polymer immediately formed was higher (first withdrawal: $3.7 \%$ ). Thus, we considered that $3.7 \%$ of polymer formed immediately by an uncontrolled process. Adjusting the $\mathrm{K}$ value in order to reach a $4.4 \%$ conversion at $t_{\text {ind }}$ did not allow refining the $\mathrm{f}$ value and the individual $\left[\mathrm{Co}^{\mathrm{II}}\right]_{\mathrm{eq}}$ and $\mathrm{K}$ values as in the previous case, the reason being that OMRP plays a much less significant role in this case. Therefore, the fitting was done by keeping $f$ fixed at $0.313, \mathrm{~K} /\left[\mathrm{Co}^{\mathrm{II}}\right]_{\mathrm{eq}}$ fixed at $2.996 \cdot 10^{-8}$, and $k_{\mathrm{d}}$ fixed at $0.0732 \mathrm{~h}^{-1}$ (value optimized in the previous case). The data were fit by only adjusting the $k_{p}\left(\frac{8 f[I]_{0}}{k_{t} k_{d}}\right)^{1 / 2}$ value. The optimized value is $0.79(3)$ (same as the value derived by the analysis of the OMRP-only region).
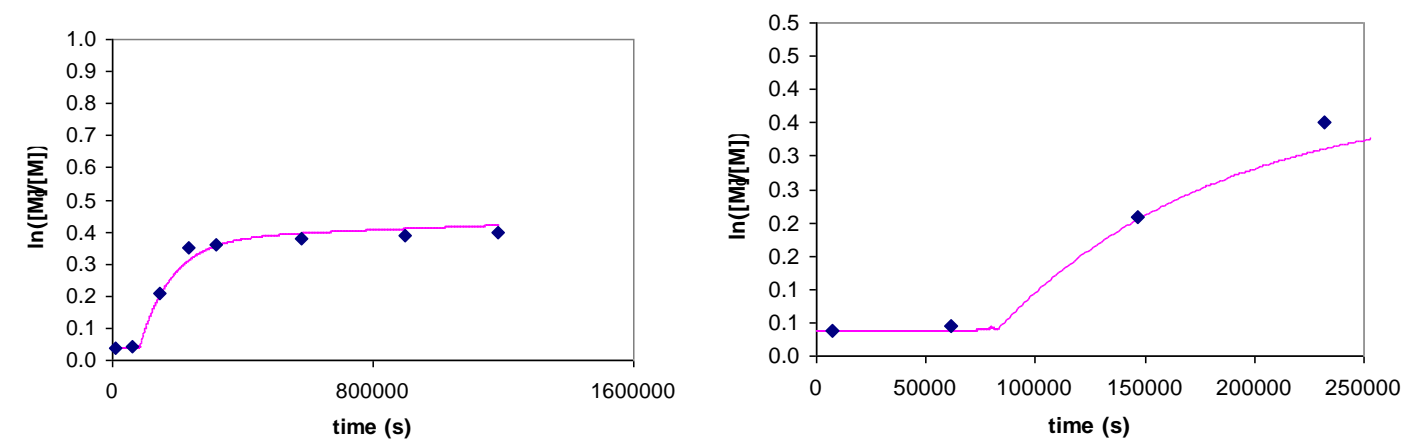


\section{Kinetic analysis of the VOAc polymerization in $25 \%$ toluene $(\mathrm{v} / \mathrm{v})$, initiated by V-70, in the presence of $\mathrm{Co}(\mathrm{tmhd})_{2}$ at $30^{\circ} \mathrm{C}$.}

Initial amounts:

VAc: $4 \mathrm{~mL}(3.73 \mathrm{~g}, 43.3 \mathrm{mmol})$

$$
\begin{aligned}
& {[\mathrm{VAc}]_{0}=8.13 \mathrm{M}} \\
& {\left[\mathrm{Co}^{\mathrm{II}}\right]_{0}=1.63 \cdot 10^{-2} \mathrm{M}} \\
& {[\mathrm{V}-70]_{0}=3.26 \cdot 10^{-2} \mathrm{M}}
\end{aligned}
$$

Co(tmhd $)_{2}: 36.9 .4 \mathrm{mg}(0.0867 \mathrm{mmol})$

toluene: $1.33 \mathrm{~mL}$

$\left([\mathrm{M}]_{0} /\left[\mathrm{Co}^{\mathrm{II}}\right]_{0} /[\mathrm{V}-70]_{0}=500: 1: 2\right)$

Total volume: $5.33 \mathrm{~mL}$

\section{Results}

$\begin{array}{cccccc}\text { time }(\mathbf{h}) & \text { conv }(\%) & \mathbf{L n}\left(\mathbf{M}_{\mathbf{0}} / \mathbf{M}\right) & \text { Mn SEC } & \text { Mn theo } & \text { Mw/Mn } \\ 7 & 2.9 & 0.02943 & & & \\ 22.5 & 8.4 & 0.08774 & 7200 & 3616 & 1.33 \\ 31.25 & 26.5 & 0.30788 & 17300 & 11407 & 1.26 \\ 48 & 46.4 & 0.62362 & 24800 & 19973 & 1.23 \\ 94.5 & 76.2 & 1.43548 & 28800 & 32800 & 1.39 \\ 173.25 & 80.1 & 1.61445 & & 34479 & \end{array}$

The induction time is estimated in this case as $t_{\text {ind }}=20 \mathrm{~h}$, giving an initiator efficiency factor of:

$$
\mathrm{f}=\frac{\left[C o^{I I}\right]_{O}}{2[\mathrm{I}]_{0}\left(1-\mathrm{e}^{-\mathrm{k}_{\mathrm{d}} t_{\text {ind }}}\right)}=\frac{1.63 \cdot 10^{-2}}{2 \times 3.25 \cdot 10^{-2}\left(1-\mathrm{e}^{-0.069320}\right)}=0.334
$$

The analysis of the OMRP-only region gives:

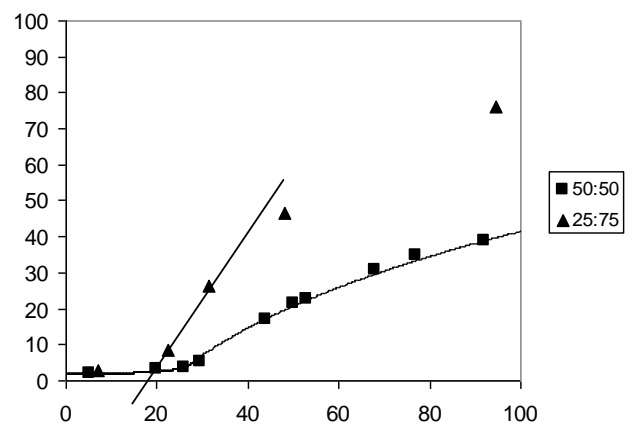

From the slope:

$$
k_{\text {eff }}=k_{p} K \frac{\left[C o^{I I}\right]_{0}}{\left[C o^{I I}\right]_{e q}}=1.775 \cdot 10^{-2} \mathrm{~h}^{-1}=4.931 \cdot 10^{-6} \mathrm{~s}^{-1}
$$

which gives:

$$
\frac{K}{\left[C o^{I I}\right]_{e q}}=\frac{4.931 \cdot 10^{-6}}{117 \cdot 1.63 \cdot 10^{-2}}=2.59 \cdot 10^{-6}
$$

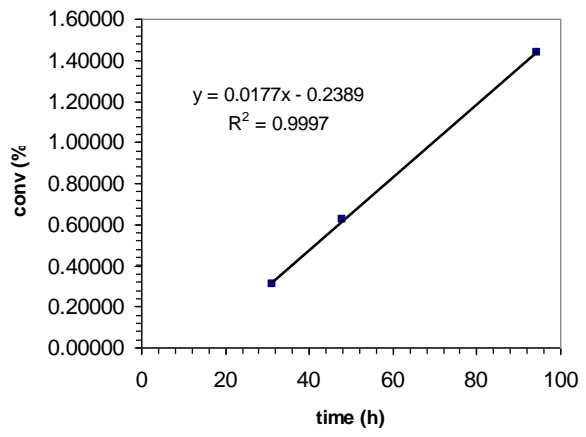

From the intercept:

$$
\left[k_{p}\left(\frac{8 f[I]_{0}}{k_{t} k_{d}}\right)^{1 / 2} e^{-\left(\frac{k_{d} t_{\text {ind }}}{2}\right)}-k_{p} K \frac{\left[C o^{I I}\right]_{0}}{\left[C o^{I I}\right]_{e q}} t_{\text {ind }}\right]=-0.2389
$$

Estimation of

$$
k_{p} K \frac{\left[C o^{I I}\right]_{0}}{\left[C o^{I I}\right]_{e q}} t_{\text {ind }}=\left(1.775 \cdot 10^{-2} \mathrm{~h}^{-1}\right)(20 \mathrm{~h})=0.355
$$


affords:

$k_{p}\left(\frac{8 f[I]_{0}}{k_{t} k_{d}}\right)^{1 / 2} e^{-\left(\frac{k_{d} t_{\text {ind }}}{2}\right)}=0.3550-0.2389=0.1161$

which, considering that $e^{-\left(\frac{k_{d} t_{\text {ind }}}{2}\right)}=\mathrm{e}^{-(0.0693 \times 20) / 2}=0.250$

yields $k_{p}\left(\frac{8 f[I]_{0}}{k_{t} k_{d}}\right)^{1 / 2}=0.1161 / 0.250=0.464$

An excellent fit was obtained by using the above parameters, except for a slightly reduced efficiency factor of 0.325 .

The optimized values are:

$k_{\mathrm{d}}=0.071(13) \mathrm{h}^{-1}$

$k_{p}\left(\frac{8 f[I]_{0}}{k_{t} k_{d}}\right)^{1 / 2}=0.16(11)$

The persistent radical effect breaks down after ca. $100 \mathrm{~h}$.
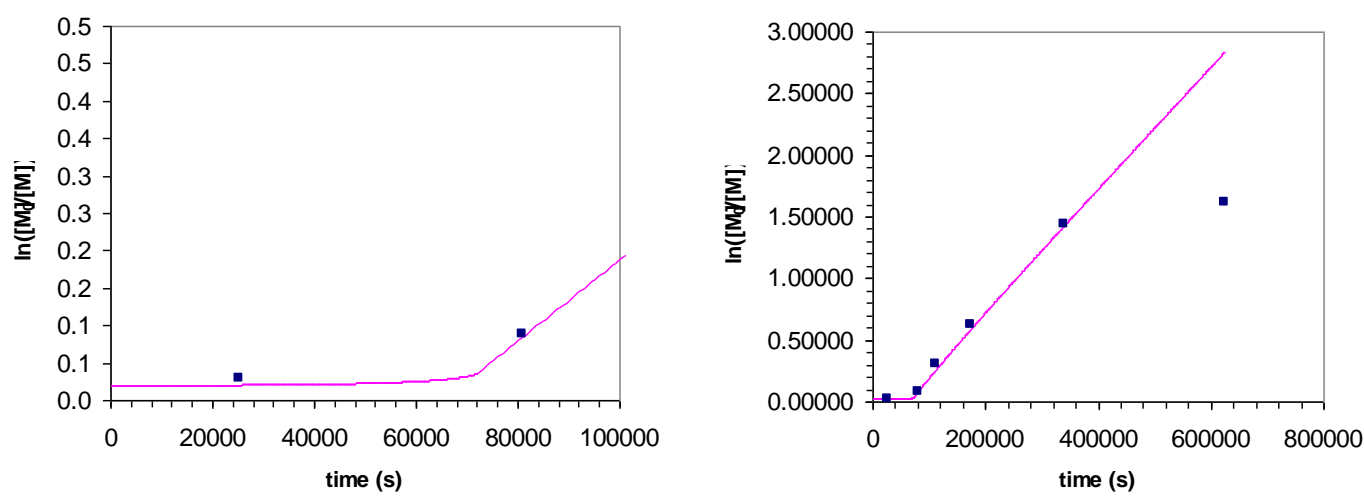


\section{Kinetic analysis of the VOAc polymerization in bulk, initiated by V-70, in the presence of $\mathrm{Co}(\mathrm{tmhd})_{2}$ at $30^{\circ} \mathrm{C}$.}

Initial amounts:

VAc: $4 \mathrm{~mL}(3.73 \mathrm{~g}, 43.3 \mathrm{mmol})$

$$
\begin{aligned}
& {[\mathrm{VAc}]_{0}=10.85 \mathrm{M}} \\
& {\left[\mathrm{Co}^{\mathrm{II}}\right]_{0}=2.17 \cdot 10^{-2} \mathrm{M}} \\
& {[\mathrm{V}-70]_{0}=4.34 \cdot 10^{-2} \mathrm{M}}
\end{aligned}
$$

Co(tmhd) $2: 36.9 \mathrm{mg}(0.0867 \mathrm{mmol})$

$\left([\mathrm{M}]_{0} /\left[\mathrm{Co}^{\mathrm{II}}\right]_{0} /[\mathrm{V}-70]_{0}=500: 1: 2\right)$

Total volume: $4 \mathrm{~mL}$

\section{Results}

$\begin{array}{cccc}\text { time (h) } & \text { time (s) } & \text { conv (\%) } & \left.\text { Ln( } \mathbf{M}_{\mathbf{0}} / \mathbf{M}\right) \\ 4 & 14400 & 2.4 & 0.02429 \\ 17.45 & 62820 & 13.8 & 0.14850 \\ 21 & 75600 & 28.7 & 0.33827 \\ 24 & 86400 & 43.3 & 0.56740 \\ 25.45 & 91620 & 50.5 & 0.70320 \\ 27.45 & 98820 & 62.9 & 0.99155 \\ 41.45 & 149220 & 82.8 & 1.76026\end{array}$

The induction time is estimated in this case as $15 \mathrm{~min}$,

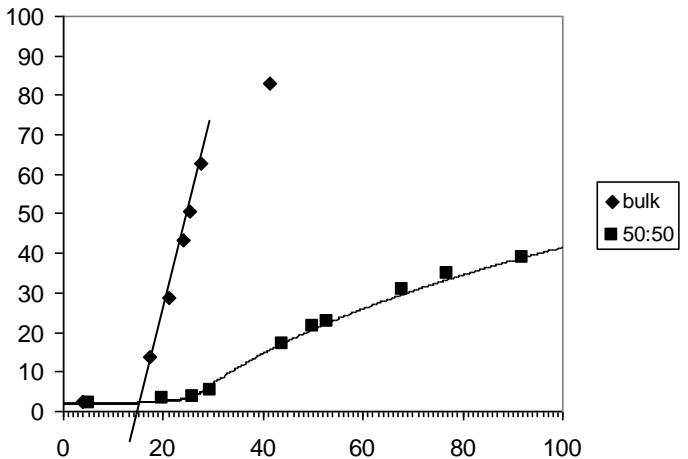

$\mathrm{f}=\frac{\left[C o^{I I}\right]_{O}}{2[\mathrm{I}]_{0}\left(1-\mathrm{e}^{-\mathrm{k}_{\mathrm{d}} t_{\text {ind }}}\right)}=\frac{2.17 \cdot 10^{-2}}{2 \times 4.34 \cdot 10^{-2}\left(1-\mathrm{e}^{-0.069315}\right)}=0.387$

In this case, there were no sufficient points in the OMRP-only region (the polymerization is almost complete while the DT mechanism is still active) to obtain graphically a good guess for the $k_{\text {eff }}$ rate constant and consequently of $\mathrm{K} /\left[\mathrm{Co}^{\mathrm{II}}\right]_{\mathrm{eq}}$. From the progression of the $\mathrm{K} /\left[\mathrm{Co}^{\mathrm{II}}\right]_{\mathrm{eq}}$ values obtained under the other conditions $\left(1.15 \cdot 10^{-6}\right.$ for $50 \% ; 2.59 \cdot 10^{-6}$ for $\left.75 \%\right)$ a fixed value of $6.0 \cdot 10^{-6}$ was attributed for this experiment. The $k_{\mathrm{d}}$ value was also fixed, on the basis of the other experiments $\left(0.073(2) \mathrm{s}^{-1}\right.$ at $50 \% ; 0.071(13)$ at $\left.75 \%\right)$, to the value of $0.072 \mathrm{~s}^{-1}$. An acceptable fit was obtained by lowering $f$ to 0.365 , giving

$k_{p}\left(\frac{8 f[I]_{0}}{k_{t} k_{d}}\right)^{1 / 2}=0.53(26)$

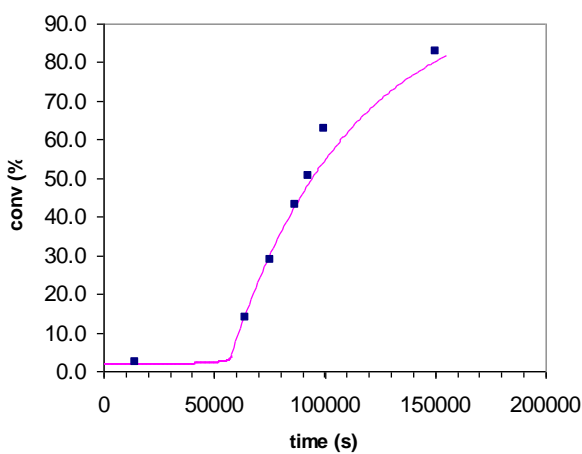




\section{E. Cartesian Coordinates for all optimized structures}

$\begin{array}{lr}\text { Co (acac) } 2 \\ 6 & 3.381217000 \\ 6 & 2.545538000 \\ 6 & 3.185305000 \\ 6 & 2.545868000 \\ 6 & 3.381832000 \\ 8 & 1.280487000 \\ 27 & -0.000004000 \\ 8 & -1.280698000 \\ 6 & -2.545741000 \\ 6 & -3.381589000 \\ 8 & 1.280840000 \\ 8 & -1.280626000 \\ 6 & -2.545663000 \\ 6 & -3.381455000 \\ 6 & -3.185301000 \\ 1 & 3.128898000 \\ 1 & 4.455218000 \\ 1 & 3.127055000 \\ 1 & 4.271077000 \\ 1 & 3.128298000 \\ 1 & 4.455788000 \\ 1 & 3.129170000 \\ 1 & -3.128496000 \\ 1 & -3.128040000 \\ 1 & -4.455440000 \\ 1 & -4.271073000 \\ 1 & -3.129027000 \\ 1 & -4.455563000 \\ 1 & -3.127841000\end{array}$

1.769550000

0.883908000

0.000224000

$-0.883814000$

$-1.769109000$

1.019577000

$-0.000109000$

1.025254000

0.888880000

1.779919000

$-1.020065000$

$-1.025136000$

$-0.888856000$

$-1.779973000$

$-0.000042000$

1.568253000

1.625917000

2.818659000

0.000475000

$-2.818356000$

$-1.624895000$

$-1.567995000$

$-2.827945000$

$-1.586398000$

$-1.634367000$

$-0.000093000$

2.827965000

1.634002000

1.586552000

$\mathrm{Co}(\mathrm{acac})_{2}\left(\mathrm{CH}\left(\mathrm{CH}_{3}\right) \mathrm{OOCCH}_{3}\right)$ 5-coord.

$\begin{array}{lrrr}6 & -0.066740000 & -0.465190000 & 1.344155000 \\ 27 & 0.456967000 & 0.142088000 & -0.423771000 \\ 8 & 1.626355000 & -1.313781000 & -0.594894000 \\ 6 & 2.889688000 & -1.301168000 & -0.410054000 \\ 6 & 3.573633000 & -2.626959000 & -0.628104000 \\ 8 & -0.609608000 & 1.665928000 & -0.518023000 \\ 6 & -1.817958000 & 1.712696000 & -0.924425000 \\ 6 & -2.550305000 & 0.615867000 & -1.401611000 \\ 6 & -1.990810000 & -0.663318000 & -1.546096000 \\ 8 & -0.794957000 & -0.974399000 & -1.225793000 \\ 6 & -2.448832000 & 3.081350000 & -0.875111000 \\ 6 & -2.811576000 & -1.796118000 & -2.101761000 \\ 8 & 1.817277000 & 1.350970000 & 0.033137000 \\ 6 & 3.064308000 & 1.094568000 & 0.124782000 \\ 6 & 3.934930000 & 2.283696000 & 0.443424000 \\ 6 & 3.640089000 & -0.172735000 & -0.047581000 \\ 1 & 3.794582000 & 3.052496000 & -0.325623000 \\ 1 & -2.467534000 & 3.435246000 & 0.162748000 \\ 1 & -1.830890000 & 3.786853000 & -1.442624000 \\ 1 & 4.994911000 & 2.021563000 & 0.501857000 \\ 1 & -3.465498000 & 3.087621000 & -1.277908000 \\ 1 & 3.617514000 & 2.723274000 & 1.396544000 \\ 1 & 4.713897000 & -0.277703000 & 0.069601000 \\ 1 & -3.575180000 & 0.773200000 & -1.723121000 \\ 1 & 3.362168000 & -2.981435000 & -1.643738000 \\ 1 & -3.763978000 & -1.455984000 & -2.518234000 \\ 1 & 4.655853000 & -2.566613000 & -0.483924000 \\ 1 & -2.238616000 & -2.322713000 & -2.872597000 \\ 1 & 3.157232000 & -3.369985000 & 0.062530000 \\ 1 & -3.004582000 & -2.509630000 & -1.290997000 \\ 1 & -0.102629000 & -1.548573000 & 1.200352000 \\ 6 & 0.890694000 & -0.004933000 & 2.413706000 \\ 8 & -1.361966000 & 0.011891000 & 1.672972000 \\ 6 & -2.400586000 & -0.864989000 & 1.675041000 \\ 8 & -2.307243000 & -2.041876000 & 1.402764000 \\ 1 & 0.591739000 & -0.442955000 & 3.378072000 \\ 1 & 1.909388000 & -0.337095000 & 2.190744000 \\ 1 & 0.886178000 & 1.084930000 & 2.512091000 \\ 6 & -3.671352000 & -0.164070000 & 2.079134000 \\ 1 & -3.966647000 & 0.534700000 & 1.288822000 \\ 1 & -4.460999000 & -0.902641000 & 2.229069000 \\ 1 & -3.514997000 & 0.417037000 & 2.993851000 \\ & & & \end{array}$

1.779529000 0.888724000 0.000050000 $-0.888465000$ $-1.779340000$ 1.025140000 $-0.000266000$ $-1.019581000$ $-0.883559000$ $-1.768799000$ $-1.024789000$ 1.019614000 0.883616000 1. 768837000 $-0.000011000$ 2.827647000 1.633543000 1.586137000 0.000001000 $-1.585847000$ $-1.633584000$ $-2.827404000$ 1.567756000 2. 818125000 1.624693000 $-0.000020000$ $-1.567530000$ $-1.624888000$ $-2.818031000$

$\begin{array}{ll}\mathrm{Co}(\mathrm{acac}) & 2\left(\mathrm{CH}\left(\mathrm{CH}_{3}\right) 00 \mathrm{OCH}_{3}\right) \\ 6 & -3.66956000 \\ 6 & -2.653455000 \\ 6 & -3.074163000 \\ 6 & -2.202333000 \\ 6 & -2.751743000 \\ 8 & -1.450419000 \\ 27 & 0.034130000 \\ 8 & 1.133879000 \\ 6 & 1.336769000 \\ 6 & 2.142725000 \\ 8 & -0.934581000 \\ 8 & -0.061048000 \\ 6 & 0.748340000 \\ 6 & 0.484666000 \\ 8 & 1.622583000 \\ 6 & 2.217429000 \\ 6 & 3.438844000 \\ 6 & 0.047601000 \\ 6 & 0.588561000 \\ 6 & 1.854732000 \\ 8 & 0.865838000 \\ 1 & -3.573008000 \\ 1 & -4.694800000 \\ 1 & -3.457737000 \\ 1 & -4.134358000 \\ 1 & -3.843642000 \\ 1 & -2.340284000 \\ 1 & -2.423172000 \\ 1 & 0.531951000 \\ 1 & -0.532698000 \\ 1 & 1.196812000 \\ 1 & 2.474470000 \\ 1 & 3.936660000 \\ 1 & 4.148955000 \\ 1 & 3.145368000 \\ 1 & 2.542564000 \\ 1 & 1.508713000 \\ 1 & 2.958231000 \\ 1 & 0.569780000 \\ 1 & -0.038051000 \\ 1 & 1.609623000 \\ 1 & -0.967415000 \\ & \\ 6 & \\ 6 & \end{array}$

2.321283000

$\mathrm{Co}(\mathrm{acac})_{2}\left(\mathrm{CH}\left(\mathrm{CH}_{3}\right) \mathrm{OOCCH}_{3}\right)$ (py)

$-2.215470000$

$-1.658785000$

$-2.082362000$

$-3.085187000$

$-3.666583000$

$-3.222908000$

$-0.083708000$

1.359884000

0.655769000

1.487421000

1.950905000

0.816216000

1.645521000

2. 303970000

$-0.904808000$

$-1.871023000$

$-2.359140000$

$-1.090044000$

$-2.048866000$

$-2.732203000$

1.993036000

$-2.476235000$

$-1.584879000$

$-3.399046000$

$-4.452248000$

$-3.647035000$

$-1.822502000$

2. 562215000

1.084404000

2.537568000

3.110029000
1.230642000

0.587120000

$-0.333353000$

$-0.979927000$

$-1.946594000$

0.951996000

0.205133000

1.292888000

2.418194000

3.457264000

$-0.837213000$

$-1.260262000$

$-2.228793000$

$-3.251348000$

$-0.437608000$

$-1.523723000$

$-1.822737000$

1.736390000

1.571520000

$-2.410506000$

2.780622000

0.944756000

0.937146000

$-0.552460000$

$-1.998817000$

$-2.945155000$

$-1.649743000$

$-2.758602000$

$-3.644482000$

$-4.081512000$

$-3.289999000$

$-2.747405000$

$-0.990331000$

$-1.902194000$

3.042422000

4. 322456000

3.803609000

2.522073000

0.847584000

1.180766000

2.151722000

$-1.596171000$

$-0.684896000$

0.287527000

1.173259000

2.193488000

$-0.885002000$

0.007662000

$-1.147972000$

$-0.657603000$

$-1.372413000$

1.214055000

$-1.335304000$

$-1.386062000$

$-2.470039000$

0.813488000

0.487301000

1. 326221000

1.184185000

2.577807000

$-0.528322000$

0.502379000

$-1.543626000$

$-1.345629000$

$-2.631455000$

0.361881000

2.170623000

2.002602000

3.196180000

$-3.448658000$

$-2.357663000$

$-2.451739000$

$-0.673661000$

1.021374000

1.250847000

2. 379945000

$-2.298846000$

$-1.596142000$

$-0.728834000$

3.130878000

3.110045000

2. 562406000

1.183769000

1. 681282000

1.190402000

1.639638000

2.598942000

2.642983000

$-0.279759000$

$-1.608154000$

0.689722000

1. 645237000

2.250490000

0.669357000

1. 615044000

2.150541000

$-1.210647000$

$-2.033031000$

$-2.623579000$

$-1.152053000$

$-1.962928000$

$-2.473774000$

2.139149000

$-2.416400000$

1.202980000

2. 935379000

3. 861090000

3.015068000

1.275540000

1.515406000

2. 472725000

3.161849000

$-1.048502000$

0.065939000

1.254103000

1.376362000

0.216854000

$-1.019713000$

$-0.034069000$

0.010649000

$-1.471345000$

$-1.348238000$

$-2.651677000$

1.320607000

1.120926000

2. 366447000

1. 401884000

1. 285379000

2. 586428000

$-1.389348000$

$-1.180238000$

$-2.426278000$

$-0.135414000$

0.078220000

2.118145000

2. 361642000

0.275853000

$-1.949331000$

$-1.978890000$

$-3.189936000$

$-3.284269000$

$-2.504401000$ 


$\begin{array}{lr}1 & 2.701683000 \\ 1 & 1.555573000 \\ 1 & 2.833318000 \\ 1 & 3.018003000 \\ 1 & -2.023693000 \\ 1 & -3.615408000 \\ 1 & -3.021642000 \\ 1 & -3.299455000 \\ 1 & -3.239014000 \\ 1 & -1.554508000 \\ 1 & -2.595945000 \\ 6 & 1.063372000 \\ 8 & 2.578910000 \\ 1 & 1.498583000 \\ 1 & 1.889152000 \\ 1 & 0.147397000 \\ 1 & 0.944061000 \\ 6 & 3.618074000 \\ 8 & 3.615457000 \\ 6 & 4.795991000 \\ 1 & 5.698193000 \\ 1 & 4.924333000 \\ 1 & 4.611291000\end{array}$

$\mathrm{Co}(\mathrm{acac})_{2}(\mathrm{py})$

$\begin{array}{lr}6 & -0.085550000 \\ 7 & -0.641273000 \\ 6 & -1.669672000 \\ 6 & -2.174669000 \\ 6 & -1.600262000 \\ 6 & -0.539367000 \\ 27 & 0.024001000 \\ 8 & -0.402184000 \\ 6 & -1.327174000 \\ 6 & -1.362270000 \\ 6 & -2.292618000 \\ 6 & -2.406473000 \\ 8 & -1.641979000 \\ 6 & -3.518365000 \\ 8 & 1.713174000 \\ 6 & 2.923272000 \\ 6 & 3.391605000 \\ 6 & 2.565074000 \\ 6 & 3.179626000 \\ 8 & 1.290919000 \\ 6 & 3.931591000 \\ 1 & -0.401394000 \\ 1 & 3.898952000 \\ 1 & 3.650505000 \\ 1 & -2.169872000 \\ 1 & 4.955095000 \\ 1 & -1.476002000 \\ 1 & -3.018189000 \\ 1 & 4.460015000 \\ 1 & -3.082718000 \\ 1 & 4.267565000 \\ 1 & -4.148043000 \\ 1 & 2.742200000 \\ 1 & -4.145445000 \\ 1 & 2.923254000 \\ 1 & -2.087047000 \\ 1 & -3.004324000 \\ 1 & -1.974343000 \\ 1 & -0.063356000 \\ 1 & 0.746089000\end{array}$

$\mathrm{Co}(\mathrm{acac})_{2}(\mathrm{py})_{2}$

$\begin{array}{lr}6 & 2.955809000 \\ 7 & 2.270983000 \\ 6 & 2.956277000 \\ 6 & 4.348385000 \\ 6 & 5.059116000 \\ 6 & 4.347903000 \\ 27 & 0.070150000 \\ 7 & -2.138511000 \\ 6 & -2.817387000 \\ 6 & -4.209690000\end{array}$

2. 961110000

2.290481000

3.091056000

1.396230000

$-3.080781000$

$-3.077895000$

$-1.628499000$

$-3.122833000$

$-3.259108000$

$-3.216335000$

$-1.817418000$

$-2.890935000$

$-1.079833000$

$-1.754410000$

$-3.604439000$

$-3.354744000$

$-2.713577000$

$-0.837610000$

$-1.010526000$

$-0.307737000$

$-0.375905000$

$-0.858571000$

0.742994000

2.730483000

1.806179000

2.164737000

3. 461418000

4.420208000

4.045639000

$-0.221698000$

$-1.245927000$

$-2.115838000$

$-2.868681000$

$-2.416656000$

$-1.777213000$

$-0.849150000$

$-2.188316000$

0.475083000

0.193334000

$-0.526872000$

$-0.995537000$

$-1.700304000$

$-0.880615000$

0.691690000

$-3.375730000$

1. 787925000

0.325999000

$-3.604932000$

0.377106000

$-2.153349000$

$-3.190478000$

$-0.701636000$

$-2.526886000$

$-1.786778000$

$-2.983000000$

$-2.701821000$

$-1.317730000$

$-1.155248000$

1. 365921000

3.706677000

5.442330000

4.759268000

2. 371269000

$-1.152507000$ $-0.000341000$

1.151552000

1.197800000

$-0.000901000$

$-1.199307000$

0.000073000

0.000476000

0.000180000

0.000196000
0.169198000
3.153606000
2.187978000
2.720643000
-3.003557000
-2.200443000
-3.060866000
0.117747000
2.452889000
3.038512000
3.290218000
-0.729912000
-0.537043000
1.085674000
-0.586584000
-0.348972000
-1.803928000
0.286859000
1.489503000
-0.494879000
0.116593000
-1.431702000
-0.747450000

0.720375000

$-0.081337000$

$-0.869393000$

$-0.893003000$

$-0.060118000$

0.762829000

$-0.140268000$

1. 507102000

1.607120000

2.918564000

0.625501000

$-0.620371000$

$-1.048073000$

$-1.559067000$

0.939875000

0.708332000

$-0.414352000$

$-1.440352000$

$-2.627218000$

$-1.482173000$

1.723870000

3.067973000

1.763193000

2.718539000

2.966821000

1.499266000

3.742079000

0.859007000

$-0.500709000$

$-2.507002000$

$-2.552471000$

$-1.148869000$

$-2.719959000$

$-1.788309000$

$-3.544081000$

$-1.479583000$

$-1.551274000$

$-0.051768000$

1.430750000

1. 322809000

$-0.000037000$

0.000004000

0.000022000

$-0.000024000$

$-0.000047000$

$-0.000041000$

$-0.000053000$

$-0.000081000$

1.154319000

1.200966000
$-4.918298000$

$-4.209812000$

$-2.817505000$

0.031443000

$-0.067517000$

$-0.103238000$

$-0.067505000$

0.031240000

$-0.146903000$

$-0.146468000$

0.031892000

$-0.066441000$

$-0.101730000$

$-0.066381000$

$-0.145336000$

0.031881000

$-0.145568000$

0.722855000

$-1.035181000$

$-0.192083000$

$-0.187181000$

$-0.191734000$

0.723531000

$-1.034518000$

$-1.034884000$

$-0.188113000$

0.723257000

$-0.185174000$

0.723672000

$-0.189616000$

$-1.034417000$

$-2.204002000$

$-4.722659000$

$-6.006913000$

$-4.722879000$

$-2.204218000$

2. 359125000

4. 858402000

6.147628000

4.857523000

2. 358321000

Co (tmhd)

$-3.367328000$

$-2.559578000$

$-1.290738000$

0.000000000

1. 290792000

2. 559624000

3.198243000

2. 559553000

3. 367274000

$-3.198243000$

$-2.559600000$

$-1.290760000$

$-3.367369000$

1. 290706000

3. 367423000

$-2.960083000$

$-4.885712000$

$-2.959481000$

$-4.278977000$

$-2.959693000$

$-4.885751000$

$-2.959979000$

2. 960009000

2.959804000

4.885800000

4.278977000

2. 959909000

4. 885663000

2. 959515000

3. 454646000

3.252672000

1. 876713000

5.384169000

5.227178000
0.000470000

0.000752000

0.000765000

$-1.446179000$

$-2.696233000$

$-3.341304000$

$-2.696232000$

$-1.446125000$

$-3.549713000$

$-3.549676000$

1.446124000

. 696224000

3.341333000

2.696352000

3.549955000

1.446230000

3.549755000

$-3.342957000$

$-3.263461000$

$-4.621996000$

$-4.424777000$

$-4.621962000$

$-3.342942000$

$-3.263395000$

3.265579000

4.622330000

3. 341359000

4. 424845000

3. 342124000

4. 622085000

3. 264366000

$-0.000091000$

$-0.000022000$

0.000465000

0.000964000

0.000993000

2.061624000

2.158115000

$-0.001116000$

$-2.159834000$

$-2.062360000$

1.813572000

0.887019000

1.011790000

$-0.000048000$

$-1.012075000$

$-0.887138000$

0.000036000

0.887229000

1.813862000

0.000001000

$-0.887122000$

$-1.012052000$

$-1.813568000$

1.012142000

$-1.813808000$

1.485158000

1. 669586000

3.263294000

0.000080000

$-3.263342000$

$-1.669438000$

$-1.485133000$

$-3.263541000$

$-1.485913000$

$-1.669404000$

0.000023000

3.263612000

1. 669444000

1. 485922000

3. 958788000

3. 535666000

3. 389657000

2. 360662000

0.656321000

0.000061000

$-1.200916000$

$-1.154409000$

$-1.451949000$

$-1.254964000$

$-0.000018000$

1.254895000

1. 451847000 
1. 914635000

2.176040000

1.577876000

0.463745000

$-2.360646000$

$-0.656291000$

$-1.914571000$

$-3.958749000$

$-3.535567000$

$-3.389573000$

$-2.176060000$

$-1.577861000$

$-0.463748000$

3.958424000

3.535675000

3. 389030000

2. 175257000

1.576732000

0.463007000

2. 360610000

0.656428000

1.915337000

$-3.958393000$

$-3.535733000$

$-3.389185000$

$-2.360408000$

$-0.656246000$

$-1.915167000$

$-2.175148000$

$-1.576819000$

$-0.462938000$

$\mathrm{Co}(\text { tmhd })_{2}\left(\mathrm{CH}\left(\mathrm{CH}_{3}\right) \mathrm{OOCCH}_{3}\right)$ 5-Coord.

\begin{tabular}{|c|c|}
\hline 6 & 3.450731000 \\
\hline 6 & 2.735667000 \\
\hline 6 & 3.444803000 \\
\hline 6 & 2.812807000 \\
\hline 6 & 3.610878000 \\
\hline 8 & 1.460777000 \\
\hline 27 & 0.220414000 \\
\hline 8 & 1.547018000 \\
\hline 6 & -0.011103000 \\
\hline 8 & -1.296550000 \\
\hline 6 & -2.192317000 \\
\hline 6 & -3.490395000 \\
\hline 6 & 1.029263000 \\
\hline 8 & -0.957833000 \\
\hline 6 & -2.213148000 \\
\hline 6 & -2.897472000 \\
\hline 8 & -1.046339000 \\
\hline 6 & -2.290213000 \\
\hline 6 & -3.044327000 \\
\hline 6 & -2.919684000 \\
\hline 8 & -1.968415000 \\
\hline 6 & 3.197981000 \\
\hline 6 & -2.646012000 \\
\hline 6 & -2.224977000 \\
\hline 6 & 5.128944000 \\
\hline 6 & -4.405080000 \\
\hline 6 & 3.211983000 \\
\hline 1 & 4.524563000 \\
\hline 1 & -3.981718000 \\
\hline 6 & 2.977592000 \\
\hline 6 & -4.568632000 \\
\hline 6 & 4.978360000 \\
\hline 6 & -2.590555000 \\
\hline 6 & 3.014460000 \\
\hline 6 & -2.642269000 \\
\hline 1 & 0.037022000 \\
\hline 1 & 0.898771000 \\
\hline 1 & 2.036812000 \\
\hline 1 & 0.937335000 \\
\hline 1 & -3.974193000 \\
\hline 1 & -4.142138000 \\
\hline 1 & -3.308332000 \\
\hline 1 & 3.712595000 \\
\hline 1 & 2.129899000 \\
\hline
\end{tabular}

$-2.633714000$

$-1.272177000$

$-0.060866000$

1.192120000

2.503712000

$-1.362651000$

0.037968000

1.360742000

$-0.236338000$

0.208514000

$-0.715485000$

$-0.049669000$

0.488089000

1.459773000

1.388473000

2.762644000

$-1.252359000$

$-1.066090000$

$-2.335393000$

0.189110000

$-1.903481000$

3.186845000

3. 518298000

3.524621000

2.294377000

2. 677187000

3.401700000

$-0.095571000$

0.239915000

$-3.371351000$

$-2.168694000$

$-2.517659000$

$-2.643965000$

$-3.428482000$

$-3.500488000$

$-1.325669000$

0.228157000

0.186848000

1.573344000

0.324674000

$-0.773265000$

0.807800000

4.374771000

3.563855000
0.656167000

3. 958240000

3.388954000

3.535576000

$-2.360024000$

$-1.914969000$

$-0.655915000$

$-2.174837000$

$-0.462642000$

$-1.576519000$

$-3.958142000$

$-3.389027000$

$-3.535556000$

$-2.175728000$

$-0.463459000$

$-1.577645000$

$-3.958550000$

$-3.389570000$

$-3.535524000$

$-2.360243000$

$-1.914378000$

$-0.655952000$

2.175797000

0.463495000

1.577574000

2.360375000

1. 914481000

0.656067000

3.958551000

3.389424000

3.535433000

$-0.237805000$

$-0.195226000$

$-0.171103000$

$-0.185404000$

$-0.288191000$

$-0.203227000$

$-0.137983000$

$-0.135564000$

1.766972000

2.176029000

2. 611131000

2.983598000

2. 582144000

$-0.340788000$

$-0.564120000$

$-0.668203000$

$-0.568292000$

$-0.795225000$

$-1.225579000$

$-0.744984000$

2.694418000

$-1.607085000$

0.650251000

$-1.827093000$

$-0.277896000$

$-0.928159000$

0.897403000

$-0.186288000$

$-0.940090000$

$-1.505094000$

$-1.199881000$

$-0.257013000$

$-2.668272000$

1.008470000

$-0.304880000$

1. 844070000

3. 643742000

2.279388000

2.478020000

2.074456000

3.476688000

3.639697000

0.816149000

0.910941000
3.505549000

3. 701890000

3.476259000

2. 115971000

5.631269000

5.468594000

5.467265000

5.420042000

5.336711000

5.362943000

3.415428000

1. 887224000

3.286191000

3. 454727000

3.347949000

1.924966000

$-2.638252000$

$-1.145167000$

$-2.396576000$

$-3.055311000$

$-3.126655000$

$-1.573731000$

$-4.822978000$

$-4.630319000$

$-4.933087000$

$-3.072948000$

$-2.861843000$

$-1.505017000$

$-3.132555000$

$-1.559332000$

$-2.933520000$

$-5.040912000$

$-4.930699000$

$-4.918860000$

2. 949781000

4.157153000

2.574692000

3. 349562000

3. 267622000

1.807633000

1. 694557000

$-3.521326000$

$-1.972814000$

$-2.017229000$

$-4.376970000$

$-3.462018000$

$-2.837077000$

$-4.433358000$

$-2.935544000$

$-3.525133000$

4.538639000

3. 595453000

3.019124000

4.534396000

3. 012320000

3.581829000

3.689956000

2. 175273000

2. 149827000

$-3.563610000$

$-1.831130000$

$-2.783065000$

$-4.422493000$

$-3.651163000$

$-3.309703000$

$-3.122048000$

$-1.887789000$

$-1.420485000$

$\mathrm{Co}$ (tmhd) $)_{2}\left(\mathrm{CH}\left(\mathrm{CH}_{3}\right) \mathrm{OOCCH}_{3}\right)$ 6-coord.

4.017775000

2.739512000

1.742210000

0.003701000

0.366216000

0.018209000

$-0.409155000$

$-0.722533000$

2.717531000

1. 583434000

0.439920000

1. 617429000

$-0.537250000$

$-0.250616000$

$-1.349053000$

$-2.562160000$

$-2.710215000$

$-4.074632000$

$-1.793074000$

$-1.279214000$

$-0.346024000$

4.360797000

5.218917000

3.699866000

3.629128000

3.003033000

0.617365000

1.157752000

$-0.803197000$

$-0.229526000$

$-2.612719000$

$-3.436509000$

$-5.192851000$

$-4.473341000$

$-3.893109000$

$-1.253190000$

0.213012000

$-1.320049000$

$-0.089426000$

$-0.040633000$

$-1.430425000$

1.853391000

$-1.701720000$

$-2.474460000$

$-1.634236000$

$-0.340692000$

0.644752000

$-1.131622000$

$-0.288364000$

$-1.139137000$

0.640303000

$-1.538967000$

$-1.513372000$

$-2.412851000$

0.985419000

1.930662000

1.044556000

$-1.899775000$

$-1.664258000$

$-2.786068000$

0.584379000

1. 496395000

0.857643000

$-0.985405000$

$-1.877178000$

$-0.123762000$

$-3.023446000$

$-3.354050000$

$-2.709384000$

$-0.642323000$ 
2. 253017000

$-4.124682000$

$-3.779486000$

$-2.900292000$

$-3.655490000$

$-2.140168000$

$-3.349000000$

$-2.438800000$

$-1.208014000$

$-0.876193000$

$-0.014005000$

$-1.371988000$

$-0.196801000$

2. 342647000

2.203723000

2. 688292000

0.677045000

0.986528000

$-0.668921000$

$-3.939053000$

$-3.863491000$

$-2.790129000$

$-2.071427000$

$-0.893455000$

$-0.634461000$

$-3.555495000$

$-2.148113000$

3.468179000

$-0.579876000$

$-1.833155000$

$-0.516568000$

$-0.124753000$

0.312972000

$-1.345039000$

1.759987000

1.875295000

2.221586000

$\mathrm{Co}(\text { tmhd })_{2}\left(\mathrm{CH}\left(\mathrm{CH}_{3}\right) \mathrm{OOCCH}_{3}\right)$ (py)

$\begin{array}{lrr}6 & -0.602609000 & 1.590094000 \\ 7 & -0.552393000 & 0.349115000 \\ 6 & -0.747399000 & -0.685467000 \\ 6 & -1.003854000 & -0.521179000 \\ 6 & -1.057281000 & 0.771511000 \\ 6 & -0.851833000 & 1.848611000 \\ 27 & -0.137905000 & -0.002405000 \\ 6 & 0.240508000 & -0.474995000 \\ 8 & 1.038602000 & 1.466494000 \\ 6 & 2.281241000 & 1.418302000 \\ 6 & 2.994853000 & 2.780510000 \\ 8 & 1.154966000 & -1.261163000 \\ 6 & 2.379564000 & -1.009474000 \\ 6 & 3.183047000 & -2.226526000 \\ 8 & -1.359156000 & -1.452903000 \\ 6 & -2.623972000 & -1.371516000 \\ 6 & -3.340470000 & -2.736689000 \\ 8 & -1.470943000 & 1.292685000 \\ 6 & -2.727062000 & 1.083723000 \\ 6 & -3.568150000 & 2.356810000 \\ 6 & 2.974994000 & 0.259158000 \\ 6 & -3.335401000 & -0.176903000 \\ 1 & -0.694929000 & -1.667549000 \\ 1 & -1.156784000 & -1.391650000 \\ 1 & -1.254703000 & 0.936673000 \\ 1 & -0.882097000 & 2.874208000 \\ 1 & -0.430762000 & 2.386046000 \\ 6 & 2.875246000 & 3.239410000 \\ 6 & 2.261666000 & 3.789519000 \\ 6 & 4.473867000 & 2.735029000 \\ 1 & 4.027563000 & 0.346984000 \\ 6 & 2.785348000 & -2.450799000 \\ 6 & 4.701644000 & -2.022477000 \\ 6 & 2.794005000 & -3.464044000 \\ 6 & -3.158048000 & 2.954781000 \\ 6 & -5.079494000 & 2.099846000 \\ 6 & -3.227053000 & 3.361211000 \\ 1 & -4.411208000 & -0.234252000 \\ & & \end{array}$

$-1.451753000$

$-2.811809000$

$-1.107839000$

$-1.924474000$

$-3.452586000$

$-3.005448000$

$-1.758881000$

$-4.616505000$

$-3.758516000$

$-4.201881000$

1.290326000

0.884716000

$-0.367453000$

1. 385053000

$-0.268735000$

1.051667000

3.166162000

2.847645000

2. 785050000

3.244138000

1. 534612000

2.143020000

4.832094000

3.762717000

4.263751000

3.917272000

3. 346044000

2.223153000

$-0.838869000$

$-0.363968000$

0.762691000

$-2.924094000$

$-2.838139000$

$-2.474760000$

$-1.336524000$

0.254576000

$-1.214826000$

2.428828000

1. 929748000

2. 757125000

4.116699000

4.635884000

3. 775101000

$-0.173995000$

$-2.035906000$

$-0.159765000$

0.119214000

$-0.001420000$

0.366499000

0.614717000

1.117293000

$-0.135885000$

$-0.279425000$

$-0.256007000$

$-0.567723000$

$-0.606319000$

$-0.837323000$

0.503101000

$-0.477858000$

2.292419000

4.750158000

5.693505000

4.135170000

1.708513000

$-1.467328000$

0.901219000

0.397903000

0.731423000

2.590572000

1.036649000

0.290771000

$-2.196149000$

$-0.834008000$

0.278712000

$-0.555863000$
$-4.868672000$

$-2.912029000$

$-2.864872000$

$-0.689584000$

1.583146000

0.182963000

$-0.440649000$

$-1.730181000$

$-0.605850000$

2.414414000

2.123159000

3.768611000

4.408481000

3.667641000

4.219644000

$-3.697246000$

$-2.083046000$

$-3.394633000$

$-3.782204000$

$-3.495495000$

$-2.156747000$

$-5.610390000$

$-5.383173000$

$-5.420483000$

$-5.307555000$

$-5.217287000$

$-5.266182000$

$-3.311468000$

$-1.775715000$

$-3.163077000$

$-3.356985000$

$-3.244679000$

$-1.822735000$

3.310677000

3. 045303000

1.707881000

3.323466000

1.717597000

3.048642000

5.207695000

5.026936000

5.052032000

4.911126000

4.608086000

5.051554000

2.721044000

1.208923000

2. 313581000

3. 318474000

3. 396340000

1. 825248000

Co (tmhd) 2 (py)

2
8
6
6
6
8
6
6
1
1
1
6
1
1
1
6
1
1
1
1
6
6
1
1

$-0.080989000$

$-1.894590000$

$-2.898430000$

$-2.947096000$

$-1.904395000$

$-0.757654000$

$-4.105926000$

$-3.622415000$

$-2.755892000$

$-4.424070000$

$-3.330659000$

$-4.548201000$

$-3.720486000$

$-5.375706000$

$-4.891210000$

$-5.301996000$

$-6.107864000$

$-5.703810000$

$-5.042411000$

$-3.863350000$

$-2.084872000$

$-1.861816000$

$-0.887037000$

$-2.636991000$
$-2.623672000$

$-3.489584000$

$-3.522002000$

0.133273000

$-0.105026000$

$-1.566325000$

$-0.250714000$

$-0.132969000$

1.224675000

$-1.065824000$

$-2.237504000$

$-0.481651000$

$-1.255481000$

0.353117000

$-0.087604000$

3.894599000

3.159075000

2.269555000

4.295555000

2. 965082000

3. 588767000

3.048885000

1. 426242000

1.673638000

$-3.627787000$

$-2.060656000$

$-2.143298000$

$-4.524274000$

$-3.626851000$

$-3.018591000$

$-4.492902000$

$-2.960676000$

$-3.590237000$

$-3.327470000$

$-1.584197000$

$-2.626157000$

$-4.345823000$

$-3.646895000$

$-3.336786000$

$-2.945043000$

$-1.794039000$

$-1.222361000$

3.736210000

2.421334000

2.058628000

4.781792000

3.867493000

3.492202000

4.236573000

2. 550107000

3.279705000

0.028315000

0.836209000

0.633096000

$-0.338847000$

$-1.229127000$

$-1.256649000$

1.553938000

3.007261000

3.199460000

3.707774000

3.207577000

1. 330953000

1. 528822000

2.006260000

0.300391000

1.310508000

2. 011949000

0.295116000

1.471478000

$-0.420943000$

$-2.289103000$

$-3.669600000$

$-3.705091000$

$-3.886221000$

$-0.222146000$

$-1.531892000$

0.978656000

$-3.058112000$

$-2.395113000$

$-2.010410000$

$-4.059348000$

$-2.845359000$

$-3.076065000$

$-2.847112000$

$-2.982412000$

$-3.166809000$

$-3.595314000$

$-3.868984000$

$-2.249007000$

$-2.372243000$

$-2.218631000$

$-3.019574000$

0.125991000

1.266405000

0.276127000

$-0.980116000$

$-1.644564000$ 
$-3.129801000$

$\mathrm{Co}(\mathrm{tmhd})_{2}(\mathrm{py})_{2}$

$\begin{array}{ll}6 & -1.146017000 \\ 7 & 0.004980000 \\ 6 & 1.157414000 \\ 6 & 1.205489000 \\ 6 & 0.007865000 \\ 6 & -1.191254000 \\ 27 & -0.000097000 \\ 8 & -1.451799000 \\ 6 & -2.707147000 \\ 6 & -3.353080000 \\ 6 & -2.710646000 \\ 6 & -3.542238000 \\ 6 & -3.286231000 \\ 7 & -0.004762000 \\ 6 & -0.003856000 \\ 6 & -0.004865000 \\ 6 & -0.006613000\end{array}$

$-4.456641000$

$-2.040485000$

$-2.042103000$

$-2.824137000$

$-1.072713000$

$-2.264192000$

$-2.456979000$

$-1.305928000$

$-3.046979000$

1. 672573000

1.882349000

0.890478000

$-0.476645000$

$-0.957618000$

3.363663000

4.157809000

5.232730000

3.861920000

3. 981049000

3.830628000

4.904364000

3. 647257000

3.296413000

3.620266000

4. 693418000

3.314079000

3.095391000

1.191445000

$-1.501818000$

$-2.132591000$

$-1.378982000$

$-2.608364000$

$-2.898300000$

$-2.589999000$

$-3.005609000$

$-3.399530000$

$-2.178607000$

$-0.900737000$

$-1.692768000$

$-0.438017000$

$-0.146781000$

$-0.750689000$

$-0.199372000$

$-0.646451000$

$-1.714759000$

$-2.292899000$

$-1.778715000$

0.613149000

$-0.165649000$

$-2.091709000$

$-2.167650000$

$-2.700552000$

$-3.640728000$

$-3.174229000$

$-4.408675000$

$-4.138096000$

$-3.259858000$

$-2.548265000$

$-3.757173000$

$-4.027959000$

0.001292000

$-0.452441000$

$-0.664730000$

$-0.347464000$

0.167904000

$-0.764152000$

0.540901000

0.353645000

1.299888000

0.946116000

$-1.807502000$

$-2.003357000$

$-1.447501000$

$-2.757513000$

$-1.298866000$

$-1.487297000$

$-0.580215000$

$-2.244931000$

$-1.081466000$

$-0.624364000$

0.719562000

1. 406088000

1.202898000

0.561711000

$-1.541107000$

$-1.102587000$

$-1.689419000$

$-2.526405000$

$-1.289055000$

$-1.475990000$

$-2.254528000$

$-0.654337000$

2. 402634000

3. 317021000

4.633847000

5.012922000

4.060830000

2.767320000

2. 953153000

5.341092000

6.033750000

4. 311306000

1. 979208000

$-0.048685000$

$-0.038676000$

$-0.052873000$

$-0.079340000$

$-0.090877000$

$-0.074974000$

0.001353000

$-1.436274000$

$-1.256291000$

$-0.000887000$

1.254607000

2.560947000

3. 260414000

0.045994000

1.210916000

1.281961000

0.093892000
$-0.006414000$

$-1.456391000$

1.455462000

2.709924000

3.352623000

2. 707003000

3. 534868000

3.030606000

1. 451665000

$-3.015448000$

$-5.048999000$

3. 541232000

5.050130000

3.269106000

3.027790000

5.046054000

3.246686000

$-3.534227000$

$-3.026290000$

$-3.249590000$

$-5.045188000$

4.430988000

$-4.431336000$

$-0.006821000$

$-0.008517000$

$-0.007305000$

$-0.004219000$

$-0.002161000$

$-2.056670000$

$-2.151197000$

0.009009000

2.166490000

2.066959000

3.538295000

1. 952915000

3.226425000

3.739300000

3.622151000

2.169166000

5.553784000

5.303233000

5.458759000

5.559829000

5.472615000

5.293743000

3.764970000

2.193541000

3. 651967000

3. 538225000

3. 213029000

1. 951417000

$-3.534183000$

$-3.219072000$

$-1.948936000$

$-5.552121000$

$-5.461489000$

$-5.299015000$

$-3.783470000$

$-3.677998000$

$-2.212535000$

$-5.559390000$

$-5.281320000$

$-5.480463000$

$-3.525978000$

$-1.940355000$

$-3.189244000$

$-3.749418000$

$-2.173127000$

$-3.618972000$
$-1.118684000$

$-1.095273000$

1.435033000

.435587000

1.255282000

$-0.000302000$

$-1.256024000$

$-2.563581000$

$-3.396073000$

$-1.436501000$

3.453529000

2.350485000

2. 561785000

2. 350471000

3.272000000

3.445075000

$-2.350575000$

$-3.329119000$

$-2.564518000$

$-3.397158000$

$-3.328250000$

$-2.352433000$

$-0.000259000$

$-0.001005000$

$-2.005590000$

$-2.068902000$

0.112842000

2.249831000

2.100832000

$-0.034374000$

$-0.082604000$

$-0.111757000$

$-0.090499000$

$-0.042140000$

$-4.369045000$

$-3.566309000$

$-2.884553000$

$-4.310206000$

$-2.777926000$

$-3.475955000$

$-3.323459000$

$-1.816033000$

$-1.791163000$

3.322760000

1.762749000

1.845987000

4.251250000

3.417859000

2. 683003000

4.416970000

2.973568000

3. 613889000

$-4.370021000$

$-2.884854000$

$-3.567531000$

$-3.325729000$

$-1.793291000$

$-1.818047000$

4.238910000

2. 664031000

3.406308000

3. 322415000

1.856255000

1.753415000

4.425367000

3. 621384000

2.989940000

$-4.305964000$

$-3.483137000$

$-2.772419000$

$-4.232159000$

$-2.839226000$

0.085053000

0.076132000

$-0.017461000$

$-0.083732000$

$-0.062604000$

$-0.107280000$

$-1.299630000$

0.017091000

$-1.147534000$

$-0.191370000$

$-0.016770000$

$-0.178807000$

1.322849000

$-1.167846000$

$-0.244194000$

1.198074000

$-0.102928000$

$-1.293899000$

1. 203175000

$-0.244952000$

$-0.158601000$

$-0.156804000$

$-2.244360000$

$-4.760668000$ 
F. Selected Bond Distances $(\AA)$ and Angles $\left({ }^{\circ}\right)$ for the Optimized Structures and View of their Geometry

F1. Co(acac)2 and Co(tmhd $)_{2}$

\begin{tabular}{|lcc|}
\hline & acac & tmhd \\
\hline Co-O & 1.932 & 1.927 \\
\hline O-Co-O(same) & 96.93 & 95.90 \\
O-Co-O(diff) & 116.08 & 116.65 \\
\hline
\end{tabular}
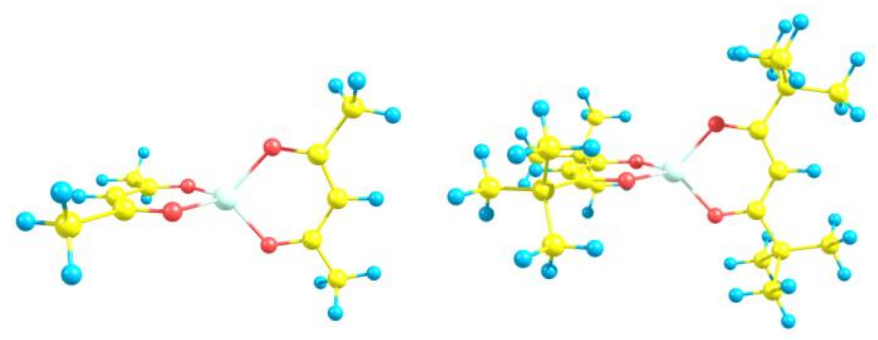

F2. $\mathrm{Co}(\mathrm{acac})_{2}\left(\mathrm{CH}\left(\mathrm{CH}_{3}\right) \mathrm{OOCCH}_{3}\right)$ and $\mathrm{Co}(\mathrm{tmhd})_{2}\left(\mathrm{CH}\left(\mathrm{CH}_{3}\right) \mathrm{OOCCH}_{3}\right)-5$ coordinated

\begin{tabular}{|l|cc|}
\hline & acac & tmhd \\
\hline Co-O & 1.868 & 1.865 \\
Co-C & 1.941 & 1.938 \\
\hline C-Co-O(front) & 90.91 & 91.59 \\
C-Co-O(back) & 99.29 & 99.30 \\
O-Co-O(same) & 94.42 & 93.81 \\
O-Co-O(diff.-cis) & 84.68 & 85.21 \\
O-Co-O(trans) & 169.78 & 169.10 \\
\hline
\end{tabular}
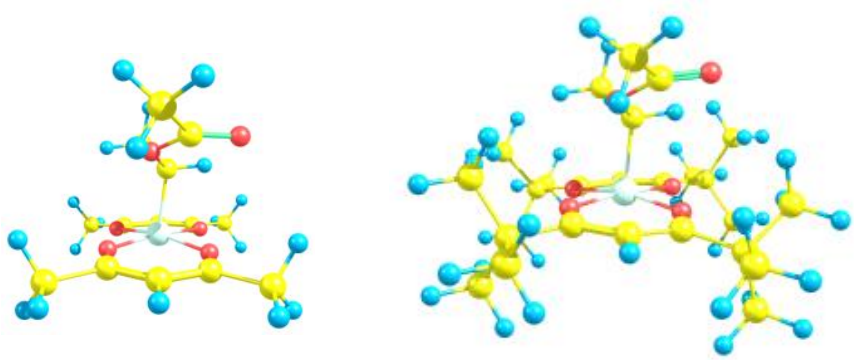

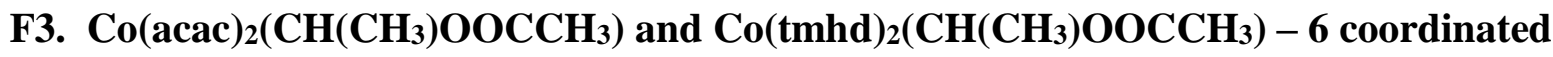

\begin{tabular}{|l|cc|}
\hline & acac & tmhd \\
\hline Co-O(trans-O) & 1.890 & 1.888 \\
Co-O(trans-CH2) & 1.990 & 1.980 \\
Co-O(trans-OC) & 1.866 & 1.861 \\
Co-OC & 1.931 & 1.933 \\
Co-C & 1.931 & 1.933 \\
\hline C-Co-O(chel.) & 85.06 & 85.01 \\
C-Co-OC & 174.51 & 174.12 \\
O-Co-O(same) & 95.62 & 94.86 \\
O-Co-O(trans) & 174.82 & 175.09 \\
O-Co-OC & 176.00 & 176.42 \\
\hline
\end{tabular}
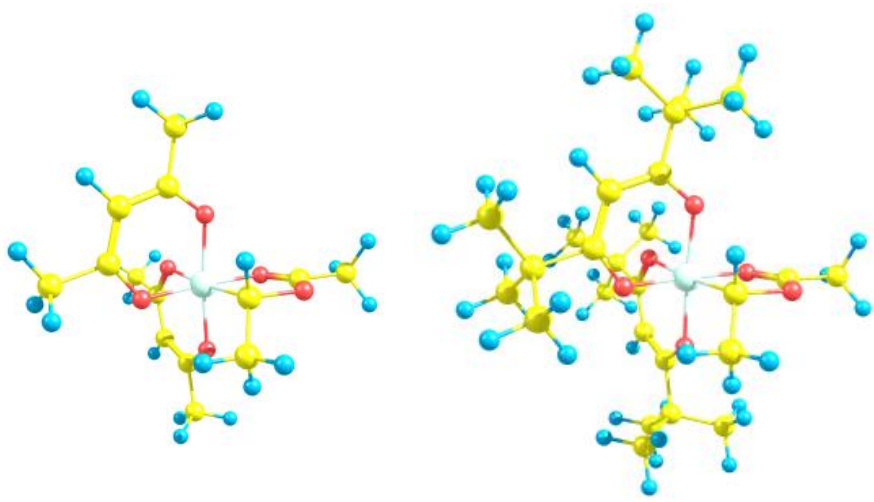

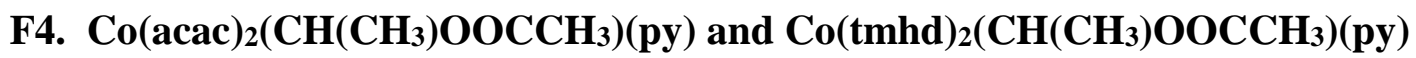

\begin{tabular}{|lcc|}
\hline & acac & tmhd \\
\hline Co-O & 1.892 & 1.891 \\
Co-C & 1.962 & 1.958 \\
Co-N & 2.157 & 2.173 \\
\hline C-Co-O(front) & 88.34 & 88.22 \\
C-Co-O(back) & 94.94 & 95.10 \\
C-Co-N & 176.02 & 175.33 \\
O-Co-O(same) & 95.37 & 94.70 \\
O-Co-O(diff.-cis) & 84.54 & 85.22 \\
O-Co-O(trans) & 176.67 & 175.58 \\
N-Co-O & 88.36 & 88.35 \\
\hline
\end{tabular}
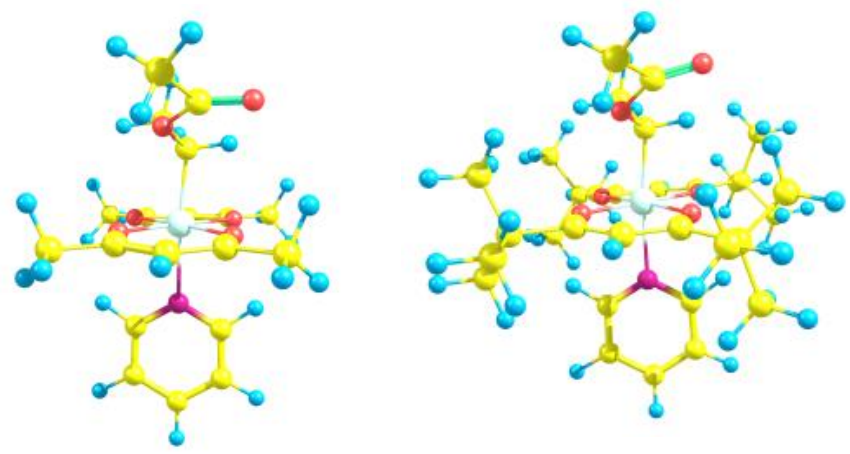
F5. $\operatorname{Co}(\operatorname{acac})_{2}(\mathrm{py})$ and $\operatorname{Co}(\mathrm{tmhd})_{2}(\mathrm{py})$

\begin{tabular}{|l|ll|}
\hline & acac & tmhd \\
\hline Co-O(trans-O) & 2.060 & 2.064 \\
$\mathrm{Co}-\mathrm{O}($ eq. & 1.973 & 1.966 \\
$\mathrm{Co}-\mathrm{N}$ & 2.135 & 2.125 \\
\hline $\mathrm{O}-\mathrm{Co}-\mathrm{O}($ same) & 89.44 & 88.57 \\
$\mathrm{~N}-\mathrm{Co}-\mathrm{O}(\mathrm{ax} 1)$ & 85.53 & 86.26 \\
$\mathrm{~N}-\mathrm{Co}-\mathrm{O}(\mathrm{ax2})$ & 92.92 & 93.58 \\
$\mathrm{~N}-\mathrm{Co}-\mathrm{O}($ eq1) & 113.58 & 113.39 \\
$\mathrm{~N}-\mathrm{Co}-\mathrm{O}($ eq2) & 122.67 & 120.40 \\
\hline
\end{tabular}

F6. $\operatorname{Co}(\operatorname{acac})_{2}(\mathrm{py})_{2}$ and $\operatorname{Co}(\text { tmhd })_{2}(\mathrm{py})_{2}$

\begin{tabular}{|l|cc|}
\hline & acac & tmhd \\
\hline Co-O & 2.050 & 2.044 \\
Co-N & 2.205 & 2.211 \\
\hline O-Co-O(same) & 90.21 & 89.29 \\
O-Co-O(diff.-cis) & 89.75 & 90.69 \\
O-Co-O(trans) & 177.84 & 178.62 \\
N-Co-O & 90.00 & 90.00 \\
N-Co-N & 180.00 & 179.88 \\
\hline
\end{tabular}
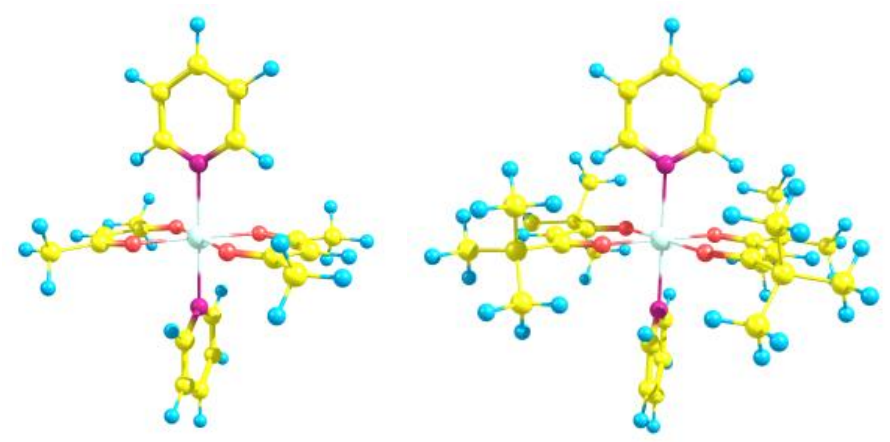

${ }^{1}$ J. Brandup, E. H. Immergut and E. A. Grulke in Polymer Handbook, Vol. (Ed.: John Wiley \& Sons, Inc., Hoboke, NJ, 1999, pp 